Old Dominion University

ODU Digital Commons

Summer 1982

\title{
Improving the Accuracy of Performance Evaluations: A Comparison of Three Methods of Performance Appraiser Training
}

Jerry Willard Hedge

Old Dominion University

Follow this and additional works at: https://digitalcommons.odu.edu/psychology_etds

Part of the Human Factors Psychology Commons, and the Industrial and Organizational Psychology Commons

\section{Recommended Citation}

Hedge, Jerry W.. "Improving the Accuracy of Performance Evaluations: A Comparison of Three Methods of Performance Appraiser Training" (1982). Doctor of Philosophy (PhD), Dissertation, Psychology, Old Dominion University, DOI: 10.25777/a8ez-gg81

https://digitalcommons.odu.edu/psychology_etds/281

This Dissertation is brought to you for free and open access by the Psychology at ODU Digital Commons. It has been accepted for inclusion in Psychology Theses \& Dissertations by an authorized administrator of ODU Digital Commons. For more information, please contact digitalcommons@odu.edu. 
IMPROVING THE ACCURACY OF PERFORNANCE EVALUATIONS:

A COMPARISON OF THREE METHODS OF

PERFORMANCE APPRAISER TRAINING

$$
\begin{gathered}
\text { by } \\
\text { Jerry willard Hedge } \\
\text { M.S., May, 1980, Old Dominion University }
\end{gathered}
$$

A Dissertation Submitted to the Faculty of

old Dominion University in Partial Fulfillment of the Requirements for the Degree of

DOCTOR OF PHILOSOPHY

INDUSTRIAL/ORGANIZATIONAL PSYCHOLOGY

Old Dominion University

August, 1982

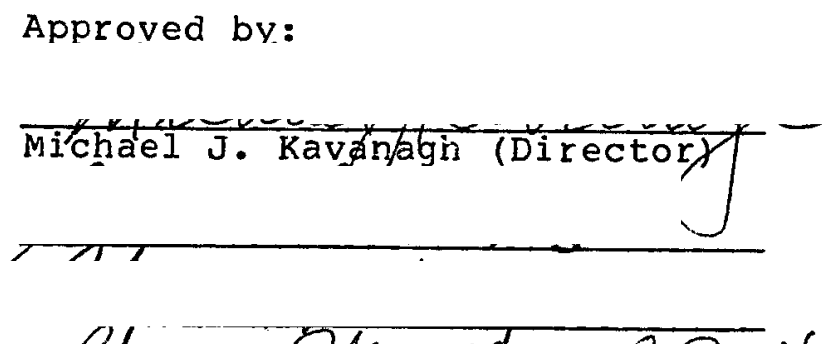




\section{ABSTRACT}

\section{IMPROVING THE ACCURACY OF PERFORMANCE EVALUATIONS: \\ A COMPARISON OF THREE METHODS OF \\ PEREORMANCE APPRAISER TRAINING \\ Jerry W. Hedge \\ old Dominion University \\ Director: Dr. Michael J. Kavanagh}

Researchers in the area of rater training have relied almost exclusively on rater error measures to assess training effectiveness. A reduction in rater tendency to commit these errors subsequent to training is viewed as evidence that these raters have become more accurate in rating their employees. This assumed relationship between rater errors and rating accuracy has recently been questioned. This uncertain relationship between psychometric errors and accuracy was the focus of the current research effort. Supervisory personnel were trained under one of three training programs (psychometric error training, observation training, or decision-making training). Halo, leniency, range restriction and accuracy measures were collected before, and after training from the three training groups, and a no-training control group. The results suggested that while psychometric error training reduced rater errors, it also detrimentally affected rating accuracy. However, observation and decision-making training had no effect on, or increased error rate, but caused performance rating 
accuracy to increase after training. The need for a reconceptualization of rater training content and focus was discussed. 


\section{DEDICATION}

To Carolyn, for her love, support, encouragement and belief in me. 


\section{ACKNOWLEDGMENTS}

As is always the case when a project of this scope is undertaken, there are many people instrumental in its successful completion. First, the contributions of the faculty, graduate students and staff of the center for Applied Psychological studies are gratefully acknowledged.

I would also like to thank the members of my dissertation and defense committees, Drs. Glynn Coates, Glenn DeBiasi, Nichael Kavanagh, Raymond Kirby, Bruce McAfee and Ben Morgan, Jr. In addition, I am indebted to Drs. Coates, Kirby, Morgan and Kavanagh, who have played an important role in my professional development while in graduate school.

A special note of appreciation is extended to Mr. J. Raymond Comstock, a friend and colleague who has contributed in many important ways, not only to this project, but to my personal and professional development as well.

I am also grateful to Mr. Woody Turpin, who "starred" as director, cameraman, technical advisor, and all-around handyman during the filming of my training programs. In addition, I am indebted to Ms. Tina Broome, Personnel 
Training Manager at old Dominion, for her support and assistance in organizing the workshops and supplying needed information. I would also like to thank Pete Mikulka for betting against me.

Finally, I would like to thank my wife, Carole, and my children, Jesse and Jordan, for their encouragement, understanding and support throughout this project. 


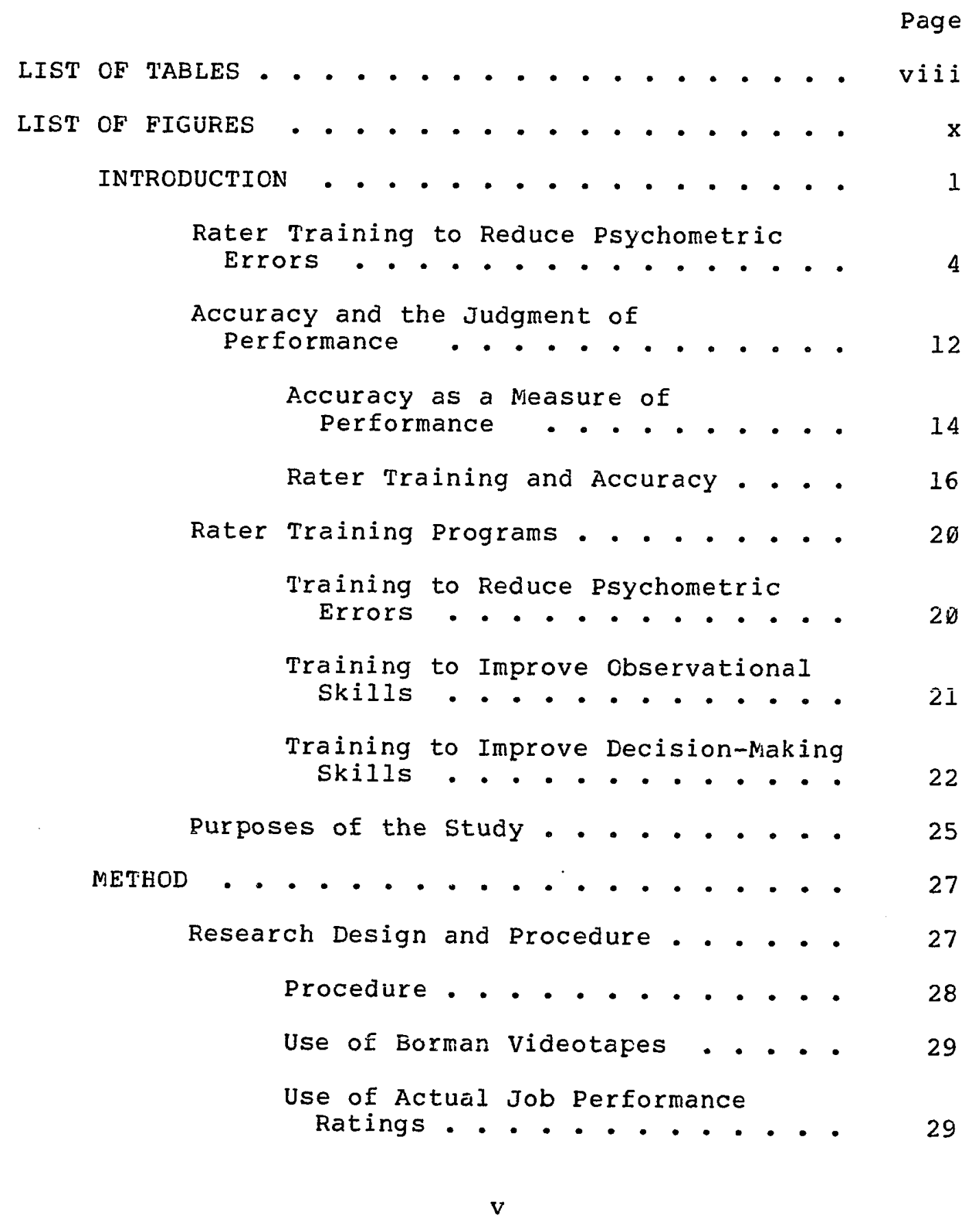


Dependent Measures . . . . . . . 31

Psychometric Considerations . . . 31

Accuracy - . . . . . . . 31

Trainee Reaction Measures . . . 33

RESULTS •. • • . • . . . . . • . . 34

Laboratory Data . . . . . . . . 34

Leniency . . . . . . . . 35

Halo . . . . . . . . . . 35

Range Restriction ....... . 39

Accuracy ........... . 42

Field Data (Actual Performance Evaluations) 47

Leniency . . . . . . . . 49

Halo . . . . . . . . . 52

Range Restriction . . . . . 52

Trainee Reaction Measures . . . . . 55

DISCUSSICN AND CONCLUSIONS . . . . . . . . 61

REFERENCES •. •. •. •. . . . . . . . 67

APPENDICES

APPENDIX A Psychometric Error Training Lecture and Discussion Naterials. . . . 73

$\begin{array}{lll}\text { APPENDIX B } & \begin{array}{l}\text { Observation Training Lecture and } \\ \text { Discussion Materials . . . . . . } 9 \emptyset\end{array}\end{array}$

$\begin{array}{lll}\text { APPENDIX } C & \begin{array}{l}\text { Decision-Making Training Lecture } \\ \text { and Discussion Materials }\end{array} \\ & \cdot \text { • • . } 111\end{array}$

APPENDIX D Schedule of Performance
Evaluation Training . . . . . 132

vi 
APPENDIX E Old Dominion University

Performance Evaluation Form . . . 133

APPENDIX $F$ Trainee Reaction

Questionnaire . . . . . . . 136

APPENDIX G Table of Mean Accuracy Scores

for Laboratory Data . . . . . . 138 
LIST OF TABLES

Table

Page

1. Expert Ratings of Manager Performance . . . 31

2. Summary Table of Analysis of Variance on Leniency Scores from Laboratory Ratings . . 36

3. Orthogonal Comparisons Between Pre-Training and Post-Training Niean Scores for Each Group . . . . . . . . . . . . . 37

4. Summary Table of Analysis of Variance on Halo Scores from Laboratory katings . . . 38

5. Summary Table of Analysis of variance on Range Restriction Scores from Laboratory Ratings... . . . . . . . . . 4 $4 \varnothing$

6. Means of Leniency, Halo, and Range Restriction Scores for Laboratory Ratings ............... 41

7. Summary Table of Multivariate Analysis of Variance on Accuracy Scores from Laboratory Ratings

8. Summary Table of Univariate F-Tests on Accuracy Scores from Laboratory Ratings for Group $x$ Time Effect . . . . . . .

9. Orthogonal Comparisons Between Pre-Training and Post-Training Mean Scores for Each Dimension and Group.......... 45

10. Trends of Means from Time one to Time T'wo . 48

11. Sunimary Table of Analysis of Variance on Leniency Scores from Field Ratings . . . 50

12. Orthogonal Comparisons Between Pre-Training and Post-Training Mean Scores for Each Group . . . . . . . . . . . . . . .

vi i 
13. Summary Table of Analysis of Variance on Halo Scores from Field Ratings . . . . . . 53

14. Summary Table of Analysis of Variance on Range Restriction Scores from Field Ratings .. . . . . . . . . . 54

15. Means of Leniency, Halo and Range Restriction Scores for Fieid Ratings . . . . . . 56

16. Summary Table of Analysis of Variance for Each Group's Trainee Reaction (Item One) . . . 57

17. Summary Table of Analysis of Variance for Each Group's Trainee Reaction (Item Two) . . . 58

18. Summary Table of Analysis of Variance for Each Group's Trainee Reaction (Item Three) . . 59

19. Table of Means and Standard Deviations for Trainee Reaction Measures........ 60 


\section{LIST OF FIGURES}

Figure

Page

1.

Research Design.

$3 \emptyset$ 


\section{Introduction}

For many years, psychologists have realized the importance of performance measurement in organizational settings. Unfortunately, this knowledge has also been accompanied by a realization that the accurate measurement of job performance is not a simple task. For this reason, some have suggested that measurement should focus on objective indices of job performance, such as production data (i.e., units produced, sales volume) or personnel data (i.e., absenteeism, turnover). While the use of these job performance measures is a logical choice (in that they serve as good indicators of organizational effectiveness), they typically fail to measure individual performance effectiveness. There are several reasons why this is so.

First, there are many situational factors beyond an employee's control (i.e., equipment malfunction, size of a salesperson's territory) that will impact directly on these data. In addition, cost-related measures are often difficult to obtain on employees in many jobs. Consequently, these measures are often useless as performance criteria, and as a result, sole reliance on judgmental indices (such as ratings) has frequently occurred. Use of subjective criteria has not occurred by 
default alone, however, but also through the belief that judgmental indices of performance can reflect the complexity of the job, are more likely to minimize situational factors, and can measure more directly what an employee does on the job.

Still, this widespread use of job performance ratings has generated numerous questions concerning the reliability, validity and accuracy of such "subjective" measures of performance. Consequently, an enormous amount of research has been conducted addressing the use of judgmental measures of performance. Researchers have focused on, among other things, the format, the content, or the most appropriate source of appraisal in hopes of answering these questions. Landy and Farr (1980) have provided an extensive review of these efforts. A recent approach to this problem has been to examine the effects of rater training on rating errors and rating accuracy.

Rater training research has typically been concerned with providing information (of one sort or another) to performance appraisers with the hope that they will become "better," "more effective" evaluators of their employees' job performance. "Better" and "more effective" have most frequently been measured by evaluating the frequency of occurrence of a variety of so-called "rating errors." The most often used error measures have been labeled halo error (inappropriate generalization from one aspect of a person's job performance to all aspects of a person's performance), 
leniency error (a tendency of the rater to rate all his or her employees too high) and range restriction error (failure of the rater to discriminate among his or her employees in terms of their respective performance levels). Numerous other rating errors have also been defined and measured, including first impression error (a tendency of the rater to evaluate someone on the basis of judgments made primarily after an initial meeting), similarity error (a tendency on the part of the rater to judge more favorably those persons he/she perceives as similar to himself/herself), and contrast error (a tendency by the rater to judge an employee in comparison to the most recently evaluated employee).

In addition to psychometric error measures, the reliability and validity of the ratings have been used as indices of training effectiveness. Reliability information typically is collected in reference to agreement between raters (interrater reliability), while validity information has been gathered by means of a comparison of job performance ratings to known performance scores (or "normative true scores"). Rating validities have also been estimated by using the Kavanagh, Mackinney and Wolins (1971) Analysis of Variance approach, thus providing convergent and discriminate validity indices.

In general, researchers in the area of rater training have relied almost exclusively on rater error measures to assess training effectiveness. A reduction in rater tendency to commit these errors subsequent to training is 
viewed as evidence that these raters have become more accurate in rating their employees. This assumed relationship between rater errors and rating accuracy has recently been questioned (Borman, 1975; Bernardin \& Pence, 1980). This uncertain relationship between rating errors and accuracy is the focus of the current research effort.

\section{Rater Training to Reduce Psychometric Errors}

Stockford and Bissell (1949) and Levine and Butler (1952) provided some of the earliest information on attempts at improving performance ratings by training performance appraisers. Stockford and Bissell (1949) were concerned with making merit ratings more objective in the Lockheed Aircraft Corporation. Toward this end they undertook a series of studies to determine the degree to which certain weaknesses inherent in the current ratings could be reduced or overcome by designing a new scale and training supervisors in the principles and techniques of rating.

Supervisors received either a two-hour general orientation to the new form, or six hours of instruction on the philosophy and principles of rating, participation in the selection of items to be used in the scale, and feedback about how they were rating. The six-hour rater training resulted in significantly more reliable ratings, and significantly fewer halo errors when compared with the general orientation training group. However, the fact that one group received three times as much training time as the 
other group reduces the researcher's ability to infer positive changes in rater behavior as a result of training content.

Levine and Butler (1952) dealt with supervisors in a large manufacturing plant who had been overrating employees in the higher job grades, yet underrating employees in the lower job grades. These researchers classified this problem as a type of halo error (in reality, this problem is more accurately described as a context error). To reduce or eliminate this problem, Levine and Butler (1952) randomly assigned supervisors to a control group, a lecture group or a discussion group. While the control group received no training or information, the lecture group was presented detailed information on rating theory and technique, including the causes of the previous problems, and how to correct them. Supervisors in the discussion group met as a group and discussed the nature of the problem and how to resolve it. A discussion leader was present, but acted only as a moderator. Rating data collected subsequent to training showed only supervisors participating in the discussion group changed their ratings of subordinates in an appropriate manner.

since these initial studies, rater training research typically has been designed to determine whether a particular type of training program will significantly reduce certain rating errors when an experimental group is compared to a no-training control group. In addition, most 
of these studies have utilized a posttest-only design. Both of these approaches must be seen as serious deficiencies in rater training research. The only conclusion that can be drawn from the first design is that something is better than nothing, while the second design (posttest-only) ignores pre-training data.

For example, Brown (1968), trained a group of student nurses in an attempt to reduce rating error. The one-hour training session consisted of discussion of: (1) the different kinds of rating scales and rating procedures, (2) the problems ir obtaining sound ratings, and (3) the errors often committed by supervisors. They were also given some practice using the rating scale. The data collected (peer ratings) from the trained group were then compared with data gathered from a group of untrained raters. The student nurses who had gone through training subsequently were able to discriminate better between employees, which was interpreted by Brown (1968) as proof that halo had been reduced.

Several other empirical studies have focused on the reduction of halo as a measure of training program success. Taylor and Hastman (1956) compared four groups of subjects that differed on the method of completing ratings (rate all ratees on one dimension before proceeding to the next dimension, or rate a ratee on all dimensions and then move to the next ratee). They found no differences between groups using a measure of halo, but they concluded that, in fact, none of the groups displayed a tendency toward halo. 
Borman (1975) also trained supervisors to reduce halo error, but developed only a five-minute training program for this purpose. Using a one-group pretest/posttest design, Borman demonstrated a significant reduction in halo errors after this short period of training. The main focus of the Borman (1975) study was on the side effects of rater training--on how training effects reliability and validity of the ratings. These criteria of rating quality will be discussed more fully in the next section.

In a much more extensive, systematic approach to training performance appraisers, Latham, wexley and Pursell (1975) trained employees in a large corporation to minimize halo, first impression, similarity, and contrast errors; and then, measured the extent of these errors six months after training. Raters received training via a workshop or group discussion approach. Their workshop treatment provided participants with an opportunity to practice observing and rating actual videotaped ratees. The group discussion format was similar to the Levine and Butler (1952) discussion group approach.

Latham and his colleagues (1975) evaluated these training approaches by comparing both the extent of errors and the subjective reactions to training with a no-training control group. Both the workshop and the group discussion approaches resulted in the reduction or elimination of all four rating errors, while the control group exhibited significant similarity and contrast errors. In addition, 
employees reacted more favorably to the workshup approach, and Latham et al. (1975) interpreted these findings as strong support for the workshop training. Once again, a posttest-only design was used.

A recent rater training study by Faye and Latham (1982) also used the Latham et al. (1975) workshop approach. Half of the subjects (business students) received training, while the other half served as a control group. subsequent to training, all subjects rated videotapes of applicants in job interviews using a trait scale, a Behavioral Expectation scale (BES) or a Behavioral observation scale (BOS). Results showed that rating errors were reduced regardiess of the rating scale used, although trainees who used the BES or BOS committed fewer psychometric errors than did trainees using the trait scale.

A different approach to training raters has been used by Bernardin and Walters (1977). They asked college students to record behavioral examples of teacher performance during the semester in a diary, and then use the information as an aid in making detailed performance ratings at the end of the term. Four experimental groups were used in the study. All four groups received some variation of the typical psychometric error-reduction training. The diary-keeping group received a one-hour lecture on rating errors at the beginning of the semester, with practice using the scale. A second group received similar training at the beginning of the semester, but without practice using the 
scale. Group Three received the same treatment as Group Two, but immediately frior to formal evaluation. Group Four served as a quasi-control, receiving only minimal instructions prior to rating. The results revealed that the diary-keeping group, which had received psychometric error training and exposure to the scale early in the semester, showed significantly less halo and leniency than all other groups. This study also utilized a posttest-only design.

A later study by Bernardin (1978) compared a short psychometric error training program (similar to Borman's 1975 study) with a more comprehensive approach (consisting of a one-hour training session). Halo, leniency and central tendency were measured across three consecutive rating periods. Immediately after training, the one-hour training was found to be significantly more effective in reducing both halo and leniency than the five-minute training, and both groups were superior to the two control groups. However, after 13 weeks, the training effectiveness had dissipated and no differences were found for the four groups.

Ivancevich (1979) also evaluated the effects of psychometric error training, using a longitudinal design. An intense training group received a lecture on psychometric errors, and how to avoid them, as well as practice evaluating high and low performers. A lecture/discussion format provided a second group with psychometric error training. Each of these groups received approximately 14 
hours of training. The tendency for raters to exhibit halo and leniency errors was measured six months before training, and six and twelve months after training. The findings revealed that the intense training group was superior to the discussion group and a control group in reducing halo and leniency error after six months. However, at twelve months after training, much of the training effect had dissipated for the intense training group.

With a somewhat similar focus, warmke and Billings (1979) evaluated the generalizability of effects from lecture and group discussion formats by comparing experimental ratings collected immediately after training, with administrative ratings collected two months later. Higher levels of halo were found in the administrative ratings compared to those collected experimentally, and no differences were found between trained and untrained groups. Not all research on psychometric error training has produced such significant training effects as suggested by the majority of the studies cited. For example, vance, Kuhnert and Farr (1978) trained students using the typical lecture/discussion format, yet found no difference in level of halo or leniency between a trained and no-training control group. In addition, sauser and Pond (1981) found no halo or leniency differences between subjects who were given psychometric error training (a two-hour lecture/discussion/practice format) and subjects who received no such training. Still, while several studies have suggested no rating error 
differences between trained and untrained raters, rater training has generally been shown to be effective in reducing rating errors soon after training.

Exactly how and why rater training reduces psychometric errors in ratings has become a recent topic of discussion. Bernardin and his colleagues (Bernardin, 1978; Bernardin \& Pence, 1980; Bernardin \& Buckley, 1981) have contended that typical rater training programs focus on changing rater response distributions by presenting certain rating distributions as representative of rating errors. Thus, training causes the raters to adopt new (but possibly inappropriate) response sets in order to eliminate these errors when they rate their employees. Bernardin has also suggested that rating errors can be reduced or eliminated with training programs of relatively short (one hour or less) duration.

Latham and his colleagues (Latham \& Wexley, 1981; Faye \& Latham, 1982) have disagreed with Bernardin's approach, and have suggested that rating errors are well-ingrained habits that are quite difficult to extinguish. Consequently, it should take many hours of training to eliminate these rating errors. In addition, these researchers have concluded that training must include practice in observing ratees committing these errors, rather than the presentation of appropriate and inappropriate response sets. Accordingly, the results of such efforts are believed to include not only a reduction in rating errors, 
but an improvement in rating accuracy. While this continuing debate may serve to generate additional research questions, when viewed from the perspective of rating accuracy, its worth as a central research issue may be rather Iimited. The limitations of such a perspective are discussed in the following section. :-

Accuracy and the Judgment of Performance

While researchers have evaluated training effects on psychometric errors, reliability, and validity, it is apparent from the foregoing literature review that the majority of research has focused on psychometric errors. Consequently, researchers have assumed that the more accurate ratings are those with reduced levels of psychometric errors. To clarify this reasoning, a discussion of the relationship between psychometric errors, reliability, validity, and accuracy is needed.

The most straightforward way to view the relationship between these variables is through a discussion of measurement theory. Central to this discussion is the recognition that performance ratings are not error-free. Rather, performance measurement contains both elements of error and elements of truth. In this context, reliability can be defined as the proportion of true variance in a set of ratings, while validity can be defined as the proportion of true variance that is relevant to the purpose of the measurement procedure (Campbell, 1976). This implies that true variance can be separated into two components, 
systematic relevant variance, and systematic error variance. Thus, observed variance in a set of ratings is determined by the proportion of true variance, systematic error variance and random error variance. As random error variance decreases, the ratings become more reliable, and the potential for valid variance increases. However, since systematic variance may be relevant or irrelevant, high reliability does not guarantee high validity.

with this framework in mind, rater training researchers have assumed that rating errors represent error variance, and training that reduces these rating errors should have a positive effect on validity and accuracy. However, the relationship between validity and accuracy is not as well defined. Generally, these two terms are used synonymously in the literature, yet theoretically (as Guion, 1965, noted), these terms are not equivalent. This is so, because systematic errors in ratings can contribute to validity as much as, or more than true variance. Thus, perfect validity would not be evidence of accuracy. Still, when defined operationally, accuracy and construct validity become synonymous, especially when construct validation is approached from a multi-trait-multi-rater perspective (see Kavanagh, et al., 1971).

Unfortunately, a major deficiency in most of these studies on performance rating errors, is that the researcher is required to assume that rating errors and random error variance are equivalent. However, what has been termed 
rating errors might be conceptualized more appropriately as rating effects. As Bingham (1939) noted, it is not at all clear if halo is valid or invalid. The same line of reasoning applies to the other rating errors. It may be that a portion of the rating effect (i.e., Ieniency) represents true score variance, and the remainder is error variance.

Still, as Borman (1979a) noted, past rater training research has failed to investigate directly rating accuracy or validity. In fact, only three published studies dealing with rater training (Borman, 1975; Borman, 1979a; Bernardin \& Pence, 1980) have used accuracy as a dependent measure. Before discussing each of these studies in detail, it is useful to focus on the concept of accuracy, and its use as a dependent measure.

Accuracy as a measure of performance. Given the foregoing discussion, the usefulness of information concerning how reliable our measures of performance are, and whether raters exhibit a tendency toward leniency, halo and the like is apparent. Yet, we are ultimately concerned with the accuracy of our performance measures. As Borman (1980) noted, accuracy is critical in personnel research involving employees' performance as a criterion. In regards to administrative ratings, accuracy is necessary in ensuring fair personnel decisions made on the basis of performance appraisals--be it for promotion, merit pay increases or training purposes. 
Still, a major problem confronts the researcher attempting to measure accuracy. This problem is related to the classic criterion problem in Industrial/Organizational psychology, namely, how we arrive at "true scores" indicative of the dimensions of job performance. In a recent paper, Borman (1930) discussed three possible approaches to studying performance rating accuracy.

One approach to addressing the criterion problem has been through the use of "paper people." This method involves the development of vignettes or stories about persons performing on a job. Given knowledge concerning the relevant dimensions for a particular job, vignettes depicting an employee performing at various levels on each of these dimensions can be generated. As a result, normative true scores may be developed for each ratee on each dimension. With the development of a number of these "paper people," it is then possible to evaluate the similarity or accuracy of a particular rater's actual ratings compared to these true scores. The flexibility afforded in generating ratees with different performance profiles is a major advantage of this approach. However, the main disadvantage to this method involves the lack of realism associated with "paper people."

A second possible solution to this problem involves the identification and use of some external criterion of performance. Unfortunately, the major pitfall to this approach is the inability to find external criteria that 
correspond conceptually to the various performance dimensions of a job. Consequently, accuracy on performance dimensions typically included in performance appraisal instruments cannot easily be studied using this approach. When faced with this dilemma in a field setting, the Kavanagh et al. (1971) NTMR approach may be a viable alternative.

A final approach used by Borman and his colleagues (Borman, Hough \& Dunnette, 1976), involves the development of videotaped vignettes of persons performing on the job. This approach combines the flexibility of the "paper people" approach with the notion that watching people performing on the job is more realistic. Still, it can be argued that the short duration of the performance episodes viewed, and the opportunity to record ratings immediately after viewing the ratee perform his or her job is less than what would be expected in a real life performance situation. In any event, normative true scores can then be generated, and a measure of accuracy derived by comparing actual ratings of these tapes (provided by supervisors/raters) to the true scores.

The paper people approach and the videotaped vignette approach have been used in the three studies cited (Borman, 1975; Borman, 1979a; Bernardin \& Pence, 198ø) in an attempt to assess the accuracy of performance ratings.

Rater training and accuracy. In a 1975 study, Borman asked first-time supervisors to evaluate written vignettes 
describing ratees performing on the job, both before and after a five-minute training session on reducing halo errors in their ratings. As noted earlier, results showed that halo was significantly reduced after training. In addition to measuring extent of psychometric errors, Borman (1975) also computed an index of validity and interrater reliability in order to assess accuracy more directly. These results revealed that validity was unaffected by rater training. However, performance ratings completed after training possessed lower reliability. While the absence of a formal control group was a definite weakness in this study, it has been instrumental in focusing attention on the relationship between rater errors and rating accuracy.

Borman (1979a) investigated further this error-accuracy issue using a much more elaborate training program (the workshop approach of Latham et al., 1975). Borman provided training to half of the student subjects, and then asked them to rate two sets of videotaped ratees (a group of eight managers in a problem-solving session with a troublesome subordinate, and a group of eight interviewers). In addition to measuring halo effects, Borman (1979a) generated a measure of accuracy (differential accuracy) proposed by Cronbach (1955).

After receiving psychometric error-reduction training, halo errors were significantly reduced. However, training had no positive effect on the accuracy of the ratings, although the accuracy of the ratings did not drop 
significantly after training. Borman (1979a) suggested it may be easier to teach persons to eliminate or reduce rating errors than to teach them to be more accurate, and, in fact, the relationship between these dependent variables may not be as clear as previously assumed. Accuracy may not be increased automatically when rating errors are reduced.

The most recent study that has examined this relationship between rating errors and accuracy was conducted by Bernardin and Pence (1980). These researchers provided student subjects with one of two types of rater training. One group received the typical type of rater error training (see Bernardin, 1978). The second group of subjects was lectured on the multidimensionality of most types of work performance, and the need to distinguish each dimension when evaluating performance. The importance of fair, unbiased and accurate ratings was also stressed. In adaition, discussion centered around seeking consensus on stereotypes of effective and ineffective teacher performance.

A posttest-only design allowed a comparison of the two training groups and a no-training control group after evaluation of written vignettes depicting performance of two faculty members. Measures of halo and leniency effects were collected, as well as a measure of accuracy (difference between actual scores and true scores). Ratings from the psychometric error training group had significantly less leniency and halo error than ratings from the other two 
groups. However, significantly less accuracy was also found for this group than for the control or "generalized training" group. Bernardin and Pence (1980) speculated that psychometric error training fosters a response set in raters that results in lower levels of leniency and halo, but lower levels of accuracy as well. In addition, they suggested the need for further research to develop rater training programs that increase rating accuracy rather than train rater response sets.

Since the publication of these three studies, several researchers have begun to address the relationship between rating errors and accuracy. Borman (1977) correlated differential accuracy scores for each rater with his or her halo, leniency and range restriction scores (using data from the Borman, l979a study), and found very little correspondence between accuracy and psychometric errors. In addition, Murphy and Balzar (1981) evaluated the relationship between six rater error measures and four measures of rating accuracy across three laboratory studies. Once again, none of the error measures showed consistent correlations with any of the accuracy measures across all three studies.

More recent studies by these authors (Borman, 1979b; Murphy, Garcia, Kerkar, Martin \& Balzar, 1982) attempted to evaluate more closely accuracy in judging performance. Borman (1979b) focused on valid predictors of accuracy, and concluded that certain individual difference variables are 
related to accuracy across a variety of situations. Murphy and his colleagues (1982) focused on the relation between observational accuracy and performance rating accuracy, and concluded that the two are correlated to some extent. Raters who overestimated the frequency of favorable teacher behaviors also tended to give higher performance ratings.

\section{Rater Training Programs}

Three separate training programs were developed or adapted for use in this research. Each differed in their content and focus. The first training program was chosen as an imitation of the typical psychometric error training found in the literature. In addition, several researchers (Borman, 1979a; Landy \& Farr, 198ø) have proposed training to improve observational skills. A second rater training program reflects these suggestions. Finally, it is the belief of the present author that this new approach must be altered to include behaviors that occur subsequent to observation, namely, decision-making processes. Consequently, the third training program was developed to fill this void. In addition, a no-training control group was included in the experiment.

Training to reduce psychometric errors. This training approach reflects the rater error training typically found in the literature. A lecture/discussion format was used to introduce subjects to the meaning and prevention of four comon rater errors (halo, leniency, range restriction and 
similarity). A videotaped lecture, approximately 20 minutes in length, introduced each of the four rating errors (For all three training groups, a videotaped lecture format was chosen to reduce experimenter bias, a problem typically ignored in the rater training literature). Definitions, graphic illustrations, examples and suggestions for preventing these errors were presented and then discussed at the end of the lecture. In addition, a discussion section followed (moderated by the present author). Discussion was initiated by the reading of two case studies, designed to demonstrate supervisors committing these errors in a work setting (see Appendix A for a transcript of the lecture, as well as the case studies).

Training to improve observational skills. This training, approach is similar to the Thorton and Zorich (1980) observer training program. Once again, a videotaped lecture, approximately 20 minutes long, introduced subjects to the importance of being a good observer of behavior. Training included instructions to observe carefully, watch for specific behaviors, and take notes, as well as, a discussion of several systematic errors of observation contamination from prior information, and over-reliance on a single source of information). The discussion session focused on two exercises. First, subjects were given performance dimensions relevant to the job of recruit interviewer (see Borman et al., 1976). These were discussed, and it was suggested that these dimensions be 
used to help focus their observations of two videotaped recruit interviewers that were to follow. Taking notes was also suggested as an aid in the subsequent rating of these ratees. Subjects then viewed each ratee and rated them on the behaviorally anchored rating scales provided. A second exercise involved the reading of a case study illustrating errors of observation. Discussion followed each of these exercises, moderated by the present author. In general, then, this approach attempted to improve observation processes, such as detection, perception, and recall or recognition of specific behavioral events (see Appendix $B$ for a transcript of the lecture, as well as the stimulus materials used in the discussion session).

Iraining to improve decision-making skills. Given the lack of success that has surrounded efforts to improve the accuracy of ratings, it was believed that the best hope for success in the future lies in the area of decision-making training. It seems apparent that attempts to effect accuracy by reducing or eliminating psychometric errors is questionable. However, a shift in focus toward the cognitive processes that occur prior to actual rating of employees may be fruitful in influencing the accuracy of those ratings. Data-driven and theory-driven inferences from diverse areas of behavioral research point to such a conclusion. For example, Cooper (1981), in a recent review of the "halo effect" suggested a study of the clinical training literature on diagnostic accuracy (i.e., Goldberg, 
1968). In addition, initial research efforts by Thorton and Zorich (1980), have attempted, with some success, to improve observation processes of raters. While such a focus is an important step in the right direction, it neglects the processes that occur subsequent to observation of ratee behavior--namely, the interpretation and weighting of those behaviors. Research efforts from the selection interview domain have addressed this weighting phenomenon and its effect on the decision process. Springbett (1958), Bolster and springbett (1961) and Holland (1972) have all concluded that negative and positive information is processed differently, with negative information being weighted much more heavily.

Finally research from the social-psychological, behavioral decision-making and cognitive domains have generated information supporting a shift in focus to rater decision-making training. The work of Kahneman and Tversky (i.e., Kahneman \& Tversky, 1972, 1973, 1981; Tversky \& Kahneman, 1971, 1974, 1978) on the use of simple heuristics, or of cognitive strategies have demonstrated both the important role these heuristics play in accurate judgments, and the judgmental inaccuracies that result when such strategies are misapplied. Hogarth (1981), in a recent review of judgmental heuristics has elaborated the conditions under which heuristics can be a valuable aid in the decision process. In addition, Nisbett and Ross (1980) have dealt extensively with the notion of strategies and 
shortcomings of human inference, outlining possible approaches to improving human inference. Through a consideration of these related concepts and inferences from numerous, diverse areas of research, it seems necessary that training directed at improving accuracy confront the strategies (both formal and informal) used by raters to arrive at final rating decisions. This training approach is an attempt to deal with these issues and concerns.

A lecture/discussion format was used to introduce subjects to the idea of intuitive and formal decision-making strategies. A videotaped lecture, approximately 20 minutes in length, included a discussion of judgmental heuristics, as well as the costs and benefits of formal versus intuitive strategies. In addition, various inferential errors were illustrated, such as insensitivity to the perils of biased data, inappropriate causal inference, over-reliance on previously formed theories, and inappropriate weighting of observed behaviors. A discussion session (moderated by the author) followed the lecture, and sonsisted of two exercises. Exercise one involved the reading of two scenarios prior to viewing, and subsequently rating two videotaped recruit interviewers (see Borman et al., 1976). Each scenario presented information irrelevant to job performance (i.e., personality information, recent personal life events or crises). After rating the performance of each ratee, a discussion of scenario effect on ratings was initiated. 
The second exercise involved viewing still-life scenes depicting people in a work setting. Subjects were asked to first generate a list of behaviors observed in the picture, and then list inferences dram from these observations. A discussion followed, focusing on the differences between behaviors and inferences, and how inferences can be made inappropriately in a given situation (see Appendix C for a transcript of the videotaped lecture, as well as the stimulus materials used in the discussion sessions).

\section{Purposes of the study}

overall, then, while it has been established that psychometric error training reduces rating errors, questions remain about what effect this training has on accuracy. It appears that not enough is known about the potential usefulness of training to enhance rating accuracy. Results of studies reviewed above suggest, however, that improvements in accuracy using established rater training programs, may be more difficult to bring about than simply changes in rater behavior. This question is the focus of the current research. Thus, the questions of interest here are the following:

(1) How effective are different types of rater training at reducing psychometric errors, and improving the accuracy of ratings? 
(2) Do effects of different types of rater training in the laboratory transfer to performance ratings on the job?

(3) To what extent do employees react differently to different types of rater training? 
Method

This section describes the research design and procedures used in conducting the experiment. In addition, a discussion of the dependent variables chosen for use in this study is included.

Research Design and Procedure

Supervisory personnel working at old Dominion University (i.e., Food Services, Financial Aid, Buildings and Grounds, Library Services, Personnel) were randomly assigned to one of three training groups, or the no-training control group. In all, 52 supervisors participated in the two-part workshop on performance appraisal. In addition, each group was subdivided into two subgroups, such that half of the members of each group met on one aay, and the other half of the group met another day of the week. In all, then, eight training sessions were held during the first week of training, with subgroups randomly assigned to either a morning or afternoon session. Sessions for the three training groups lasted approximately three-and-one-half hours, while the no-training control group session lasted approximately two-and-one-half hours. 
During week Two of the workshop a similar procedure was followed, resulting in eight training sessions. Sessions for the three training groups lasted approximately two-andone-half hours, while the control group sessions lasted approximately three-and-one-half hours (after data collection was completed, the control group received training as well). In all, then, the performance appraisal workshop for each of the four groups lasted approximately six hours over a two-week period (see Appendix D for the schedule of training sessions).

procedure. During the initial training session, supervisors were given a general introduction to the purposes of the workshop, and then viewed five videotaped managerial vignettes one by one, making their ratings after each performance. Each of the training groups then received their specific rater training program. In addition, the three training groups were asked to fill out a short questionnaire concerning their reactions to the training program. Supervisors then returned the following week, and once again viewed and rated the five managerial tapes. Also, they were asked to evaluate several of their current employees, using the Commonwealth of Virginia's Performance Evaluation form. Subsequent to all data collection the Control Group was given rater training. This training included viewing the Psychometric Error Training videotaped lecture, plus two case studies. A discussion session followed (moderated by the present author), incorporating 
comments and suggestions on how to be better decisionmakers, and observers of behavior. Thus, the research employed a pretest/posttest design, with a control group. The data collection design and procedure is shown in Figure 1.

Use of Borman videotapes. As noted previously, few rater training studies have been designed to evaluate rating accuracy, due to the absence of performance dimension true scores. This problem was dealt with in the current study by using the Borman videotapes previously developed (Borman et al., 1976). Subsequent to development, Borman (1979a) revalidated the dimensional true scores by having a group of expert raters evaluate all taped ratees. Interrater agreement between experts ranged from .84 to .97 , while correlations between these new expert ratings and intended true scores were also high (median $r=.81$ ). Consequently, the means of the new experts' ratings were adopted as the normative true scores. For purposes of this study, five of the managerial videotapes were used to collect performance ratings from supervisors attending the workshop. The seven dimensions and the normative true scores are shown in Table 1 .

Use of actual job performance ratings. In addition to ratings gathered from use of the Borman videotapes, actual job performance ratings of university employees were collected from each supervisor subsequent to rater training. The Commonwealth of Virginia's Employment performance Evaluation form is included in Appendix $\mathrm{E}$. 


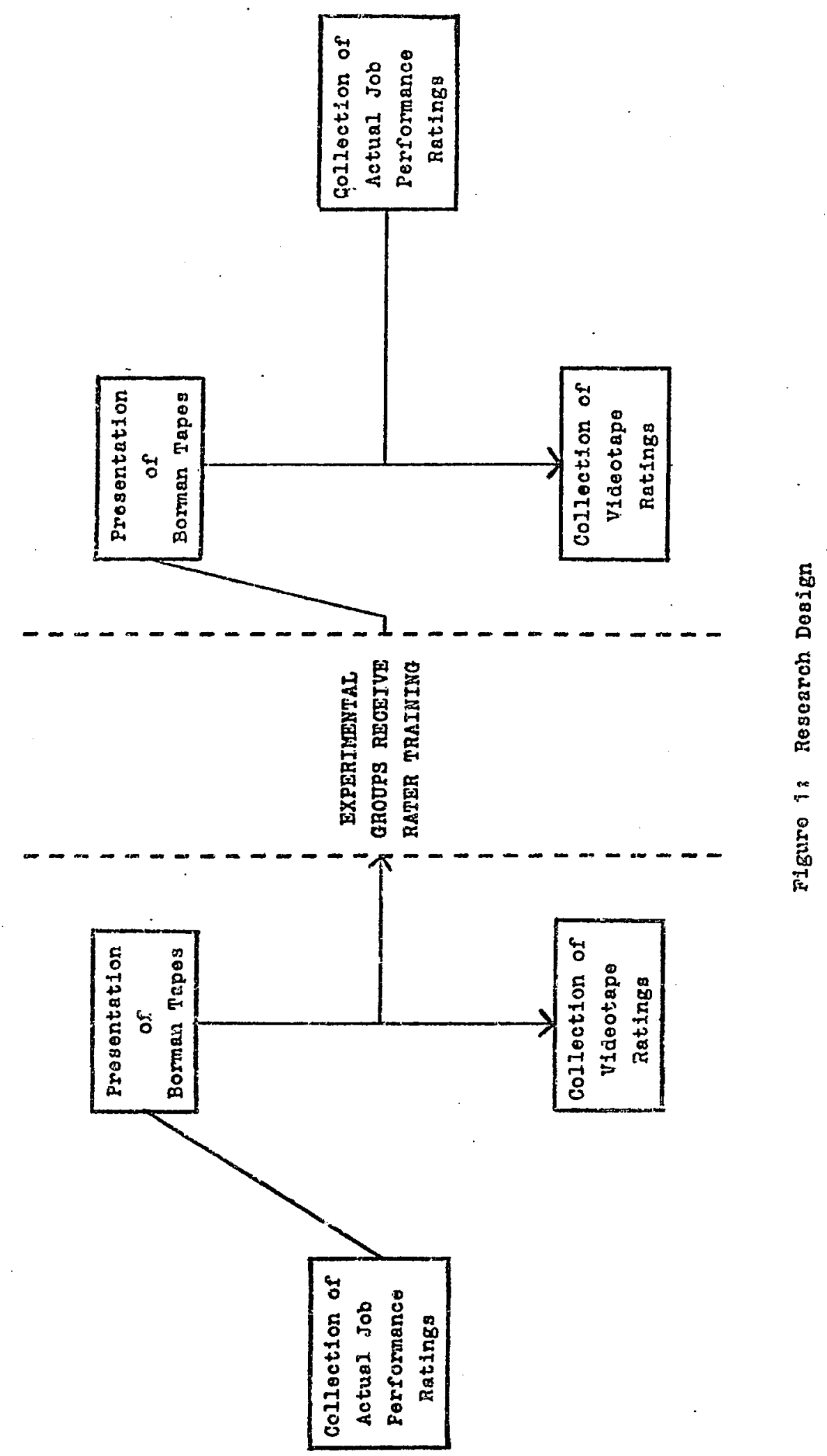


Table 1

EXPERTS' RATINGS OF MANAGER PERFORMANCE

RATEES

PERFORMANCE FACTORS

$\begin{array}{lllll}1 & 2 & 3 & 4 & 5\end{array}$
A. STRUCTURING/CONTROLLING
$5 . \emptyset \quad 2.5 \quad 6 . \emptyset \quad 2 . \emptyset \quad 3 . \emptyset$ INTERVIEW
B. ESTABLISHING/MAINTAINING RAPPORT
$2.5 \quad 5.5 \quad 4.5 \quad 6.0 \quad 4.0$
C. REACTING TO STRESS
$\begin{array}{lllll}1.5 & 4.5 & 5.0 & 3.5 & 2.5\end{array}$
D. OBTAINING INFORMATION
$\begin{array}{lllll}3.5 & 3.5 & 6.0 & 2.5 & 2.0\end{array}$
E. RESOLVING CONELICTS
$1.52 .0 \quad 6.0 \quad 5.0 \quad 5.0$
F. DEVELOPING ENPLOYEES
$\begin{array}{lllll}2.5 & 3.5 & 3.5 & 3.5 & 5.5\end{array}$
G. NOTIVATING EMPLOYEES
$2 . \emptyset \quad 5 . \emptyset \quad 5 . \emptyset \quad 2.5 \quad 6 . \emptyset$ 
Dependent Measures

Dependent measures assessed in the present study are grouped according to the focus of measurement.

Psychometric considerations. Measures of halo, leniency and range restriction were gathered for both pretraining and post-training videotape performance ratings. In addition, these same psychometric variables were measured on the actual job performance ratings. Both pre-training (the most recently completed Employment performance Evaluations were supplied by the Personnel Department) and post-training evaluations were collected. For purposes of this study, halo was operationally defined as the variance across dimensions of the rater's ratings of a particular ratee. Leniency was operationally defined as a shift in the mean ratings from the midpoint of the scale in the favorable or higher rating direction. Restriction of range was designated as the standard deviation of the rating distribution, over ratees and dimensions.

Accuracy. Utilizing data collected from ratings of the videotaped ratees both before and after training, and compared to the normative true scores, accuracy data were derived. The measure of accuracy chosen for use in this study (per Cronbach, 1955) was differential accuracy (DA). The DA measure provided accuracy scores for each rater on each job dimension. The DA for a rater on a dimension was computed by correlating the rater's rating of the five videotaped managers on that dimension with the mean true 
scores provided by the expert juages. The Fisher $r$ to $z$ transformation was then applied to each DA correlation. Each rater, therefore, had a total of seven pre-training accuracy scores, and seven post-training accuracy scores, corresponding to the seven managerial dimensions.

Trainee reaction measures. Three items on the Trainee Reaction Questionnaire administered to all employees after training (see Appendix F) were used to measure participants' reactions to (1) the overall training program, (2) the videotaped lecture portion of training, and (3) the discussion portion of the training program. 


\section{Results}

\section{Laboratory Data}

Leniency, halo, range restriction and differential accuracy measures were calculated from performance ratings of the Borman managerial videotapes. The pretest/posttest design allowed a comparison of means across groups and time. Consequently, psychometric errors were analyzed using a Group (4) x Time (2) x Rater (12) Analysis of Variance (ANOVA), with raters nested within groups. Differential accuracy was measured by computing a Group (4) $x$ Time (2) $x$ Rater (12) Nultivariate Analysis of variance (MANOVA) (with raters nested within groups), with the seven dimensions designated as dependent measures. In addition, because the central focus of the research concerned identifying the changes in error rate and accuracy within groups across time, orthogonal comparisons were applied to all Group $x$ Time interactions, regardless of statistical significance. In fact, wherever orthogonal comparisons are analyzed, the ANOVA interaction effect is of secondary concern. In addition, because of unequal levels of the Rater factor, four subjects were randomly excluded from the analyses (two subjects from the Psychometric Error Training Group, and one subject each from the Decision-Making and Control groups). 
Leniency. Leniency was operationally defined as a shift in the mean ratings from the midpoint of the scale in a higher rating direction. Thus, mean ratings for all raters in the four groups, both before and after training were compared. Results of the $4 \times 2 \times 12$ ANOVA indicated significant Time and Time $x$ Group leniency effects (see Table 2). Orthogonal comparisons between each group's pretraining and post-training ratings were subsequently performed, and indicate a significant change in level of leniency for the Psychometric Error Training group $(p<$ - 05$)$. In addition, this change was in the expected direction, with error-training causing a drop in rater leniency (Table 3). However, no other groups showed a significant increase or decrease in level of leniency as a result of training.

Halo. Halo was operationally defined as the variance across dimensions of the rater's ratings of a particular ratee. Thus, the variance of the ratings across ratees and dimensions was also analyzed using the Group $\mathbf{x}$ Time $\mathrm{x}$ Rater ANOVA. Significant Group and Group $x$ Time effects resulted, as shown in Table 4. Once again, orthogonal comparisons were used to test for significant time differences within each group. Just as with leniency, significant halo differences were found in the group that received training to reduce halo. This significant difference was also in the expected direction (see Table 3), with a drop in halo occurring after training. A statistically significant 
Table 2

Summary Table of Analysis of Variance on Leniency

Scores from Laboratory Ratings

\begin{tabular}{|c|c|c|c|c|}
\hline $\begin{array}{l}\text { Source of } \\
\text { Variation }\end{array}$ & Sum of Squares & $d f$ & Mean Squares & F Ratio \\
\hline GROUP & 0.5744 & 3 & $\emptyset .1915$ & $\emptyset .6777$ \\
\hline RATER (G) & 12.4307 & 44 & $\emptyset .2825$ & ----- \\
\hline TINE & 9.9429 & 1 & $\emptyset .9429$ & $13.1182 *$ \\
\hline $\mathrm{TR}(\mathrm{G})$ & 3.1626 & 44 & $\emptyset . \emptyset 719$ & $-\cdots-\infty$ \\
\hline TG & 1.1339 & 3 & $\emptyset .378 \emptyset$ & $5.2586 *$ \\
\hline Total & 18.2445 & 95 & ------ & $----\infty$ \\
\hline
\end{tabular}


Table 3

Orthogonal Comparisons Between Pre-Training and Post-Training Mean Scores for Each Group

\begin{tabular}{|c|c|c|c|}
\hline Type of Training & Leniency & Halo & Range Restriction \\
\hline Control (I) & $\emptyset .0170$ & 3.1256 & $4.7840 *$ \\
\hline $\begin{array}{l}\text { Psychometric } \\
\text { Error (2) }\end{array}$ & $26.1269 *$ & $17.5971 *$ & $3.1066 *$ \\
\hline Observation (3) & 0.6828 & $4.8276 *$ & $6.9915^{*}$ \\
\hline $\begin{array}{l}\text { Decision-Making } \\
\text { (4) }\end{array}$ & $2 . \emptyset 6 \emptyset \emptyset$ & 0.0219 & 0.7649 \\
\hline MS error & 0.0719 & 0.1447 & 0.7457 \\
\hline $\begin{array}{l}\text { Direction of } \\
\text { Significant } \\
\text { F Values** }\end{array}$ & $21>22$ & $\begin{array}{l}21>22 \\
31<32\end{array}$ & $\begin{array}{l}11<12 \\
31<32\end{array}$ \\
\hline \multicolumn{4}{|c|}{$\begin{array}{l}\text { * These values reflect significant changes from Pre-Training } \\
\text { to Post-Training for each group. For example, the } \\
\text { leniency score for Group } 2 \text { (psychometric error training) } \\
\text { prior to training was significantly larger than leniency } \\
\text { after training. }\end{array}$} \\
\hline
\end{tabular}

* $\underline{p}<.05$ 
Table 4

Summary Table of Analysis of Variance on Halo

Scores from Laboratory Ratings

\begin{tabular}{|c|c|c|c|c|}
\hline $\begin{array}{l}\text { Source of } \\
\text { Variation }\end{array}$ & Sum of Squares & $\mathrm{df}$ & Niean Squares & $\underline{F}$ Ratio \\
\hline GROUP & 10.9113 & 3 & 3.6371 & $10.2466 *$ \\
\hline $\operatorname{RATER}(G)$ & 15.6181 & 44 & $\emptyset .355 \emptyset$ & $-\cdots-$ \\
\hline TIME & $\emptyset .0052$ & 1 & 0.0052 & 0.6357 \\
\hline $\operatorname{TR}(G)$ & 6.3883 & 44 & 0.1447 & $---\cdots$ \\
\hline TG & 3.6966 & 3 & 1.2322 & $8.5135^{*}$ \\
\hline Total & 36.6195 & 95 & $\ldots-\infty-\infty$ & $\cdots-\infty-\infty$ \\
\hline
\end{tabular}


difference $(p<. \varnothing 5)$ between pre- and post-training means was also discovered for the observation Training group. This change, however, was in the opposite direction, with degree of halo in the performance ratings increasing after Observation Training. The control group and the Decision-Making Training group once again showed no significant change in level of halo.

Range Restriction. Range restriction was operationally defined as the standard deviation of the rating distribution over ratees and dimensions. Thus, a comparison of range restriction levels was once again accomplished by using a 4 $x 2 \times 12$ ANOVA. A summary of the Analysis of Variance of these data are presented in Table 5. These results show a statistically significant Time effect $(p<.05)$. In addition, orthogonal comparisons within groups across time found significant differences between levels of range restriction for the control group and the observation Training group. These results indicate increased range restriction for these two groups subsequent to training. Levels of range restriction did not change significantly for either the Psychometric Error Training group or the Decision-Making group (see Table 3).

Leniency, halo and range restriction means collected before and after training from each of the four groups are presented in Table 6. A summary of the psychometric findings suggests, then, that training to reduce psychometric errors did, in fact, cause a significant 
Table 5

Summary Table of Analysis of Variance on Range Restriction Scores from Laboratory Ratings

\begin{tabular}{|c|c|c|c|c|}
\hline $\begin{array}{l}\text { Source of } \\
\text { Variation }\end{array}$ & Sum of Squares & $d f$ & Mean Squares & F Ratio \\
\hline GROUP & 0.5699 & 3 & $\emptyset .1900$ & 0.1738 \\
\hline $\operatorname{RATER}(G)$ & 48.0853 & 44 & 1.8929 & ----- \\
\hline$T I M E$ & 10.3549 & 1 & 10.3549 & $13.8867 *$ \\
\hline $\operatorname{TR}(G)$ & 32.89093 & 44 & $\emptyset .7457$ & $-\cdots$ \\
\hline TG & 1.2504 & 3 & 0.4168 & 0.5590 \\
\hline Total & $93 . \emptyset 698$ & 95 & ------ & $-\cdots$ \\
\hline
\end{tabular}


Table 6

Means of Leniency, Halo and Range Restriction

Scores for Field Ratings

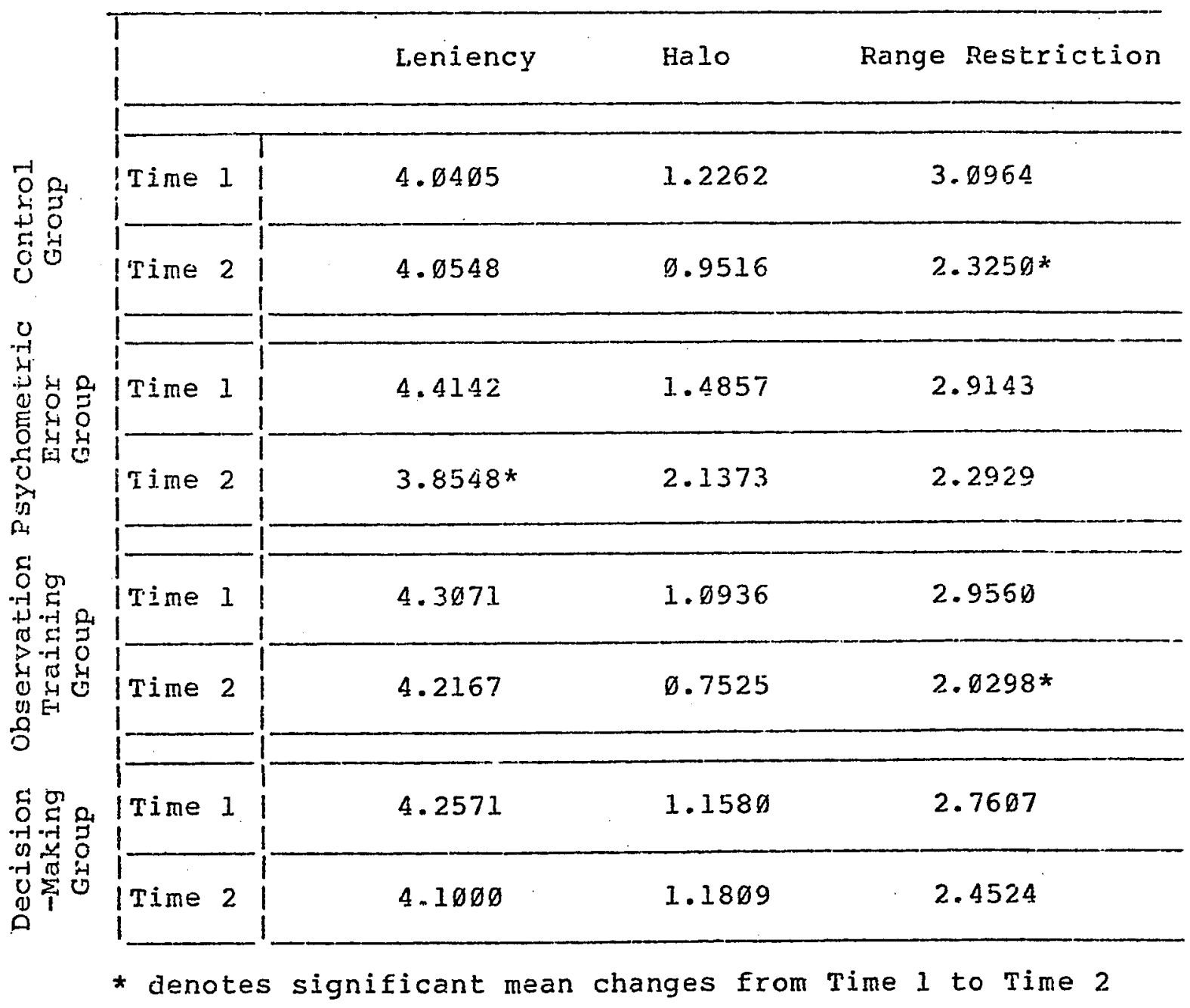


reduction in halo and leniency. However, observation Training caused an increase in halo errors and range restriction errors, while Decision-Making Training appeared to have no significant effect on psychometric error rate.

Accuracy. Differential accuracy scores for each rater on each dimension were compared using a Group $x$ Time $x$ Rater MANOVA, with the seven dimensions as multiple dependent measures. Results of the $4 \times 2 \times 12$ NiANOVA showed a statistically significant Group $x$ Time effect $(p<. \emptyset 5)$. Table 7 presents the summary MANOVA Table. Subsequently, seven separate univariate analyses were computed for each of the dependent measures on this factor. As shown in Table 8, three of the seven ANOVAs were also statistically significant at the .05 level (Dimensions $4,5, \& 7$ ). In addition, given the rationale presented earlier, orthogonal comparisons were performed on all seven dimensions for each group, comparing pre-training and post-training DA scores. Table 9 presents the results of these planned comparisons. Orthogonal comparisons on Dimensions One, Three and Six resulted in no significant differences in accuracy for the four groups across time. Dimension Two, however, shows a significant change in accuracy for the Decision-Making Training group. In addition, this change in accuracy was in a positive direction, increasing significantly after training. No other group showed a significant training effect on this dimension. Thus, the results indicate that training aimed at improving a rater's decision-making skills also improves the accuracy of the ratings on Dimension Two. 
Table 7

Summary Table of Nultivariate Analysis of Variance on Accuracy Scores from Laboratory Ratings

\begin{tabular}{lcc}
\hline $\begin{array}{l}\text { Source of } \\
\text { Variation }\end{array}$ & $\begin{array}{c}\text { Degrees of } \\
\text { Freedom }\end{array}$ & $\begin{array}{c}\text { Approximate } \\
\text { F-Value }\end{array}$ \\
\hline Group & 21,110 & 1.0524 \\
\hline Time & 7,38 & 1.3059 \\
\hline GX T & 21,110 & $2.0846 *$ \\
\hline
\end{tabular}


Table 8

Summary Table of Univariate F-Tests on Accuracy Scores from Laboratory Ratings for Group x Time Effect

\begin{tabular}{|c|c|c|c|}
\hline Variable & Sum of Squares & Mean Squares & $\underline{E}$ Ratio** \\
\hline Dimension 1 & 0.2800 & 9.0933 & 0.3868 \\
\hline Dimension 2 & 1.0147 & 0.3382 & 2.3325 \\
\hline Dimension 3 & 0.6865 & 0.2288 & 1.2075 \\
\hline Dimension 4 & $5.184 \emptyset$ & 1.7280 & $5.1896^{*}$ \\
\hline Dimension 5 & $1.9 ø 8 \emptyset$ & 0.6360 & $3.7583^{*}$ \\
\hline Dimension 6 & 3.3692 & 1.1231 & 2.5903 \\
\hline Dimension 7 & 2.3285 & 0.7762 & $2.9951 *$ \\
\hline
\end{tabular}




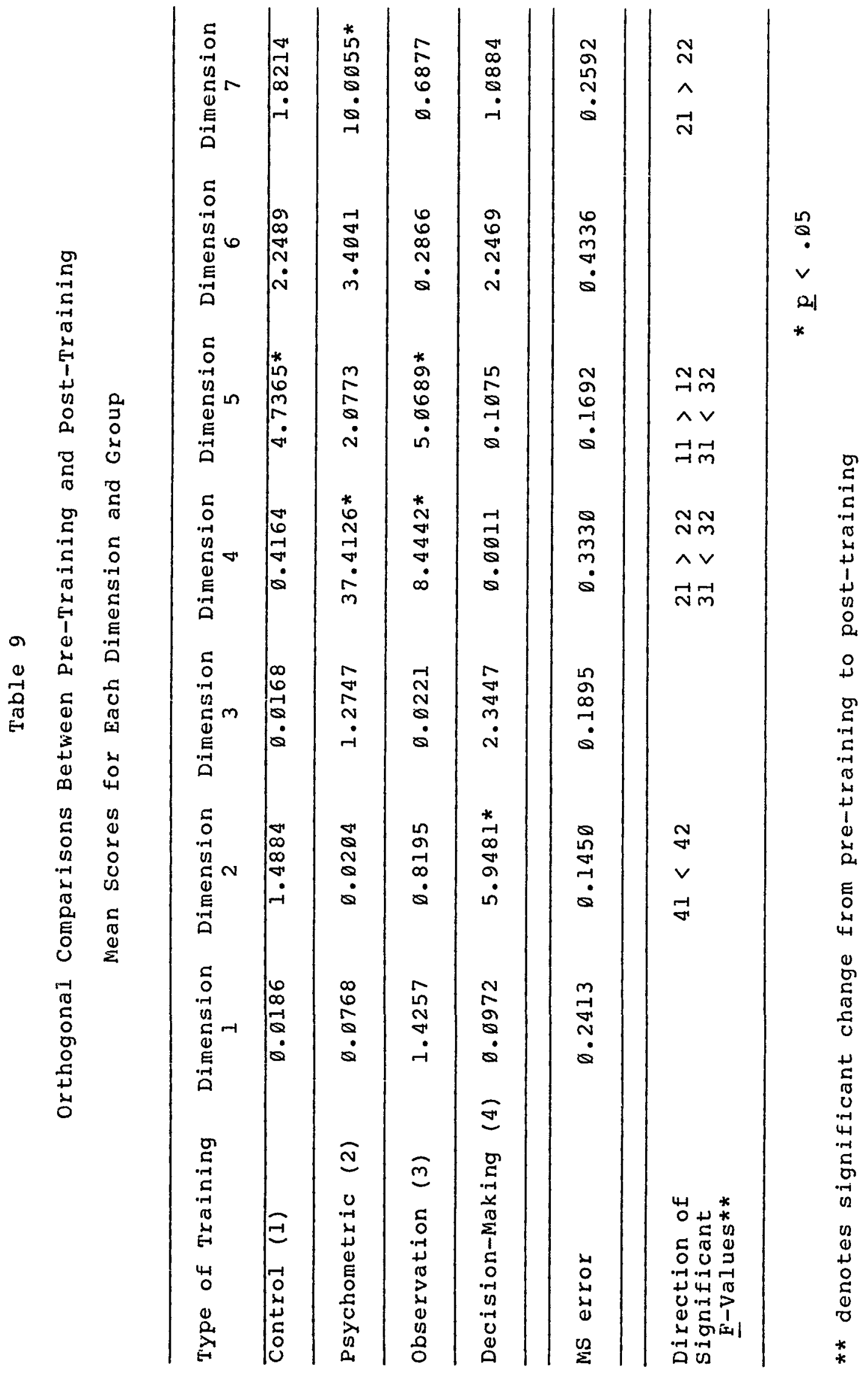


As shown in Table 9, significant differences were also uncovered for the remaining three dimensions (Dimensions 4, 5. \& 7). For both Dimension Four and Dimension Seven, significant decline in accuracy was found in subjects exposed to the psychometric error training. In addition, the Observation Training group changed significantly in Dimensions Four and Five. The direction of change for the Observation Training group on these two dimensions was opposite that of the scores for the Psychometric Error Training group; namely, an improvement in the accuracy of the ratings occurred after training. Finally, the Control group was found to have decreased in accuracy at Time Two (after training) on Dimension Five.

Overall, significant changes in accuracy were found on four of the seven performance dimensions. The Psychometric Error Training group became significantly less accurate on two of the seven dimensions, the observation Training group became more accurate on two of the dimensions, the DecisionMaking group was significantly more accurate on one dimension, and the control group was found to be less accurate on one dimension. The mean DA scores for all groups both before and after training are listed in Appendix G.

Additional insight into the effects of the different training approaches on psychometric errors and accuracy can be gained by looking at a summary table of trends depicting mean changes across training. While these changes do not 
represent statistically significant differences, they do suggest direction of change for each group. Table 10 illustrates these changes for all laboratory dependent measures. A "+" signifies an improvement in scores on that dependent variable subsequent to training. A "-" denotes a decrement in performance, and an "=" signifies no noticeable change in pre-to-post training performance ratings (For the accuracy, halo, and range restriction measures a . fluctuation was considered a change, while for the leniency measure, a .36 fluctuation was considered a change).

As is apparent, while psychometric error training reduced halo and leniency, it also tended to reduce accuracy on five of the seven performance dimensions. However, for the other two training groups, psychometric errors either persisted or increased, but more importantly, accuracy improved. For the observation Training group, an improvement in accuracy is noted on four of the seven dimensions, while the Decision-Making Training group improved on five of the seven dimensions. Thus it appears from this analysis of trends, that while psychometric error training does indeed reduce rating errors, it has a negative impact on accuracy. observation and decision-making training, on the other hand, appear to have a positive effect on accuracy.

Field Data (Actual Performance Evaluations)

Leniency, halo and range restriction measures were calculated from actual performance ratings. After the 
Table $1 \emptyset$

Trends of Means From Time one to Time Two

CONTROL PSYCHOMETRIC OBSERVATION DECISION-

MAKING

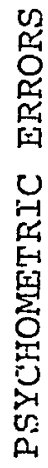

LENIENCY

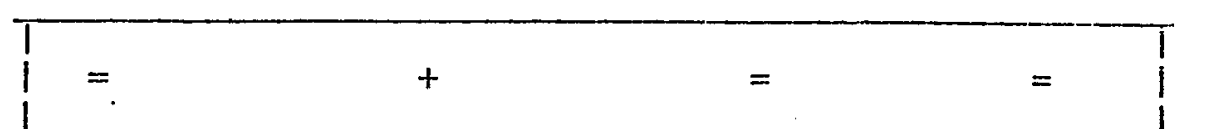

HALO

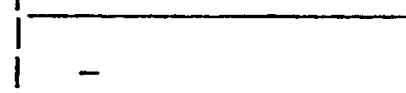

1

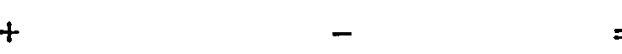

\section{RANGE}

RESTRICTION
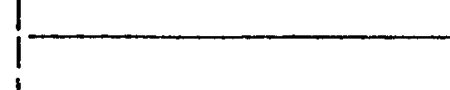

忌

DIMENSION

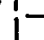

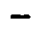

11

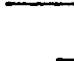

DIMENSION

I

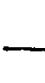

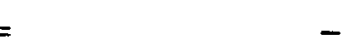

$-$

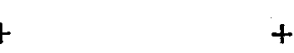

DIMENSION
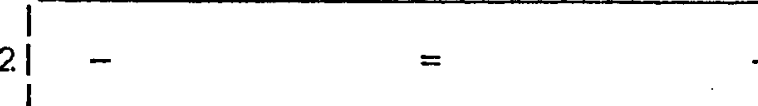

$31=$
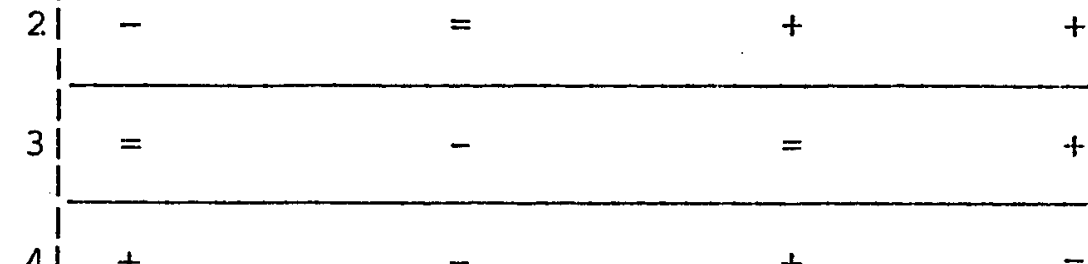

DINENSION

5

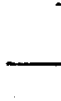

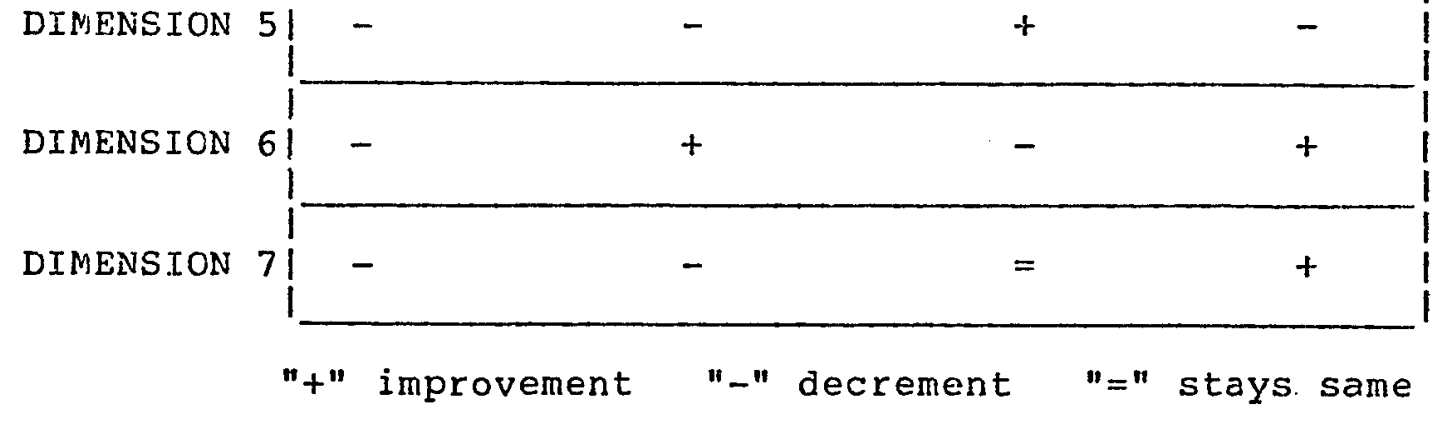

Note: These signs indicate direction of change, not statistical significance. 
completion of training, supervisors attending the workshop were asked to fill out evaluations for the employees they evaluated on the job. Employees rated were then identified, and the most recent pre-training evaluation was supplied by the Personnel Department. However, because some employees had never been rated previously, some supervisors in the workshop were new and had never rated before, and a supervisor needed to evaluate more than one employee for psychometric measures to be computed, a significant number of raters had to be dropped from the pre-training/posttraining analyses (five subjects remained in the control and Decision-Making Groups, six subjects in the observation Training Group, and eight subjects in the Psychometric Error Training Group). Once again, unequal levels of the rater factor required additional elimination of subjects. As a result, only five raters per group were used in analyses of the field data.

Leniency. A Group $x$ Time $x$ Rater ANOVA (with raters nested in groups) was used to evaluate mean ratings. As illustrated in Table 11, no significant main or interaction effects were found. Applying the same rationale used in analyzing the laboratory data, orthogonal comparisons were computed to test for pre-training-to-post-training differences within each group. Table 12 presents these comparisons. Both the Psychometric Error Training group and the observation Training group showed significant changes in leniency after training. However, the change for the two 
Table Il

Summary Table of Analysis of Variance on Leniency

Scores from Field Ratings

\begin{tabular}{|c|c|c|c|c|}
\hline $\begin{array}{l}\text { Source of } \\
\text { Variation }\end{array}$ & Sum of Squares & $d f$ & Mean Squares & $\underline{E}$ Ratio \\
\hline GROUP & 0.5419 & 3 & $\emptyset .1806$ & 1.4992 \\
\hline $\operatorname{RATER}(G)$ & 1.9277 & 16 & $\emptyset .1205$ & ----- \\
\hline TIME & $\emptyset .0043$ & 1 & $\emptyset .0043$ & 0.3135 \\
\hline $\operatorname{TR}(G)$ & 0.2212 & 16 & 0.0138 & ----- \\
\hline TG & $\emptyset .1151$ & 3 & $\emptyset .0384$ & 2.7755 \\
\hline Total & 2.8102 & 39 & ----- & ---- \\
\hline
\end{tabular}


Table 12

Orthogonal Comparisons Between Pre-Training and Post-Training Mean Scores for Each Group

\begin{tabular}{|c|c|c|c|}
\hline $\begin{array}{l}\text { Type of } \\
\text { Training }\end{array}$ & Leniency & Range & Restriction \\
\hline Control (1) & 0.1287 & 0.5486 & 0.5388 \\
\hline Psychometric (2) & $6.7599 *$ & $\emptyset .0805$ & $4.9105 *$ \\
\hline observation (3) & $5.2242^{*}$ & $0 . \emptyset 851$ & 0.5529 \\
\hline $\begin{array}{l}\text { Decision-Making } \\
(4)\end{array}$ & 0.0723 & 0.4920 & $44.3992 *$ \\
\hline MS error & 0.0138 & 0.0045 & 9.0031 \\
\hline \multirow[t]{2}{*}{$\begin{array}{l}\text { Direction of } \\
\text { Significant } \\
\text { F-Values** }\end{array}$} & $\begin{array}{l}21>22 \\
31<32\end{array}$ & & $\begin{array}{l}21>22 \\
41<42\end{array}$ \\
\hline & & & $* \underline{\mathrm{p}}<.05$ \\
\hline $\begin{array}{l}\text { * denotes signi } \\
\text { Training for }\end{array}$ & $\begin{array}{l}\text { ficant changes } \\
\text { each group }\end{array}$ & from Pre-Training & $g$ to Post- \\
\hline
\end{tabular}


groups differed in direction. While the Psychometric Error Training group reduced significantly their leniency errors, the group of supervisors trained to improve observational skills became more lenient after training. There were no significant changes in level of leniency for either the Control group or the Decision-Making group.

Halo. A $4 \times 5 \times$ ANOVA was computed using the variances of ratings across ratees and dimensions. A significant Group effect was found in these halo data (see Table 13), but using orthogonal comparisons, no statistically significant difference were obtained within groups across training (see Table 12). Thus, training had no impact on level of halo for the four groups.

Range restriction. Finally, the same ANOVA procedure was used to test for differences in restriction of range. As noted in Table 14, no statistically significant effects resulted from the $4 \times 2 \times 5$ ANOVA. Orthogonal comparisons, however, uricovered two significant changes in level of range restriction. First, the Psychometric Error Training group demonstrated a significant decrease in amount of range restriction (evidenced by an increase in the standard deviation of the performance ratings). In addition, the group of supervisors who underwent decision-making training showed an increase in restriction of range (see Table 12). Thus, it appears that psychometric error training was beneficial in reducing leniency and range restriction, while observation training caused an increase in leniency, and 
Table 13

Sumary Table of Analysis of Variance on

Halo scores from Field Ratings

\begin{tabular}{|c|c|c|c|c|c|}
\hline $\begin{array}{l}\text { Source of } \\
\text { Variation }\end{array}$ & Sum & of squares & $d f$ & Mean Squares & E Ratio \\
\hline GROUP & & $\emptyset .0440$ & 3 & $\emptyset . \emptyset 147$ & 3.2827 \\
\hline RATER (G) & & 0.0715 & 16 & 0.0045 & $-\cdots-$ \\
\hline TIME & & $\emptyset . \emptyset \emptyset \emptyset 4$ & 1 & $\emptyset . \emptyset \emptyset \emptyset 4$ & 0.1218 \\
\hline $\operatorname{TR}(G)$ & & $\emptyset .0513$ & 16 & $\emptyset . \emptyset 032$ & $-\cdots--$ \\
\hline TG & & 0.0052 & 3 & 9.9017 & $\emptyset .5353$ \\
\hline Total & & $\emptyset .1724$ & 39 & ----- & \\
\hline
\end{tabular}


Table 14

Summary Table of Analysis of Variance on Range Restriction Scores from Field Ratings

\begin{tabular}{|c|c|c|c|c|}
\hline $\begin{array}{l}\text { Source of } \\
\text { Variation }\end{array}$ & Sum of squares & $d f$ & Mean Squares & $\underline{F}$ Ratio \\
\hline GROUP & 0.0133 & 3 & 0.0044 & 0.9327 \\
\hline $\operatorname{RATER}(G)$ & 0.0762 & 16 & $\emptyset . \emptyset \emptyset 48$ & $--\cdots--$ \\
\hline TIME & 0.0002 & 1 & $\emptyset . \emptyset \emptyset \emptyset 2$ & $\emptyset .0686$ \\
\hline $\operatorname{TR}(G)$ & 0.0492 & 16 & 0.0031 & $\dot{-1}-\cdots--$ \\
\hline TG & 0.0269 & 3 & $\emptyset .009 \emptyset$ & 2.9167 \\
\hline Total & 0.1658 & 39 & ----- & ---- \\
\hline
\end{tabular}


decision-making training caused an increase in range restriction. A table of means for these three psychometric errors appears in Table 15.

\section{Trainee Reaction Measures}

Supervisors' reactions to the four training programs (the Control group completed a questionnaire following their post-data collection training) were evaluated on the basis of three trainee reaction measures (items $1,2, \& 3$ of the questionnaire that appears in Appendix F).

Trainee reactions to whether they benefitted from the training program were evaluated by means of a one-Way Analysis of Variance. As shown in Table 16, there were no significant differences in the perception of overall training worth across the four groups. The second ratee reaction measure concerned the worth of the videotaped lecture. Once again, a One-way ANOVA resulted in no significant group differences (see Table 17). Finally, reactions to the practice/discussion section of training were evaluated using a One-hay ANOVA, but no significant Group differences were found (see Table 18). In summary, then, no single training program was perceived by the trainees as more beneficial. Means and standard deviations on these three trainee reaction measures are shown in Table 19 . 
Iable 15

Means of Leniency, Halo and Range Restriction

Scores for Field katings

\begin{tabular}{|c|c|c|c|c|}
\hline \multirow{3}{*}{ 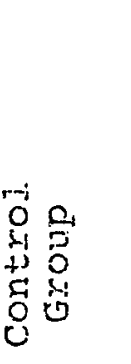 } & 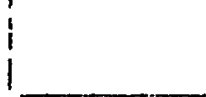 & Leniency & Hale & Range Restriction \\
\hline & Time 1 & 3.4333 & 0.1313 & 0.0833 \\
\hline & Time 2 & 3.4600 & 0.1627 & 0.1089 \\
\hline 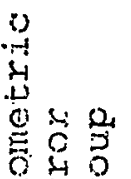 & Time I & 3.3857 & 0.2053 & 0.9856 \\
\hline 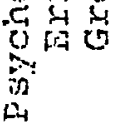 & Time 2 & $3.1933 *$ & 0.2173 & $0.1633^{*}$ \\
\hline 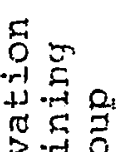 & Tims 1 & 3.17333 & 0.1753 & 0.1467 \\
\hline 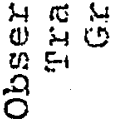 & Time 2 & $5.3433 \%$ & 0.1 .877 & 0.021 .6 \\
\hline 兵焉 & Time 1 & 3.5500 & 0.2500 & 9.1750 \\
\hline 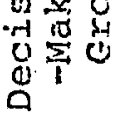 & Time 2 & 3.5790 & 0.2283 & $0.1161 *$ \\
\hline & $\begin{array}{l}\text { * denote } \\
\text { Post-T }\end{array}$ & icant & mean & Pre--Trajning to \\
\hline
\end{tabular}


Table 16

Summary Table of Analysis of Variance for Each Group's Trainee Reaction (Item One)

\begin{tabular}{|c|c|c|c|c|}
\hline $\begin{array}{l}\text { Source of } \\
\text { Variation }\end{array}$ & Sum of squares & $d f$ & Mean Squares & E Ratio \\
\hline \multicolumn{5}{|l|}{ Between } \\
\hline Groups & 5.2715 & 3 & 1.7572 & $\emptyset .8795$ \\
\hline \multicolumn{5}{|l|}{ Within } \\
\hline Groups & 97.8984 & 49 & 1.9979 & $-\cdots-\cdots$ \\
\hline Total & 103.1699 & 52 & ------ & ---- \\
\hline
\end{tabular}


Table 17

Summary Table of Analysis of Variance for Each

Group's Trainee Reaction (Item 2)

\begin{tabular}{lcccc}
\hline $\begin{array}{l}\text { Source of } \\
\text { Variation }\end{array}$ & Sum of Squares & df & Mean Squares & F Ratio \\
\hline $\begin{array}{l}\text { Between } \\
\text { Groups }\end{array}$ & 8.5244 & 3 & 2.8415 & 1.5022 \\
\hline $\begin{array}{l}\text { Within } \\
\text { Groups }\end{array}$ & 92.6832 & 49 & 1.8915 & ----- \\
\hline $\begin{array}{l}\text { Total } \\
101.2076\end{array}$ & 52 & --05 & $\underline{p}$
\end{tabular}


Table 18

Summary Table of Analysis of Variance for Each

Group's Trainee Reaction (Item Three)

\begin{tabular}{|c|c|c|c|c|}
\hline $\begin{array}{l}\text { Source of } \\
\text { Variation }\end{array}$ & Sum of Squares & $d f$ & Mean Squares & $\underline{E}$ Ratio \\
\hline \multicolumn{5}{|l|}{ Between } \\
\hline Groups & 7.7999 & 3 & $2.60 \emptyset \emptyset$ & $1.5 \emptyset 5 \emptyset$ \\
\hline \multicolumn{5}{|l|}{ Within } \\
\hline Groups & 84.6529 & 49 & 1.7276 & $-\cdots-\cdots$ \\
\hline Total & 92.4528 & 52 & ----- & ------ \\
\hline
\end{tabular}


Tabie 19

Table of Means and Standard Deviations for Trainee Reaction Measures

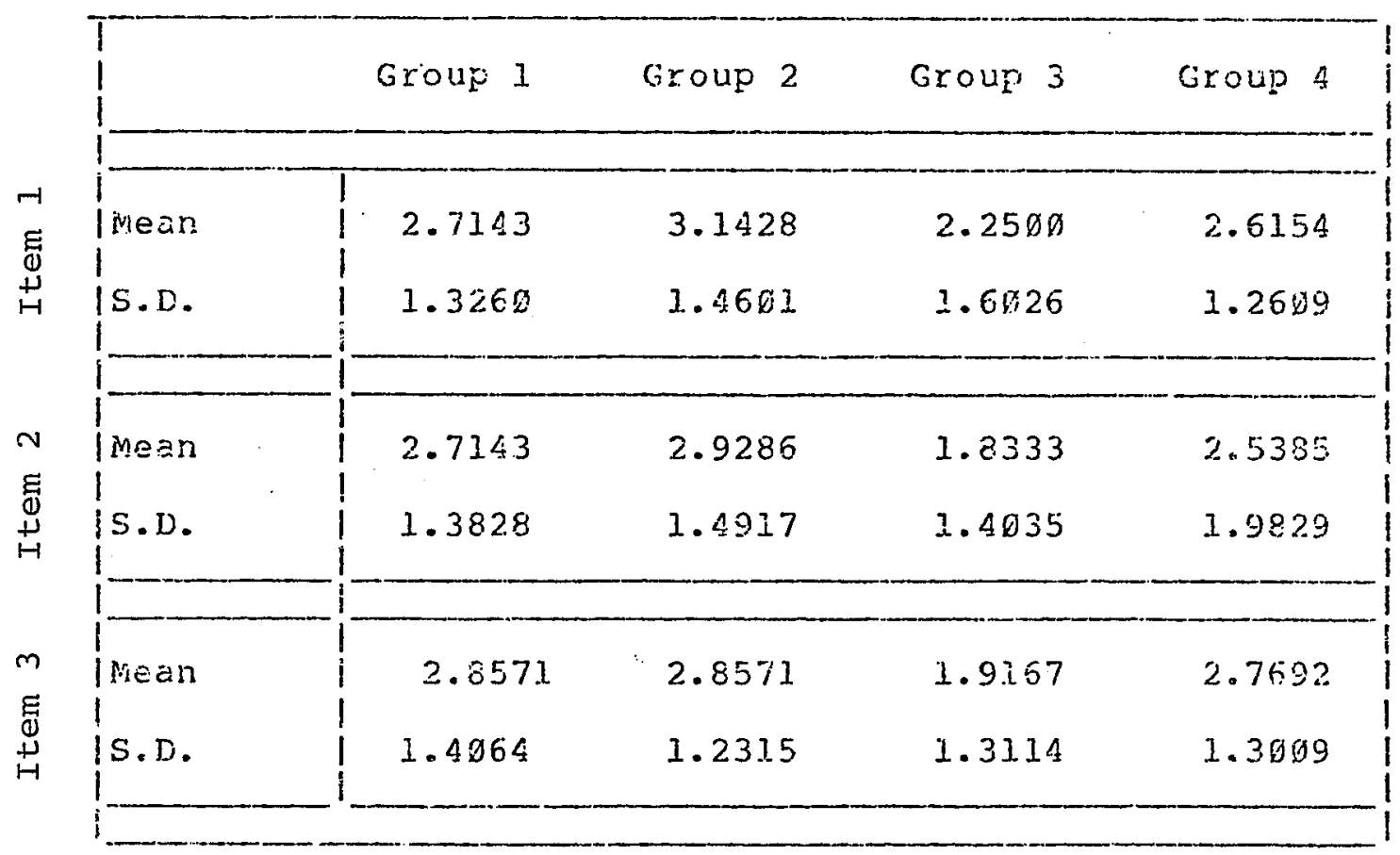




\section{Discussion and Conclusions}

The present study was designed to investigate differential effects of three training programs on psychometric errors and accuracy in performance ratings. As noted in the previous section, psychometric error training significantly reduced levels of leniency and halo, thus supporting earlier research in this area (i.e., Levine \& Butler, 1952; Borman, 1975; Bernardin, 1978). From such results, researchers in the past have inferred that the accuracy of the ratings would be increased. Instead, it appears that differential accuracy scores decrease after rater error training. These findings lend support to the Bernardin and Pence (1980) study, and suggest that such training has an adverse impact on rating accuracy. Perhaps training subjects to be aware of certain rating errors oversensitizes them to where on the scale they are rating, rather than how accurately they are rating.

When viewed from a measurement theory approach, these findings suggest an alternative interpretation. As noted previously, rater training researchers classify rating errors as error variance, and consequently, assume training to reduce these errors will increase accuracy. However, if these rating errors contain both error variance and true variance, training that reduces these errors would not only 
reduce error variance, but would affect true variance as well. When viewed from this perspective, rater error training could, in fact, reduce the accuracy of the ratings, rather than improving accuracy as previously assumed.

Results from this study also support the recent recommendations by Borman (1979a) and Bernardin and Buckley (1981) concerning observation training, and the findings of Thorton and Zorich (1980). Supervisors receiving training to improve observation skills showed overall improvement in the accuracy of their ratings, but this was not reflected in the psychometric error measures. A closer look at the content and focus of such training is an important area for future research. For example, Borman (1979a) has recommended that more emphasis be placed on training individuals to observe performance-related behaviors, and to agree on and to learn correct performance standards.

Consonant with this line of thinking, Bernardin and Buckley (1981) have suggested a formal, standardized diarykeeping system as an aid in increasing observational skills. In addition, they have recommended the use of frame-ofreference training whereby raters with idiosyncratic work standards could be identified, and attempts made to bring their perceptions into closer congruence with the rest of the organization.

In relation to the Decision-Making Training Program developed for this study, results suggest such an approach may be a fruitful avenue for further investigation. While 
supervisors trained using the decision-making approach did not show reduced levels of psychometric errors, an improvement in rating accuracy was evident. Nuch additional work is needed to clarify and improve decision-making training in the area of performance appraisal. Much can be learned from existing cognitive and decision-making literature. It is the belief of the present author that training to improve observational skills deals only with the early stages of the Decision-Making Model (namely, the reception and storage stages), and that increased emphasis on the recall and/or response selection stages of decisionmaking are required. In a recent review article, Feldman (1981) focused on cognitive processes in performance appraisal and suggested further research efforts in this direction.

In general, both the Observation and Decision-Making Approaches to training offer some hope for improving the accuracy of performance ratings. Both of these training approaches view performance appraisal as a dynamic process that occurs throughout the year. The typical psychometric error training takes a much more static approach to appraisal. Consequently, the focus remains on an awareness of what errors "look like" when the evaluation is filled out. When these three training approaches are viewed in this manner, it is not illogical to propose that a longitudinal design may even uncover more dramatic changes. Thus, while psychometric errors may return to former levels 
as time since training increases (Ivancevich, 1979), the accumulation of additional data points may increase the power and effect of training to improve observation and decision-making skills, by increasing the accuracy of decisions about performance.

Results of field data analyses suggest a closer look at transfer of training. While significant reduction in leniency and range restriction levels were found, sample size $(n=5)$ limits the significance of the results. In addition, raters were aware that post-training évaluations would impact in no way on merit increases, thus possibly confounding the results. Still, the direction of psychometric error changes for the field data were consistent with those in the laboratory data (namely, the Psychometric Error Training group showed decreases in errors, while the other groups either increased or stayed the same).

Finally, the results of the current study suggest several other avenues for future research. Because of an increased concern for assessing the accuracy of performance ratings, and the relation between psychometric errors and accuracy, additional research needs to focus on identifying predictors of rating accuracy. Borman (1977; 1979b; 1986) and Murphy and his colleagues (Murphy \& Balzar, 1981; Murphy, et al., 1982), as noted earlier, have begun to address some of these issues. 
Also, additional research needs to evaluate the relation between training, accuracy and dimensions of performance. Borman (1979a), found a significant dimension effect when analyzing differential accuracy scores using a Format $x$ Dimension $x$ Training ANOVA. He suggested that certain kinds of dimensions may be inherently more difficult than others for evaluating others accurately. Given the results of the present study, a Dimension $x$ Type of Iraining Interaction is suggested. As shown in Table 10 , the accuracy of performance ratings varied widely across the four groups. Consequently, different types of rater training may improve or limit one's ability to make accurate judgments about different aspects of job performance.

In general, the current research makes a fairly strong indictment against the traditional psychometric error approach to rater training, at least when viewed from the perspective of performance rating accuracy. In addition, further research is necessary to determine whether observation (and decision-making training are viable new approaches. Research may, in fact, determine that none of these approaches are worthwhile from a management perspective. The possibility also exists that different approaches to rater training may be more effective at different supervisory levels, or in some combination. Finally, while psychometric error training may not prove useful as a means for improving rating accuracy, its worth may lie in how such training affects rater attitudes. 
Programs of rater training must meet an acceptability criterion if they are to be deemed useful. While no differences were found in trainee reactions to the three training approaches used in this study, this variable must be considered before abandoning a particular approach to rater training. 


\section{$\underline{\text { References }}$}

Bernardin, H.J. Effects of rater training on leniency and halo errors in student ratings of instructors. Journal of Applied Psychology, $1978,63,301-308$.

Bernardin, H.J. \& Buckley, M.R. Strategies in rater. training. Academy of Management Review, 1981, $\underline{6}$, 205-212.

Bernardin, H.J. \& Pence, E.C. The effects of rater training: Creating new response sets and decreasing accuracy. Journal of Applied Psychology, 1980, 65, $60-66$.

Bernardin, H.J. \& Walter, C.S. Effects of rater training and diary-keeping on psychometric error in ratings. Journal of Applied Psychology, 1977, 62, 64-69.

Bingham, W.V. Halo, invalid and valid. Journal of Applied Psychology, 1939, 23, 221-228.

Bolster, B.F. \& Springbett, B.M. The reaction of interviewers to favorable and unfavorable information. Journal of Applied Psychology, 1961, 45, 97-103.

Borman, W.C. Effects of instructions to avoid halo error on reliability and validity of performance evaluation ratings. Journal of Applied Psychology, 1975, 60, $556-560$. 
Borman, W.C. Consistency of rating accuracy and rating errors in the judgment of human performance. Organizational Behavior and Human Performance, 1977 , 20, $258-272$.

Borman, w.C. Format and training effects on rating accuracy and rater errors. Journal of Applied Psychology, $1979(a), 64,41 \emptyset-421$.

Borman, W.C. Individual differences correlates of accuracy in evaluating others' performance effectiveness. Applied Psychological Measurement, 1979(b), 3, 103-115. Borman, W.C. Performance judgments: The quest for accuracy in ratings of performance effectiveness. Paper presented at First Annual Scientist-practitioner Conference. Old Dominion University, Norfolk, Virginia, $198 \emptyset$.

Borman, W.C., Hough, L.M. \& Dunnette, M.D. Performance ratings: An investigation of reliability, accuracy, and relationships between individual differences and rater error. Minneapolis: Personnel Decisions, Inc., 1976.

Brown, E.M. Influence of training, method and relationship on halo effect. Journal of Applied Psychology, 1968, 52, 195-199.

Campbell, J.P. Psychometric theory. In M.D. Dunnette (Ed.). Handbook of Industrial and Organizational Psychology, Chicago: Rand-McNally, 1976.

Cooper, W.H. Ubiquitous halo. Psychological Bulletin, $1981, \underline{90}, 218-244$. 
Cronbach, L.J.' Processes affecting scores on "understanding of others" and "assumed similarity." Psychological Bulletin, 1955, 52, 177-193.

Faye, C.H. \& Latham, G.P. Effects of training ard rating scales on rating errors. Personnel Psychology, 1982, 35. $105-116$.

Feldman, J.M. Beyond attribution theory: Cognitive processes in performance appraisal. Journal of Applied Psychology, 1981, 66, 1.27-148.

Goldberg, L.R. Man versus model of man: A rationale, plus some evidence, for a method of improving clinical inferences. Psychological Bulletin, 1970, 73, 422-432. Guion, R.M. Personnel testing. New York: McGraw-Hill, 1965.

Hogarth, R.M. Beyond discrete biases: Functional and dysfunctional aspects of judgmental heuristics. Psychological Bulletin, 1981, 9Q, 197-217.

Ivancevich, J.M. A longitudinal study of the effects of rater training on psychometric errors in ratings. Journal of Applied Psychology, 1979, 64, 5ø2-5ø8.

Kahneman, D. \& Tversky, A. Subjective probability: A judgment of representativeness. Cognitive Psychology, $1972, \underline{3}, 430-454$.

Kahneman, D. \& Tversky, A. On the psychology of prediction. Psychological Review, 1973, 80, 251-273. 
Kahneman, D. \& Tversky, A. Intuitive prediction: Biases and corrective procedures. In S. Makridakis \& S.C. wheelright $\left(E d_{0}\right)$, studies in the management sciences: Forecasting. New York: John Wiley, 1981.

Kavanagh, M.J., Mackinney, A. \& Wolins, L. Issues in managerial performance: Multitrait-multimethod analysis of variance. Psychological Bulletin, 1971, 75, 34-49.

Landy, F.J. \& Farr, J.L. Performance rating. Psychological Bulletin, $1980,87,72-107$.

Latham, G.P. \& Wexley, K.N. Increasing productivity through performance appraisal. Reading, MA: Addison-Wesley, 1981 .

Latham, G.P., wexley, K.N. \& Pursell, E.D. Training managers to minimize rating errors in the observation of behavior. Journal of Applied Psychology, 1975, 60, $550-555$

Levine, J. \& Butler, J. Lecture vs. group discussion in changing behavior. Journal of Applied psychology. $1952, \underline{36}, 29-33$.

Murphy, K. \& Balzar, W. Rater errors and rating accuracy. Paper presented at the Annual Meeting of the American Psychological Association, Los Angeles, August, 1981. Murphy, K., Garcia, M., Kerkar, S., Martin, C., \& Balzar, W. Relationship between observational accuracy and accuracy in evaluating performance. Journal of Applied Psychology, $1982,67,320-325$. 
Nisbett, R. \& Ross, L. Human inference: Strategies and shortcomings of social judgment. Englewood Cliffs, NI: Prentice-Hall, 1980 .

Sauser, W.I. \& Pond, S.B. Effects of rater training and participation on cognitive complexity: An exploration of Schneier's cognitive reinterpretation. personnel Psychology, 1981, 34, 563-577.

Springbett, B.M. Factors affecting the final decision in the employment interview. Canadian Journal of Psychology, 1958, 12, 13-22.

stockford, L. \& Bissell, H.W. Factors involved in establishing a management-rating scale. Personnel, 1949, 26, 94-116.

Taylor, E.K. \& Hastman, R. Relation of format and administration to the characteristics of graphing rating scales. Personnel Psychology, 1956, 9, 181-206. Thorton, G.C. \& Zorich, S. Training to improve observer accuracy. Journal of Applied Psychology, 1980, 65, $351-354$.

Tversky, A. \& Kahneman, D. Judgment under uncertainty: Heuristics and biases. Science, 1974, 185, 1124-1131. Tversky, A. \& Kahneman, D. Belief in the law of small numbers. Psychological Bulletin, 1971, 76, 105-110.

Tversky, A. \& Kahneman, D. Causal schemata in judgment under uncertainty. In M. Fishbein (Ed.), Progress in social psychology. Hillsdale, NJ: Lawrence Erlbaum, 1978 . 


\begin{abstract}
Vance, R.J., Kuhnert, K.W. \& Farr, J.L. Interview judgments: Using external criteria to compare behavioral and graphic scale ratings. Organizational Behavior and Human Performance, 1978, 22, 279-294.

Warmke, D. \& Billings, R.S. Comparison of training methods for improving the psychometric quality of experimental and administrative performance ratings. Journal of Applied Psychology, 1979, 64, 124-131.
\end{abstract}




\section{APPENDIX A}

Psychometric Error Training Lecture and Discussion Materials 
PSYCHOMETRIC ERROR TRAINING

Training Appraisers

Evaluating employee performance is an important and necessary part of any supervisor's job. Regardless of whether your organization employs a formal system of employee evaluation, juagments about how individual employees are performing are made almost daily. People are constantly making judgments about others. Unfortunately, many of these informal judgments may be erroneous.

Consequently, a formal system of performance evaluation is usually adopted to help reduce the possibilities of bias and uninformed judgments; to standardize the types of information that will be forthcoming; and to ensure that the resulting appraisal information that will be forthcoming; and to ensure that the resulting appraisal information is gathered in a form that permits its use across the entire organization.

While a formal system of appraisal helps to standardize this process in the organization, it in no way guarantees consistent, accurate evaluation. Therefore, the purpose of today's talk will focus on helping you be more accurate in your judgment of employee performance. We will deal with this problem by focusing on some of the most common types of errors supervisors make in evaluating their employees. By becoming familiar with these errors, and discussing ways to avoid them, we hope to improve the accuracy of performance evaluations in general. 
Insert overhead about here

Psychometric Errors

Halo Effect

Probably the most common rater error encountered is known as the halo effect. The halo effect refers to inappropriate generalization from one aspect of a person's performance to all aspects of a person's job performance. By attending to a global impression of each ratee (employee) rather than carefully distinguishing between performance factors, the supervisor commits a halo error.

For example, a person who is quite outstanding in one area of the job (e.g., job knowledge/skills) may be rated inaccurately as outstanding in all areas of the job (e.g., quality of work, productivity, initiative, dependability, etc.). Conversely, if a person is rated as deficient in one area of the job, that person may be rated incorrectly as doing poorly on all aspects of the job.

As you can see, ratings plagued by this error often do not provide an accurate portrayal of an individual's performance on different factors.

Insert overhead here 
This does not necessarily mean that certain individuals cannot be superior on all performance factors, only that certain strengths or weaknesses can sometimes influence your ratings. Remember, people have both strengths and weaknesses, and each needs to be evaluated separately. Don't let one strength or weakness influence your ratings of all performance factors.

\section{Leniency/Severity}

A second type of error often committed by those persons who must evaluate their employees is known as a leniency error, and its converse--severity error. These types of error reflect a tendency by a supervisor to be either too easy or too hard in rating all their employees.

Insert overhead about here

For example, a supervisor may rate all his/her people at one end of the scale, or the other. The problem with doing this is that in the performance evaluation process, leniency may raise unwarranted expectations of the employee for raises, promotions or challenging job assignments.

On the other hand, with severity, the employee may get tired of banging his/her head against the wall, because no matter how hard the individual tries, the supervisor cannot be satisfied. Thus, it is the rater who is either too harsh, or too lenient on subordinates. The harsh rater tends to give evaluations that are lower than what they 
should be, while the easy supervisor tends to give ratings that are higher or better than they should be--better than their performance warrants.

Restriction of Range

A third rating error which in some ways is similar to the leniency/severity error is known as restriction of range. When a supervisor rates all his/her employees harshly, or all of them leniently, or all of them about average, it's difficult to distinguish between employees. Thus, restriction of range refers to rating all your employees at about the same level. Range restriction errors are committed by supervisors who want to play it safe. Consequently, the obtained ratings will not allow the supervisor or the organization to differentiate between employees according to levels of performance.

Insert overhead about here

As you can see, just as with leniency/severity, restriction of range occurs when the rater does not use the whole scale when rating. By not singling out certain individuals as exemplary or overly deficient in certain areas, the supervisor avoids (at least temporarily) having to deal with what he feels will be unhappy or jealous employees. 


\section{Similarity}

A fourth and final rating error that you need to be aware of is what's known as the "similar-to-me" effect, or similarity error. This type of error involves a tendency on the part of raters to judge more favorably those people whom they perceive as similar to themselves. The more closely an employee resembles the rater in attitudes or background, the stronger the tendency of the rater to judge that individual favorably.

Why might this error occur? he all tend to like, and think more highly of others whom we perceive as like us, rather than unlike us because it is flattering and reinforcing. While it's true that in social situations we tend to associate with, and like those who are "similar-tome," when we let these sorts of impressions influence our evaluations, we hurt the accuracy of our evaluations. $\underline{\text { Summary }}$

In summary, error can be involved anytime we attempt to evaluate other people. For this reason, it is important that we be as objective as possible when we rate our subordinates. An awareness of the most common rating errors is an important step toward increasing the accuracy of our 
evaluations. We discussed four of the most common rating errors:

Insert overhead about here

1) Halo error -- which comes into play when a rater feels that a particular performance factor is extremely important. Ratings are then assigned on the other factors that are consistent with the rating on the most important factor.

2) Leniency/Severity error -- results when the rater gives ratings that are unusually harsh or unusually easy to all his/her subordinates.

3) Range Restriction error -- comes into play when supervisors play it safe, and rate all their employees at a fairly even level, without even using the full range of scale values available.

4) Similarity errors -- result when we let similar attitudes and background of our employees influence our ratings of those employees. Thus, the important thing to keep in mind is that we need to evaluate each performance factor separately and make sure to concentrate on actual job-related behaviors. 
COMMON RATING ERRORS

1) Halo error -- which comes into play when a rater feels that a particular performance factor is extremely important. Ratings are then assigned on the other factors that are consistent with the rating on the most important factor.

2) Leniency/Severity error -- results when the rater gives ratings that are unusually harsh or unusually easy to all his/her subordinates.

3) Range Restriction error -- comes into play when supervisors play it safe, and rate all their employees at a fairly even level, without even using the full range of scale values available.

4) Similarity errors -- result when we let similar attitudes and background of our employees influence our ratings of those employees. Thus, the important thing to keep in mind is that we need to evaluate each performance factor separately and make sure to concentrate on actual job-related behaviors. 
CASE ONE

The Case of Ambition Exceeding Ability

In 1961, John senn was hired by the University as a bookkeeper trainee. Prior to this job, he had worked for a short time on a weekly newspaper, but he had been replaced by a man who could sell as well as write. He also had a brief job as an apprentice sign painter, but had quit due to lack of interest. From 1961 to 1967, he had shown little promise of success in his job, advancing only one step from bookkeeper to clerk. In addition, during this time John and his supervisor had several bitter arguments, the result of personality clashes.

In 1967, a Public Relations Department was organized at the University. A woman was brought in from the outside to initiate and develop this activity. She had a considerable amount of experience in the public relations field, having worked for a large newspaper in that capacity. In addition, she had been a business writer for the wall street Journal, and more recently headed her own advertising agency.

John senn had asked for a transfer to this new department because of his earlier experience in writing for the weekly newspaper. Based on information gathered from John's supervisor, the new head of Public Relations was reluctant to approve the transfer, but was persuaded to do so by her boss. John was assigned to writing publicity for the department. During the period from 1967 to 1972 , he 
handled his tasks reasonably well. He was also sent to special workshop school during two summers to study public relations. After his completion of this workshop program he was given his second pay-grade promotion in the organization or group. He did not wish to appear before any group to give speeches or to attend any other functions that were required in the public relations program.

In the past few years, the Public Relations Department has grown and expanded. Several young people have been added to the department. A couple of these have already passed the level of authority that is still held by John Senn. John performs the duties assigned to him quite adequately, and has developed into a capable writer. In general, Management is convinced that he performs his assigned tasks well enough, but that he does not have an outgoing personality. He is considered to be too introverted to attain a position of higher authority. He also has a tendency to receive rather than to initiate.

One month ago, you were made Department Head when the past department head took a job with another university. At the beginning of this week, John approached you and said that he wanted to be given more important tasks to handle. He believes that as a long-term employee of the University, he should be given more responsibility. In short, he feels that it is quite unfair and ungrateful of the University to promote younger and less-experienced people to positions higher than his. 
The past department head did not feel that John was qualified to handle problems any more complex than those he deals with at present. However, she did not want to hurt his feelings or discourage him in his present job. Consequently, her annual ratings of him reflected an aboveaverage employee. In addition, both informal and formal meetings between the two were congenial, and she rarely mentioned any need for improvement in performance. Still, she was convinced that John could not now, nor in the future, be promoted to a position involving more responsible work. Yet, John is a steady and dependable worker. If John should quit, his departure would constitute a loss to the department. You have asked John for some time to think over the request. You are concerned that he will not receive the department head's appraisal of him positively. Still, he should be told that he has, in upper management's opinion, realized all his potential and will not go any higher in the organization. 


\section{CASE T'WO}

The Case of the Ambitious Unhappy Instructor

In 1970, the Carnation Simulation Training Center was started with a complement of three employees and very little equipment. At present, the company has over 400 employees and assets in excess of $\$ 10$ million. The rapid growth has been due in large to the higher cost for maintaining inhouse training programs and the recognition that simulation is a bona fide training technique.

At the center, there is a head of each branch who reports directly to the vice president in charge of the Simulation Division. At present, the Personnel Department occupies a relatively low position in the structure of the Carnation Center. It is small in size and is largely manned by former technical personnel. Its activities are confined primarily to screening applicants, administering employee benefits, directing company security, and maintaining personnel records. All personnel who hold supervisory or executive positions at Carnation have strong technical backgrounds.

Bob Rose, who is 29 years of age, and has been with the company for six years is an Assistant Instructor (a nonsupervisory position). Assistant Instructors are responsble for helping Executive Instructors run training sessions. Part of Bob's job involves writing training programs. Bob feels that he is entitled to a position of Executive 
Instructor (a supervisory position that involves supervising Assistant Instructors, making assignments to new simulation tasks, as well as supervising some clerical personnel). In the opinion of Bob's supervisor, he is highly competent technically. He always completes his work on time, but prefers to keep to himself. While his fellow employees recognize Bob's technical expertise as an Assistant Instructor, and in fact, come to him for advice on matters pertaining to writing training programs and helping out at training sessions, he is not overly popular (but not disliked either).

According to his supervisor, Bob's biggest weakness is his ability to supervise others. To some he gives too much and too detailed instruction, and they soon feel that their intelligence is being insulted. Others feel that they are not getting enough information, and that they are lost and do not know what to do.

Bob is unhappy in his position as Assistant Instructor and has appealed to his supervisor for support in being promoted to Executive Instructor. While Bob's boss feels unsure about the promotion, Bob's supervisor's boss believes Bob's technical expertise would make him a fine Executive Instructor. Consequently, based on these recommendations, Bob is promoted to Executive Instructor.

once promoted, however, Bob soon begins to have problems with his subordinates. He has a hard time making assignments, and often, when technical problems occur, he 
prefers to do the work himself. Six months after being promoted Bob leaves the Carnation simulation Center, unhappy with his job, and upset about complaints from his subordinates and criticism from his bosses. 
Common Rating Errors

- haLO EFFECT

- LENIENCY/SEVERITY ERRORS

- RESTRICTION OF RANGE

- SIMILARITY ERROR 
Illustration of Halo Effect

\section{PERFORMANCE FACTORS}

Job Knowledge
Quality of Work
Productivity
Record Keeping
Dependability
Adaptability
Initiative
Attendance
Relations with others
Safety

4

4

4

3

4

4

3

4

4

4 
Overall Evaluation

3.50

4

3.80

3.75

5

3.75

1.75

6

$3.7 \varnothing$

3.25 
Overall Evaluation

1

2

3

4

5

6
2.75

3.50

2.60

$3.7 \emptyset$

2.70

2.20

3.00

3.20

2.85

3.80

$2.9 \emptyset$

1.90 
APPENDIX B

Observation Training Lecture and Discussion Materials 
OBSERVATION TRAINING

\section{Training Appraisers}

Evaluating employee performance is an important and necessary part of any supervisor's job. Regardless of whether your organization employs a formal system of employee evaluation, judgments about how individual employees are performing are made almost daily. People are constantly making judgments about others. Unfortunately, many of these informal judgments may be erroneous.

Consequently, a formal system of performance evaluation is usually adopted to help reduce the possibilities of bias and uninformed judgments; to standardize the types of information that will be forthcoming; and to insure that the resulting appraisal information is gathered in a form that permits its use across the entire organization.

While a formal system of appraisal helps to standardize this process in the organization, it in no way guarantees consistent, accurate evaluation. Therefore, the purpose of today's talk will be to begin to help you be more accurate in your judgment of employees. We will deal with this problem by focusing on the importance of developing good observation skills. 
General Instructions/Hints/Precautions

First, I'd like to focus on three things to keep in mind when observing behavior, namely, careful observation, the observation of specific behaviors, and the need to take notes if possible.

Insert overhead about here

An extremely important part of evaluating an employee's performance is being a careful observer.

Careful Observation of Behavior

Prior to filling out the formal performance evaluation, you periodically come in contact with (often daily/sometimes less frequently) that employee in the course of performing his or her job duties. It is important that at these times you observe carefully their job-related behavior.

In addition, it may be helpful to think of the behaviors that you have observed during an evaluation period, as a sample of all the job behaviors exhibited by your subordinate during the rating period. Consequently, the behaviors you're actually seeing are only a small portion of the total number of behaviors, and therefore it's important to observe these behaviors carefully.

In addition, keep in mind that when observing an employee's job behavior, you do not necessarily have to be 
physically present. There are many ways you can obtain sound information on performance. For instance, you might rely on a subordinate's oral or written reports that might reflect employee performance. Also, another supervisor may have had occasion to observe directly one of your employees, and thus can provide you with feedback concerning the subordinate's behavior. In general, then, the key is to collect as many relevant observations as possible, both through direct, careful observation and from other relevant observers.

Watch for Specific Behaviors

Insert overhead about here

It would be nice to believe that the task of making specific, accurate observations could be done objectively with only minimal interference from subjective factors. obviously, however, the subjectivity involved in evaluating people is always going to be a factor, simply because we choose to pay attention to certain things or activities while we ignore others. It is impossible to observe everything in a given situation at the same time; while we are focusing on some attributes of a situation, we are naturally missing others. One way to use this selective 
attention to our advantage in terms of evaluating employees, is to keep in mind those performance factors on the evaluation form on which we rate employees.

Insert overhead about here

For example, your evaluation form consists of factors like job knowledge, dependability, initiative, relation with others; or work habits, managerial skills, communication skills, planning and development skills. By keeping these performance categories in mind, they can helf us to focus on those specific job behaviors that relevant when it comes time to evaluate our employees.

Take Notes

While it is not feasible to write down continually all observed behaviors, it's often beneficial to jot down (and file) behaviors you observe from time to time.

Insert overhead about here

Keep in mind that 12 months is a long time between evaluations, and many important behaviors occur, most of which will be forgotten unless recorded in some fashion. In addition, if nothing is written down, what will tend to be 
4 - exceeds normal job reguirements

3 - meets normal job requirtments

2 - improvement is needed to meet job regitir ments

1 - fails to meet job requirements

Acceptitble satisfactory performance requires an aver age rating of 2.7 .5 , when rated "performance factors" are conbinsd.

CO:HFIOENTIAL

EME'LOYEE PERFORMANCE EVALUATION

Name

figency Narise

Class Title

Describe Briefly the Principal Duties in Present Job

\section{Date of Evaluation}

Soc. Sec. No.

Sub. Division

Class Code
Position No.

Agency Code Date Entered Present Position

Describe Briatly the Principal Duties in Present Job

\section{DART - BETFOKMANCE FACTORS - CIRCLE THE APPROPRIATE PERPOR MANCE LEVEL
1- JOS KVOWLEOGE/SKILLS - To what extent does the employee maintain a satisfactory level of jos
knowiedge and/or job skills?}

Remarks
: $:$ :
2
3- QUDLITY OF WORK - To what extent does the empleyee's work niect the required quality standards; i.e., accuracy, neatness and thoroughtriess?
Remarkis

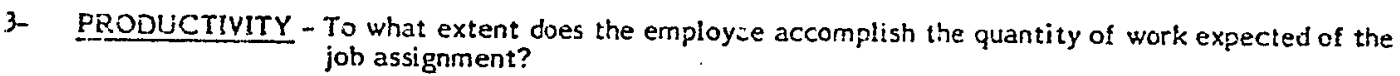

Remarks

4- RECORD KEEPING/OOCUMENTATION - To what extent does the employee adequately prepare and maintain records, wititen reports, correspondence, and files?

Rernarks 
5. DEPENOABILITY - To what extent does the employee perform :vork without close super vision or ussistance?

Remarks

6- ADRPTABHI!IY - To what extent does the empioyee readily adapt to new situations and changes in routines, work load, and/or work assignments?

Rernarks

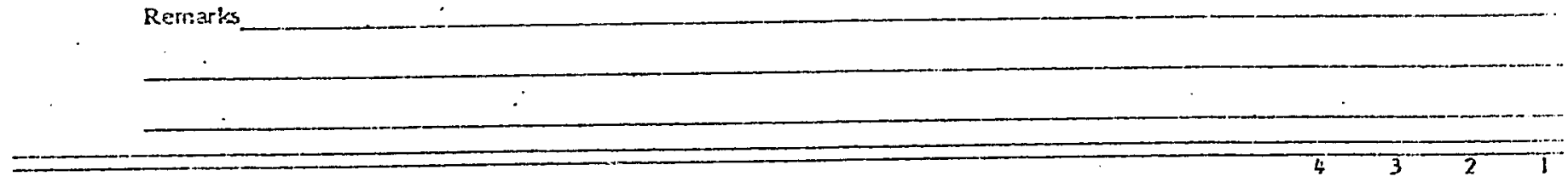

7- INUTIATIVE - To what extent does the employee present new ideas, improve procedures or otherwise demonstrate an awareness of clerical or technical changes related to the job?

Remarks .

8- ATTENDALCE - To what extent does the employee maintain satisfactory aitendance performance in regard to tardiness, early departures, and/or absences?

Remarks

9- RELATIONS VITH OTHERS - To what extent does the employes establish effective working relationships when dealing with supervision, co-workers, and/or the public?

Remarks

10- SAFETY - To what extent does the employee work in a sate menner and observe safety practices?

Remarks 


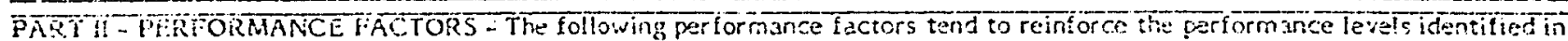
Part 1. The super visor in completing Part ll should indicate the employee's performance level by circting the aproprizte level of performance. Use the reiratks section to record your coinenenis.

iand a serise of friorities?

Remaurts

3- PLANN!NG AND ANALYTICAL ABILITY - To what extent Wes the employee demonstrate the skilis to analyze and solye problems?

Remarks

3. MANAGERIAL SKILLS - To what extent does the employee ef fectively work well with and through others to complete assignments in a timely and productive mainer?

Reinierks

COM.MUIVICA TIONS SKILLS - To what extent can the employee ef fectively express

himseltherse!f or ally and in writing including correspondence and reports and

presentations at conferences, seminars, workshops, etc., as required by the job?

Remisks

5- DEVELOPMENT OF OTHER S - To what extent does the employee de velop others to becoine more effective in work assignments and betier prepared for future job opportunities?

Remarks 
remembered will be those especially negative events, and the most recently observed behaviors--neither of which may be very representative of a particular employee's job performance during the entire year.

Insert overhead about here

Remember, observe performance carefully, watch for specific behaviors, and take notes when possible. If, when you're in contact with a particular employee, you are careful in what you observe or think you observe; if you focus on the behaviors relevant to the performance factors you'll be rating on, and if you jot down a few notes when possible, it ought to help you be more accurate when you sit down to formally evaluate them.

Systematic Errors of Observation

In addition to talking about what sorts of things we should do to be more accurate observers, we must also discuss some of the errors observers of behavior often make. I'd like to talk about two general areas where errors in observation may occur, and consequently, adversely affect your ratings.

Insert overhead about here 
Contamination from Prior Information

several sorts of common observational errors result from contamination from prior information about the employee being evaluated.

First, it is often an unintentional tendency of people to distort information observed, in a way that makes it similar to previously received information. Thus, for example, a supervisor might have noticed that a particular employee has left work 10-15 minutes before quitting time several times in the last several weeks. Now, whenever the end of the workday approaches and the supervisor notices the employee away from his/her assigned station, it is assumed immediately that the employee has left work early again, and subsequently, is marked down on attendance on the next performance evaluation. Thus, prior information, regardless of how accurate it is can influence your expectations, which may influence your observations.

In addition, one aspect of observed behavior may tend to influence unduly your overall observation and evaluation of an employee. Consequently, while the evaluation form has ten separate areas to evaluate each employee, a poor score on one observed factors (such as attendance) may influence you to give low ratings on many of the other performance factors, regardiess of whether poor performance was observed on the other factors. So, be aware that prior observation can and may affect future observations. 
Insert overhead about here

Overdependence on a Single Source of Information

Another prevalent observational source of error is that generated by an overreliance on a single source of information. While this source is often the most reliable source of information, it may also be a major source of error. This is so because in many instances what causes one observational source to take precedence, and to be relied on almost exclusively, is ease of acquisition. In other words, whatever way some information about an employee can be gathered most quickly and easily (regardless of whether it's accurate) that way is often relied upon. Unfortunately, as I'm sure you're aware, this can lead to misleading and inaccurate evaluations. In addition, if you collect only a limited amount of observational information, your judgments have to be based on what's available (and not necessarily what's a more complete, accurate picture). 
Thus, due to the ease and frequency with which these observational errors are committed, it is important to remember the things we have talked about today:

Things to do -- observe carefully. watch for relevant behaviors. take notes whenever possible. Things to avoid -- contamination from prior information overreliance on a single source of information

Therefore, if you keep in mind some of these things to do to be better observers, and be aware of some errors that can occur, they should help you be more accurate when you evaluate your employees. 


\title{
DO'S AND DON'TS
}

\author{
Things to Do -- GBSERVE CAREFULLY \\ WATCH FOR RELEVANT BEHAVIORS \\ TAKE NCTES WHENEVER POSSIBLE
}

\author{
Things to Avoid -- CONTAMINATION FROM PRIOR INFGRMATION \\ OVER-RELIANCE ON A SINGLE DATA SOURCE
}




\section{EXERCISE ONE}

\section{RECRUITER PERFORMANCE FACTORS}

1. Creating a Fayorable Image of the Company presenting a positive, but realistic image of GCI; spelling out clearly the advantages of working for GCI.

2. Organizing the Interview

structuring the interview to allow for an appropriately balanced information exchange between recruiter and interviewee; giving the interviewee a chance to ask questions; defining the purpose of the interview.

3. Providing Relevant Information About the Company

giving the interviewee specific information about the characteristics of various jobs so that he/she can make informed decisions; displaying familiarity with programs at GCI and their requirements; demonstrating knowledge about benefits, promotions, pay, etc.

4. Asking Relevant Questions

asking questions which maximize the amount of meaningful information available to the interviewer; asking the interviewee questions he/she can understand and respond to readily; making clear the information desired.

5. Answering Recruitees' Questions

providing complete, clear, concise and accurate answers to interviewees' questions; answering interviewees' questions so that they have the information desired; ensuring that the interviewee understands the recruiter's answer.

6. Establishing Rapport with Interviewees developing a nonthreatening relationship with the interviewee; creating a relaxed atmosphere; gaining the friendship and trust of the interviewee. 


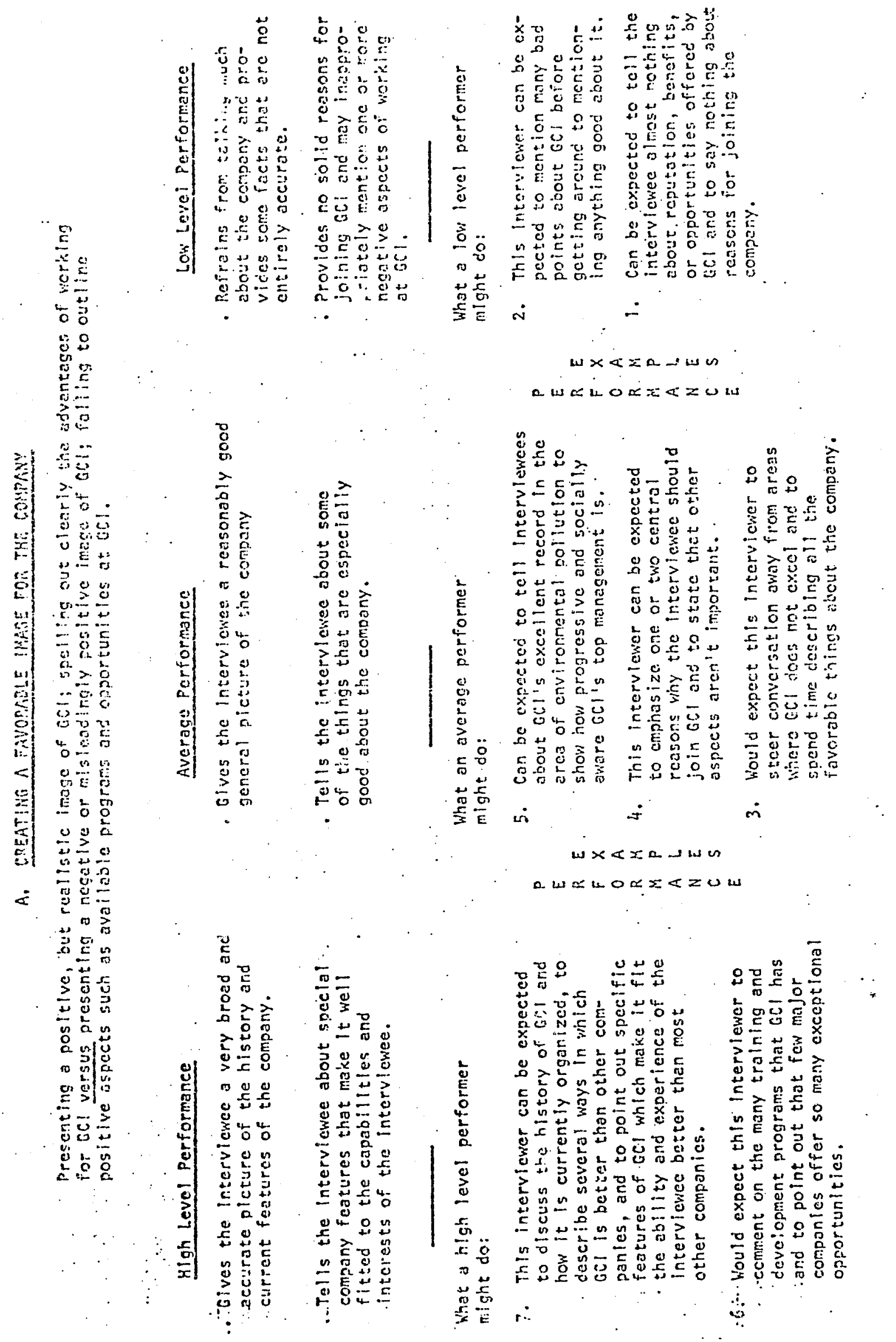

Reproduced with permission of the copyright owner. Further reproduction prohibited without permission. 


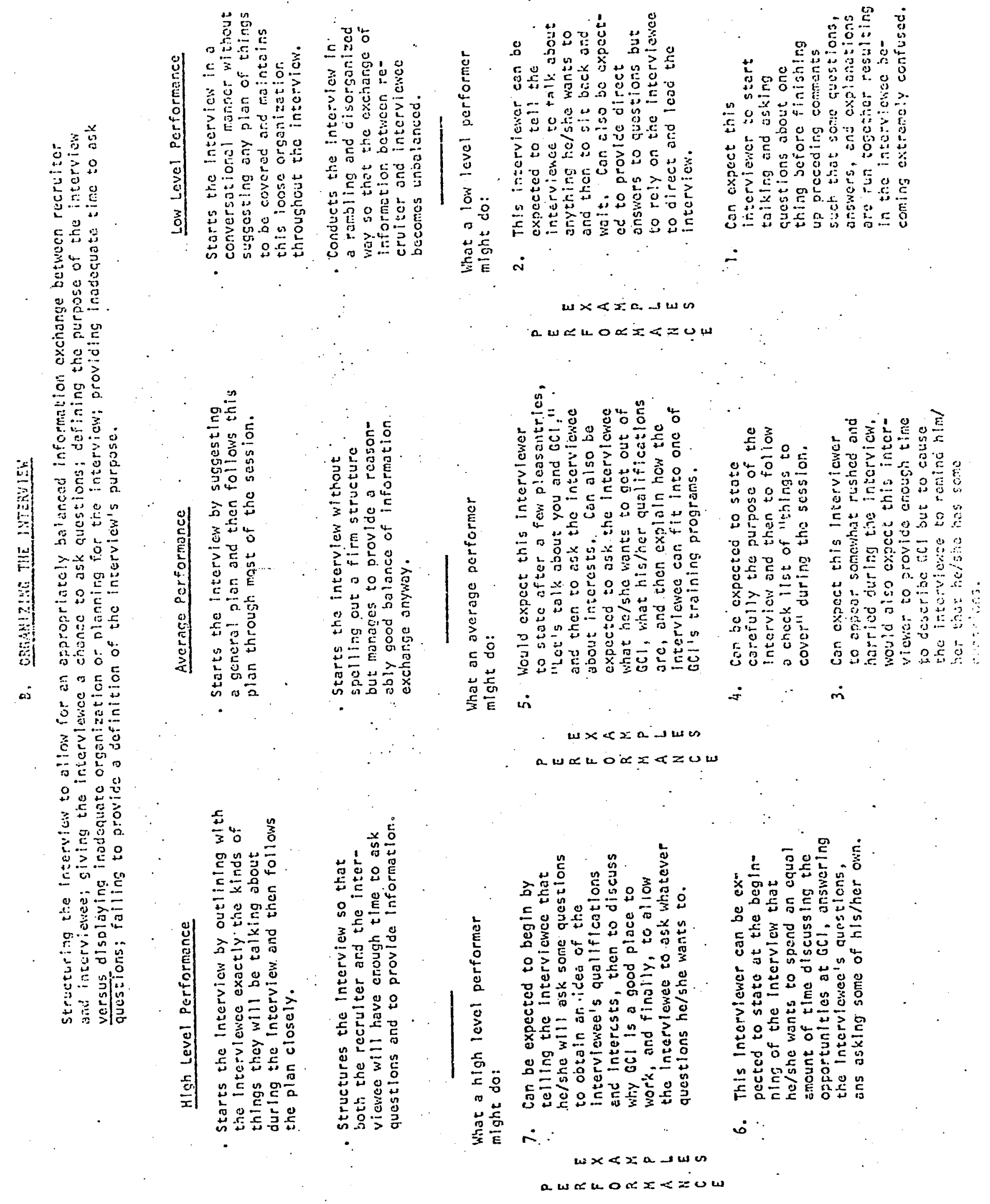


总
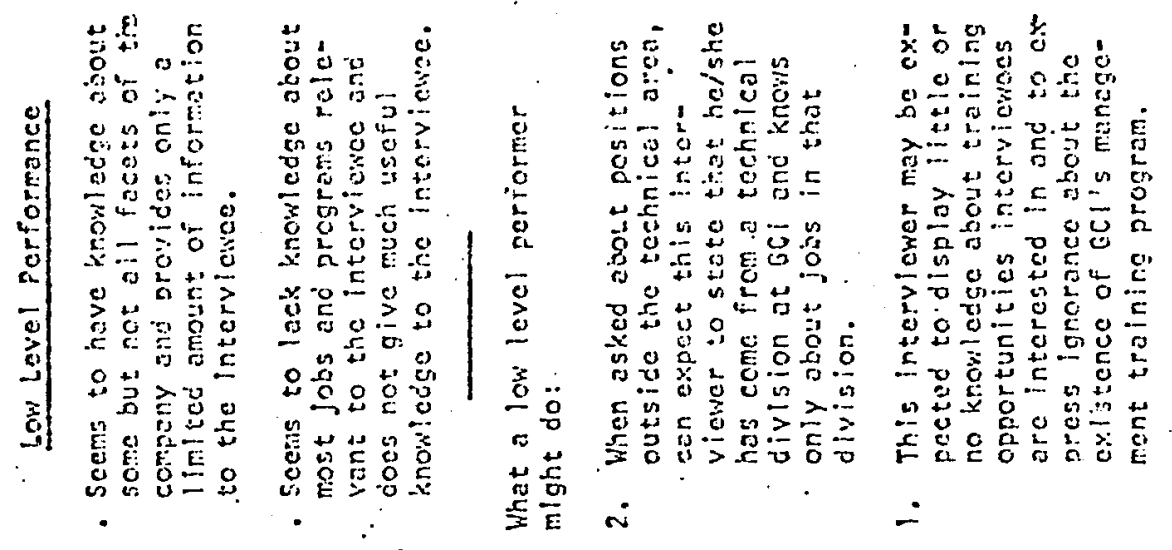

w $x<x a$ in in

ㄴ山叫
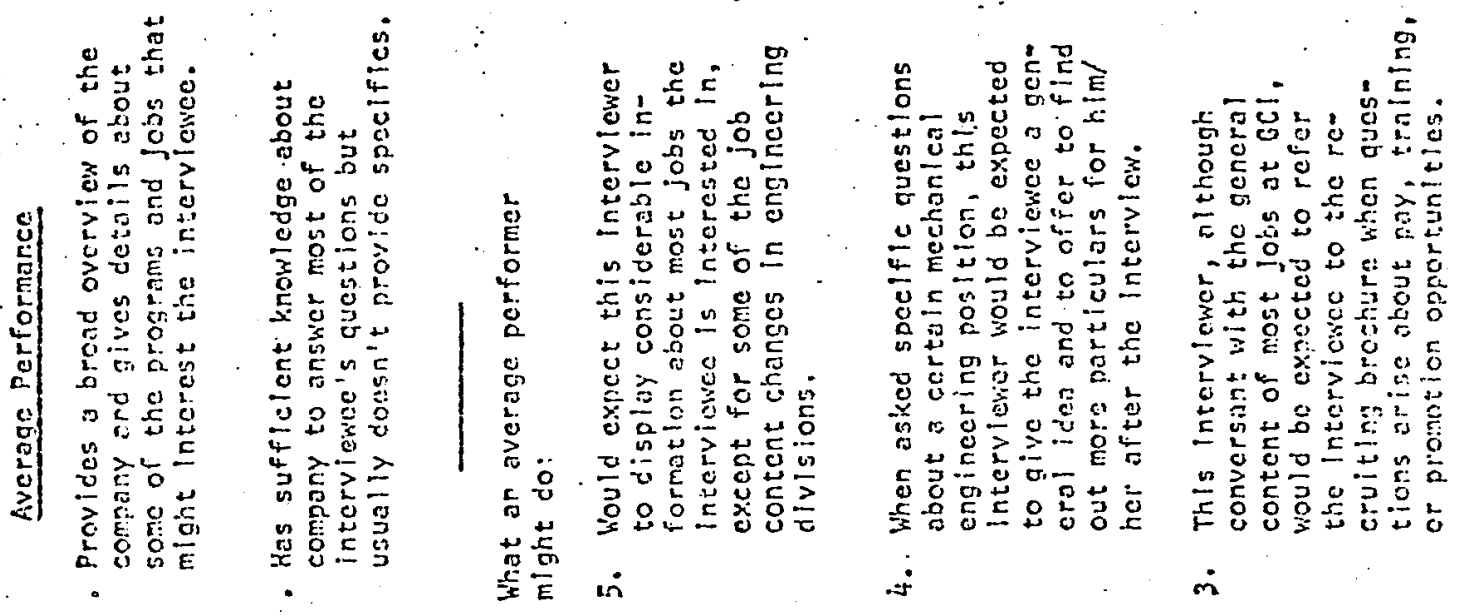

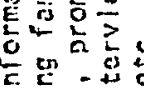

$w x<z a-w$ w

a w $\approx$ L $0 \propto I<z \omega \omega$

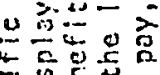

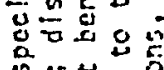

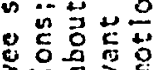

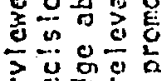

㝴步它

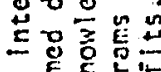

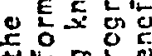

此造起

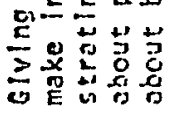
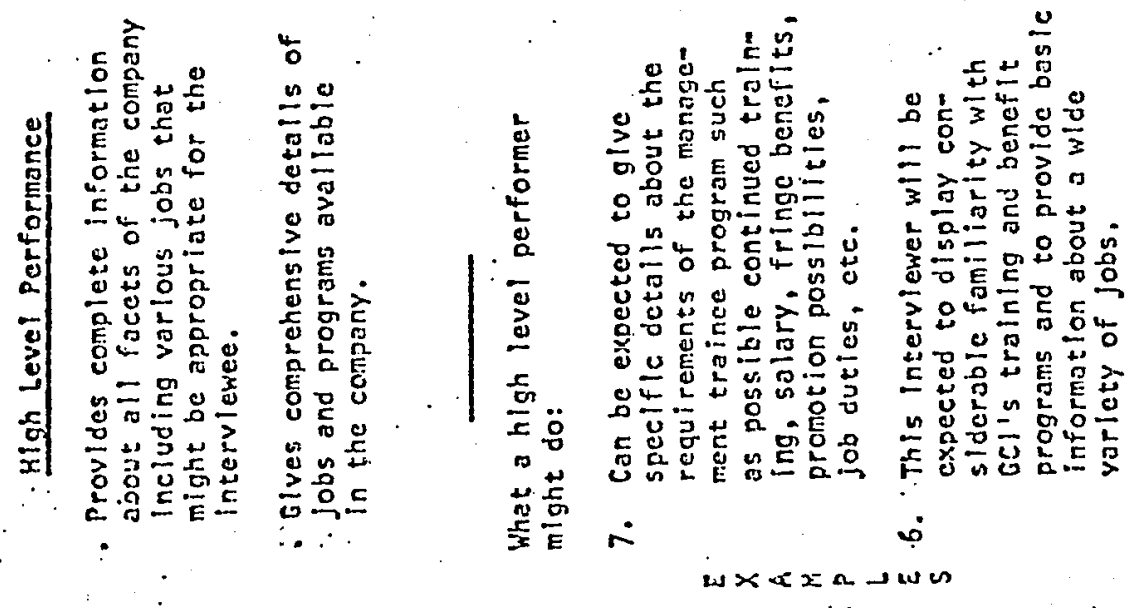

$\therefore$ 

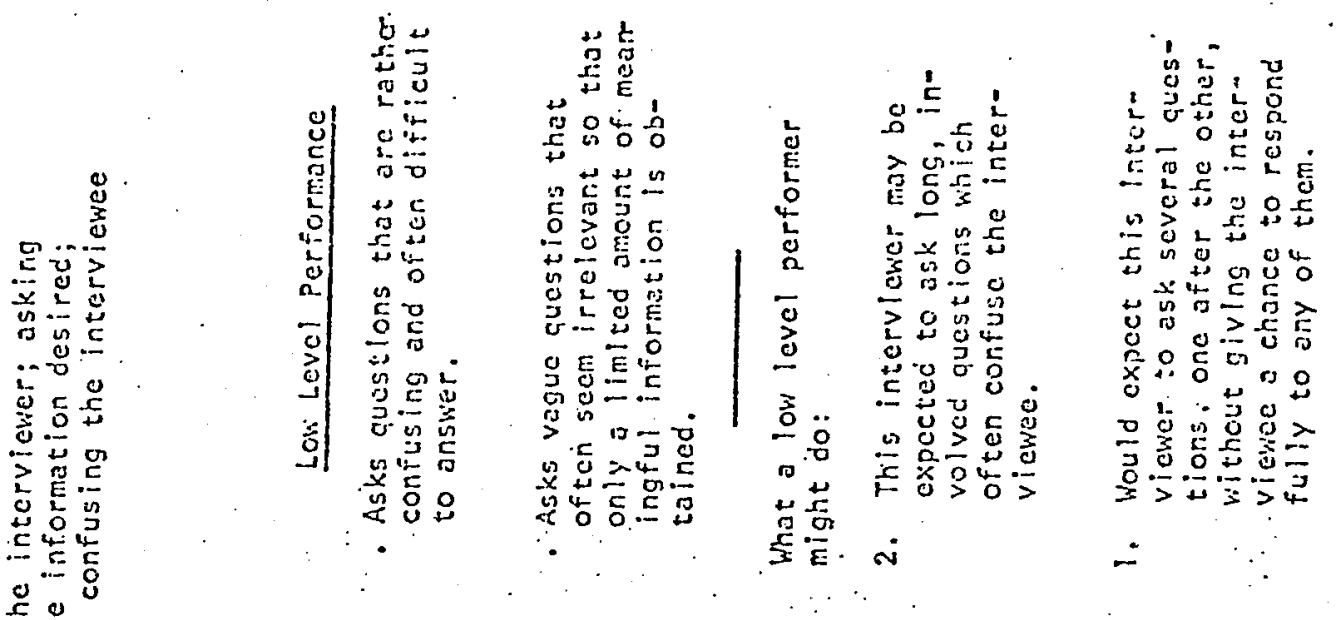

us $x<x$ a d es us

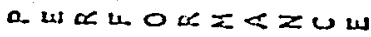
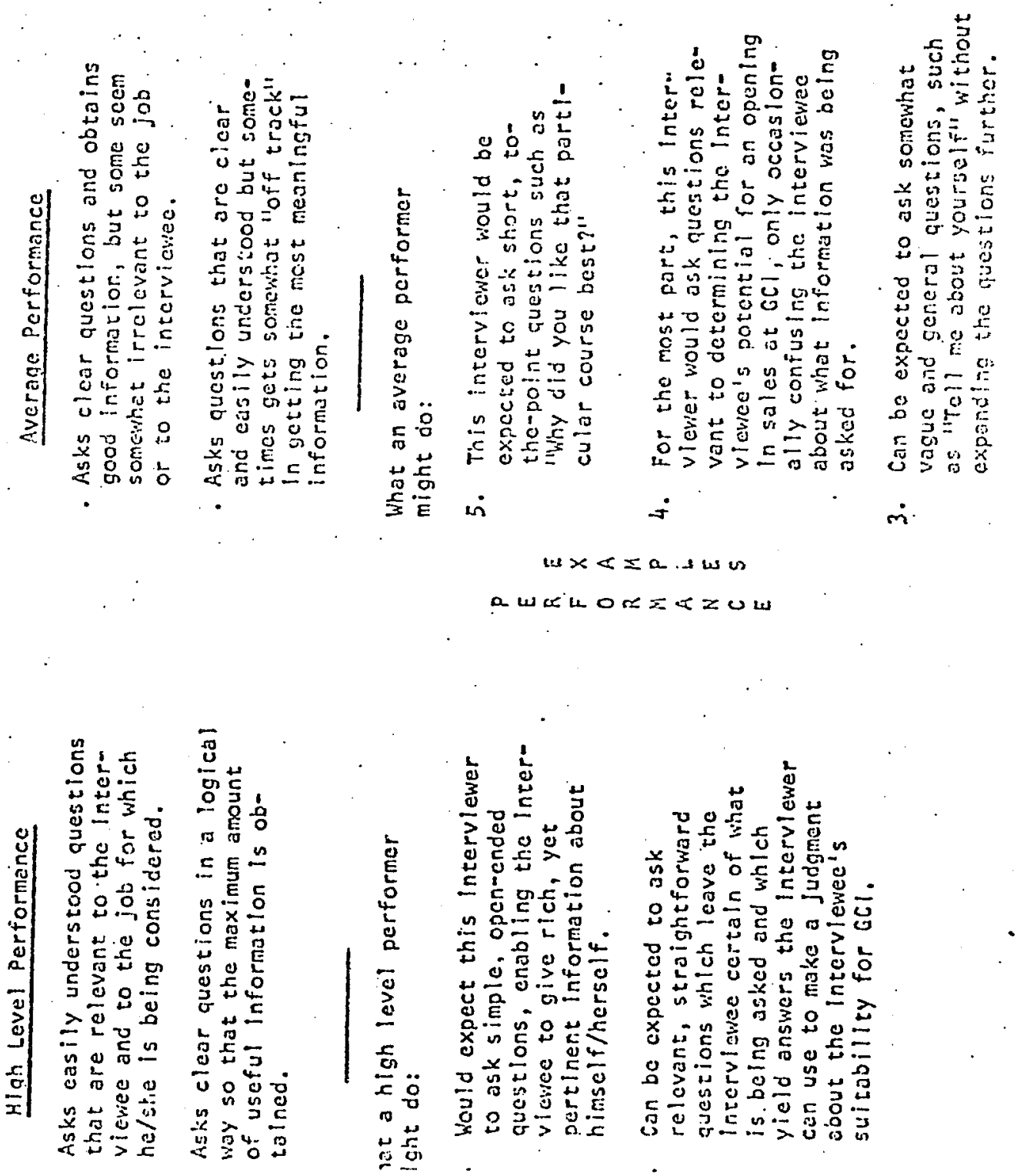

Reproduced with permission of the copyright owner. Further reproduction prohibited without permission. 


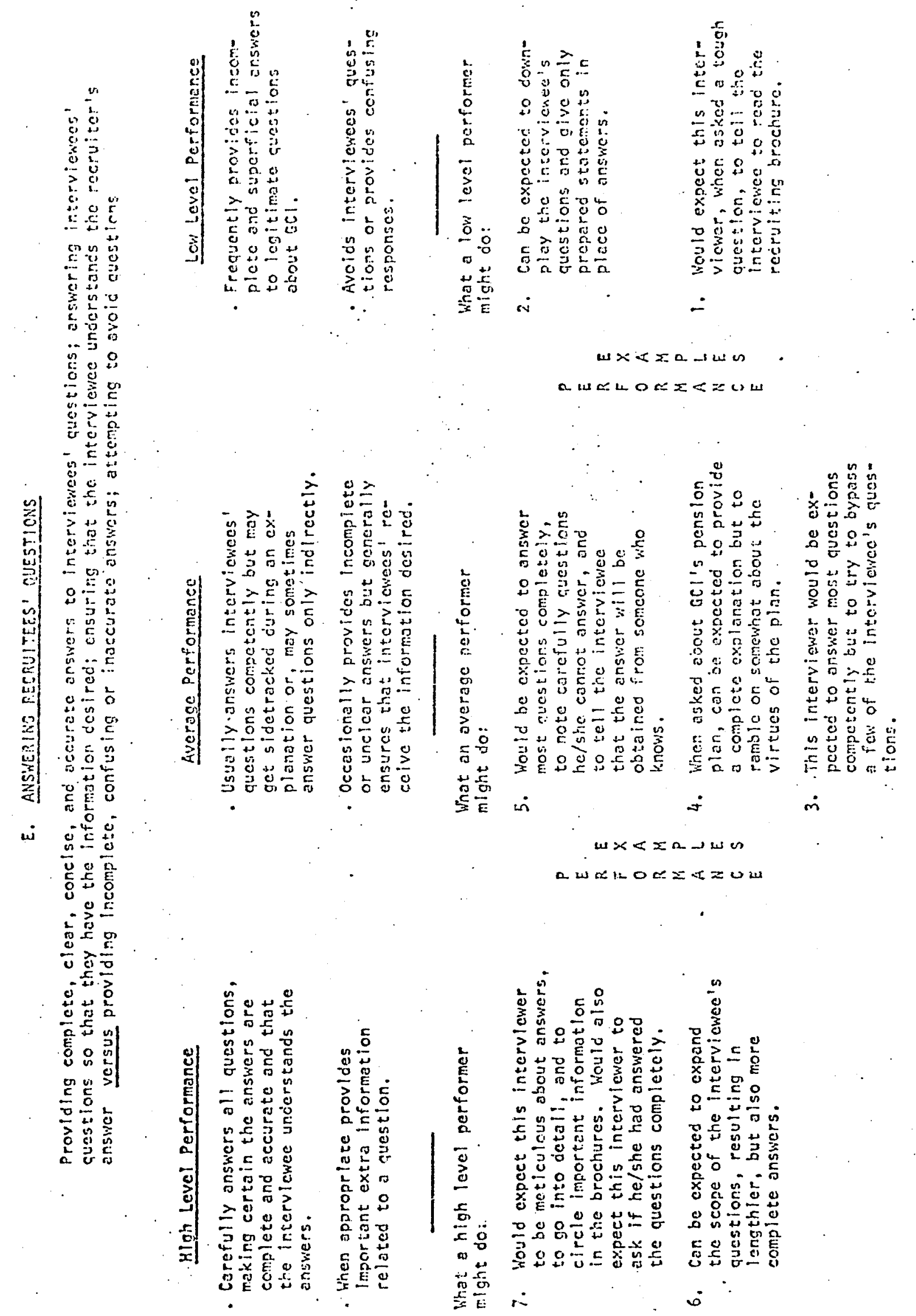

Reproduced with permission of the copyright owner. Further reproduction prohibited without permission. 


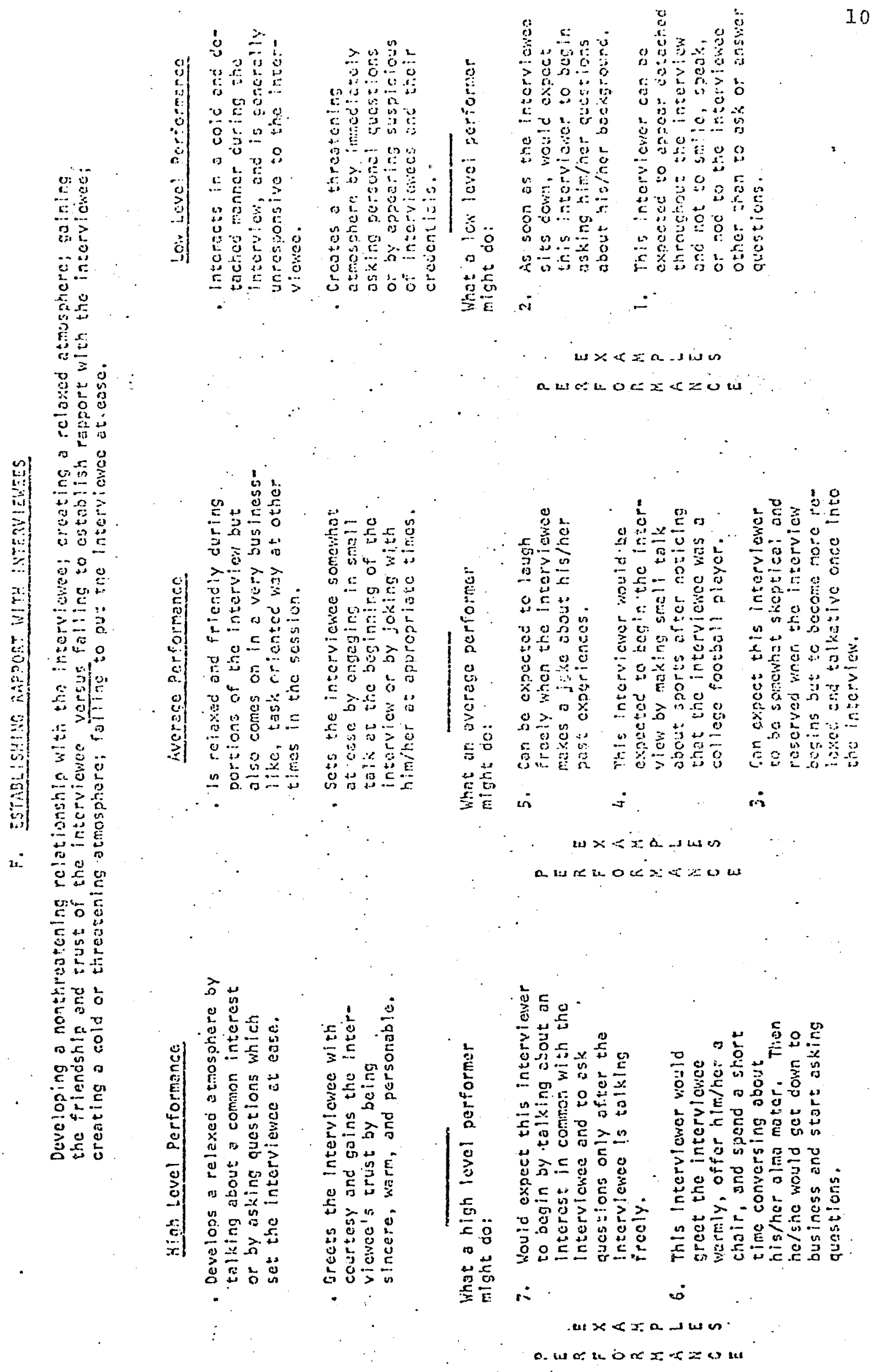




\section{EXIRCISE THO}

The Case of Ambition Excesding sbility

In 1961, John Sann was hired by the University as a bookkeeper trainee. Prior to this job, he had worked for a short time on a weekly newspaper, but he had been replaced by a mar viho sould sell, as well as write. He also had a brief job as an apprentice sign painter, but had quit due to lack of intereat. From 1961 to 1967 , he had shown little promige of succssa in his job, advancing only one step from boolnseper to clark. In addition, during this time John and his supervieng had sevara? bitter argumerits, tino roault of personaliti c.Ieshes.

In 1967, a Public Rolations Depariment was organised in. the Jniversity. A woman was brought in from ths outsice to initinto and dovolop this acivity. She nad a consjidrabis arnount of experience in the public relationa fleld, having worlzod for a largo newspapor in that capacity. In adistion, gho had besn a business writer for the Wall stret Journal, and more recentIy headed her own edvertising ageney.

John Serm asked for a transier to this nat department because of his earlier experience in writing for the weekly newspaper. Based on information gathered from John,s supervisor, the new hoad of Public Relations was reluctant to approve the transfex, but was persuaded to do so by her boss. John wes assignea to writing publicity for the department. 
During the period froin 1967 to 1972, he bandled his tasks roasonably we1.1. He was also sent to speclal workshop school during two sumers to study puolic relations. Aster his complotion of this workshop program, ho was given his second pay-grado promotion in tho organization.

In the past fow years, the Public Relations Department. has grown and expanded. The departmant has been divided into two divisions, a Hriting Division (or which John is e mombar), and a Public Locture Division (of which you are a member). Even trough you are in separate divisions you see John dain, and rate samples of his work above-averege. You feel John. has dereloped into a capablo writer. In general, the Writing Division supervisom is convinced that ho parforms his assignod taskrs well enough, but that he does not have an outgoing persorality. Also, his file indichtes he has g tenderey to reo Q6iva rather than initiato.

One month ago, you were nemed the new supervisor of the Writing Diviaion, when the past supervisor took a Job in anotzex city. At the beginning of this week, John approached yolx and said that he wanted to be given more Important taskg to handie. He believes that as a long-tem emplojes of the University, ho should bo given more responsibility. In ghort, ho feola that it is quite unfair and ungrateful of the Jnivergity to promote younger and less-experienced peopie to higkar positions than his.

Romember, you are the supervisor... What do you do? Do you tell him gou agree with him, you disagres with him, te11 him gou w1.11 think about $1 t$, or tell hin something else? 


\section{APPENDIX $C$}

Decision-Making Training Lecture and Discussion Materials 


\section{DECISION-MAKING TRAINING}

\section{Training Appraisers}

Evaluating employee performance is an important and necessary part of any supervisor's job. Regardless of whether your organization employs a formal system of employee evaluation, judgments about how individual employees are performing are made almost daily. People are constantly making judgments about others. Unfortunately, many of these informal judgments may be erroneous.

Consequently, a formal system of performance evaluation is usually adopted to help reduce the possibilities of bias and uninformed judgments; to standardize the types of information that will be forthcoming; and to ensure that the resulting appraisal information is gathered in a form that permits its use across the entire organization.

While a formal system of appraisal helps to standardize this process in the organization, it in no way guarantees consistent, accurate evaluation. Therefore, the purpose of today's talk will focus on helping you be more accurate in your judgment of employees. Specifically, we will talk about some common strategies that are used by supervisors to arrive a final evaluation decisions. In addition, we will talk about how some of these strategies are effective, while others can cause errors in judgments. 
Intuitive-vs-Formal Decision-Making strategies

In the work setting, suprevisors are continually confronted with information they must identify and use in making decisions. However, each decision-maker utilizes only a limited amount of information in arriving at any particular decision. Applied to the area of performance evaluation, this tendency for people to make decisions without full use of the available information is greatly increased by the fact that each supervisor can devote only a limited amount of time to evaluating employees.

As a result of this time limitation, decision-makers often rely on simple cognitive or judgmental strategies to make quick, hopefully accurate decisions. For example, when a supervisor is told that a particular person has behaved in a particular way, he may quickly review the behaviors that stand out in memory, and make a decision about whether to believe the information. These simple intuitive strategies (or rules of thumb) are quite often used unconsciously, and yet they are used appropriately and effectively in the great majority of cases. Such strategies allow us to deal with problems and make decisions without processing a great deal of information. However, our concern in the remainder of this lecture will focus on the times when these intuitive strategies are used inappropriately, and consequently, effect out ability to make accurate judgments when evaluating our employees. 


\section{Judgmental Errors}

Insert overhead about here

Insensitivity to Biased Data

An overreliance on intuitive strategies can result in a judgmental error, for example, when a supervisor relies on too few samples of behavior. If you were to check samples of an employee's work only a few times during the rating period, your conclusions (and therefore, your evaluation) might be based on biased information. For example, if you were to observe her four times during the year (and two of these times you found work quality below par), it's possible that work quality might have slipped just two times out of 50, but two of your (say) four pieces of information were collecteà on those days.

Insert overhead about here

In addition to this bias in how and what we observe, judgmental error can also result from what we remember. It often occurs that we do not remember all that we observe. However, what we do remember is typically the information that confirms our beliefs about the evidence we currently possess. In other words, we possess a biased system of 
recollection as well. This biased system can also be affected by the vividness of these events, in that vivid information (an employee caught dozing) will stand out in memory (even if it was only one time).

One way to deal with the fact that biased information can and may affect the accuracy of our evaluations, is to collect as much information as possible about an individual's behavior--by increasing the frequency of observing work samples and collecting information from other sources (e.g., co-workers). In addition, it is important that we observe behavior carefully so that we are collecting accurate information on which to base our evaluation.

Insert overhead about here

\section{Inappropriate Causal Inference}

Another cognitive strategy that is often beneficial, yet when used inappropriately can cause us to err in our judgments about the behavior of others, is often used when we observe behaviors, objects or situations together. In order to make sense of the scene we observe, we often link things together in a cause-and-effect relationship. This view that the events are related is then strengthened when the two are observed together more than one time.

For example, if you were to observe a particular employee on several occasions, and each time a piece of 
equipment he/she was using broke down, you might interpret the information to mean that the employee was the cause of equipment breakdown.

Once again, let me emphasize I'm not trying to imply that making these cause and effect judgments is always inappropriate--but rather, it's an error that can occur, and therefore, we should keep it in mind when we are evaluating the behaviors we've observed.

Insert overhead about here

Overreliance on Previously Formed Theories

Another way that we make inappropriate decisions is through an overreliance on previously formed beliefs. The behaviors we have seen in the past, and the information read or heard concerning a particular employee, as well as any stereotypes or prejudices we possess will influence the way we look at current behaviors, or if we notice them at all. Research has shown that once people have applied a particular label to a given object, or formed a particular opinion about a set of behaviors, they place too much emphasis on that opinion when making future evaluations.

Insert overhead about here 
For example, if you are supervising a group of clerk Typists, and you believe females are superior to males at this position, this stereotypic view may effect how you evaluate a male clerk typist--regardless of the actual behaviors you observe.

Consequently, it is important to be aware that previous views can effect what is observed and how those behaviors are evaluated.

Insert overhead about here

Inappropriate weighting

A final intuitive strategy that is frequently used involves the weighting of information that is available to us. This strategy is often valuable in helping us make accurate evaluations. However, how a supervisor weights the importance of a particular behavior or event is often due to the vividness of the information. And it is this vividness emphasis that can tend to distort our decisions, or the information we use to make our decisions. This distortion occurs because the vividness of the information is often not related to its true value as evidence to be used in an evaluation.

Insert overhead about here 
For example, if during the past year, a particular employee of yours was late for work two times, that information probably would not figure significantly in our evaluation of that employee's behavior. However, if it so happened that the two mornings the employee was late, coincided with emergencies that arose requiring timely completion of a letter or work assignment, those two late arrivals may be vividly remembered and weighted quite heavily when evaluating that employee's dependability. In addition, even though dependability is only one of the performance factors you evaluate an employee on, an especially well-remembered behavior may affect how you rate that person on the other performance factors as well. In fact, research has shown us that negative information is typically weighted more heavily than is positive information.

Factors such as you emotional interest or involvement with the event or employee, the concreteness of the event, and how close the person or information is to us all tend to affect vividness, and consequently your weighting. Therefore, the key here seems to be to observe behaviors carefully, and if you know you cannot avoid giving a particular incident far more weight then is justified, then avoid using that piece of information, and rely on evidence that will be more trutheul, and allow you to be more accurate in your evaluation. 
$\underline{\text { Summary }}$

There are several important things to remember when evaluating your employees.

1) We frequently "fall back" on judgmental strategies that help us to make decisions quickly and accurately with as little information as possible.

2) However, this can lead to problems--and therefore, when we are evaluating others we should be aware of these potential problems resulting from:

a) an insensitivity to biased data, including a reliance on too few examples of behavior, and the frequent recollection of biased information.

b) allowing prior beliefs/theories about an employee effect the information we use to make decisions.

c) inappropriately establishing cause-effect relationships between employees and incidents that are observed together.

d) inappropriate weighting of behavioral incidents.

Insert overhead about here 
EXERCISE ONE

A. INFORMATION ABOUT RECRUIT INTERVIEWER ONE

Recruit Interviewer Bill Smith has been with GCI for five years, during which time he has received three promotions and four pay increases. At the present time, Bill is in charge of $P$ e $r$ o $n \quad n$ e 1 Recruitment at GCI's branch office located near the University. Recently, events in Bill's life have left him quite confused and troubled. Six months ago, Bill's wife was diagnosed as having terminal cancer, and given less than one year to live. In addition, Bill's mother was killed in a tragic train-automobile collision less than two weeks ago. Needless to say, Bill is still in the process of trying to get his life in order, and prepare himself and his four children for the possible death of his wife.

B. INFORMATION ABOUT RECRUIT INTERVIEWER TWO

Recruit Interviewer Daniel Reeves has been with GCI for six weeks in his present position. Prior to coming to GCI, Daniel had spent several years in a similar capacity with one of GCI's competitors. He was terminated from that job, however, because of his inability to establish rapport with the prospective employees. In addition, his file indicated that he had an inability to "sell" these interviewees on the benefits of working with his company. 


\section{RECRUITER PERFORNANCE FACTORS}

1. Creating a Favorable Image of the Company presenting a positive, but realistic image of GCI; spelling out clearly the advantages of working for GCI.

2. Organizing the Interview structuring the interview to allow for an appropriately balanced information exchange between recruiter and interviewee; giving the interviewee a chance to ask questions; defining the purpose of the interview.

3. Providing Relevant Information About the Company giving the interviewee specific information about the characteristics of various jobs so that he/she can make informed decisions; displaying familiarity with programs at GCI and their requirements; demonstrating knowledge about benefits, promotions, pay, etc.

4. Asking Relevant Questions asking questions which maximize the amount of meaningful information available to the interviewer; asking the interviewee questions he/she can understand and respond to readily; making clear the information desired.

5. Answering Recruitees' Questions providing complete, clear, concise and accurate answers to interviewees' questions; answering interviewees' questions so that they have the information desired; ensuring that the interviewee understands the recruiter's answer.

6. Establishing Rapport with Interviewees developing a nonthreatening relationship with the interviewee; creating a relaxed atmosphere; gaining the friendship and trust of the interviewee. 


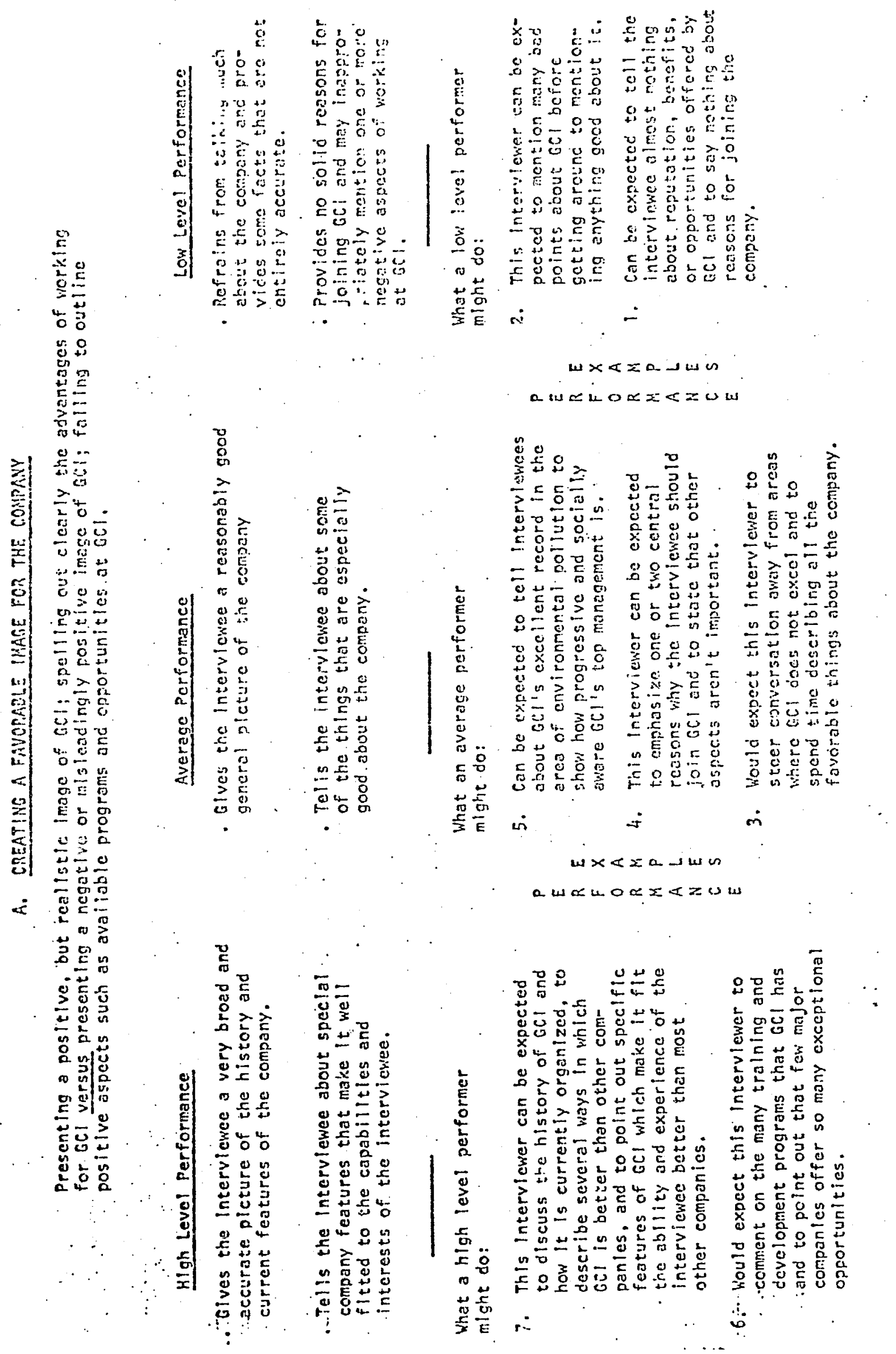

Reproduced with permission of the copyright owner. Further reproduction prohibited without permission. 


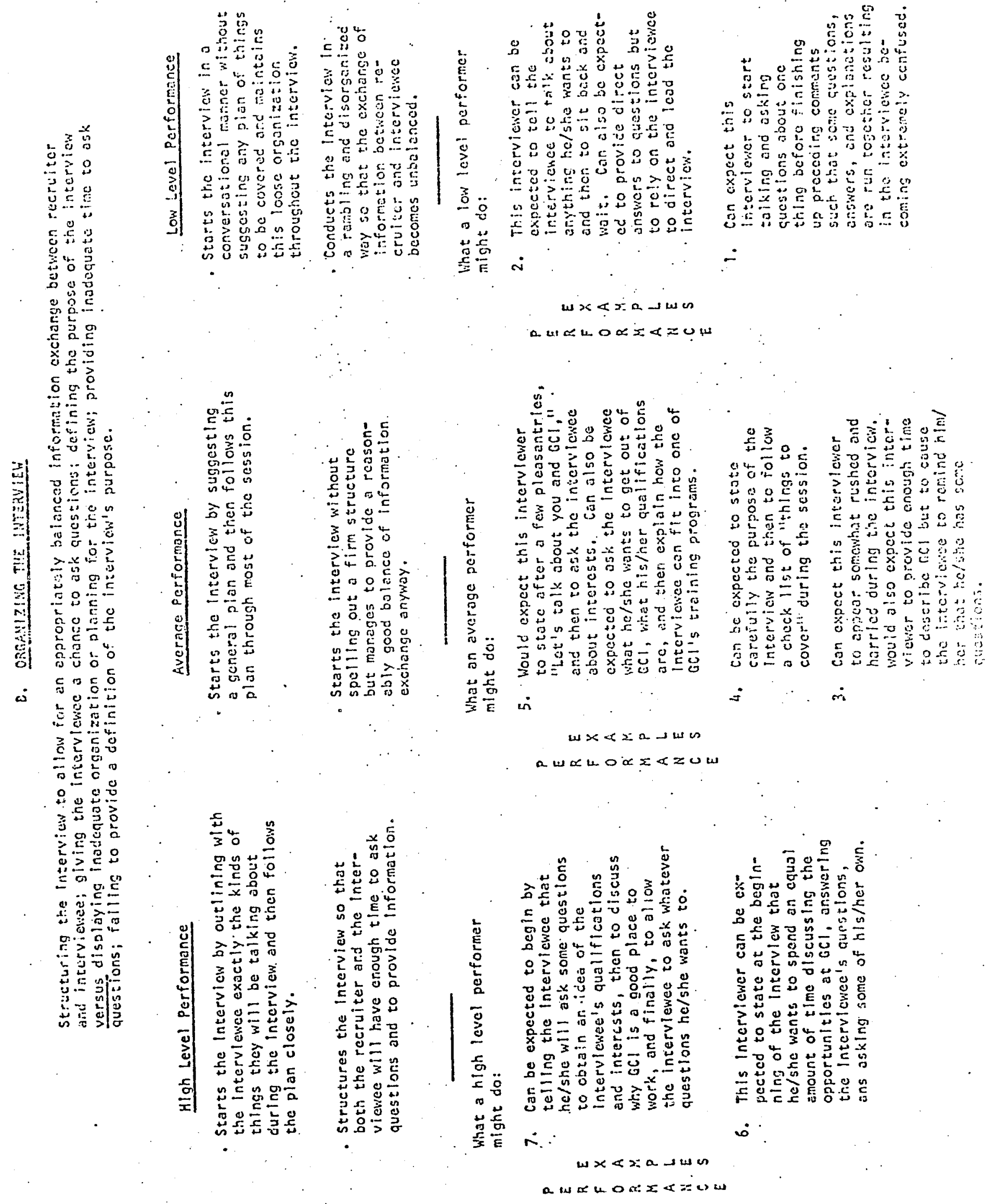


5

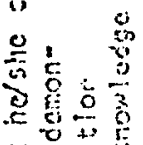

+3

胥访至

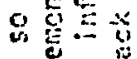

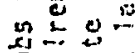

으룰

प.

으늘

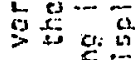

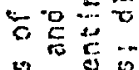

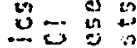

언ㄴ․

3 s

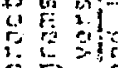

造求

I $=0$

स

要过

$=58$

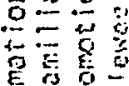

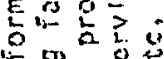

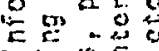

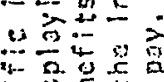

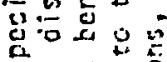

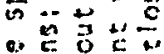

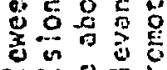

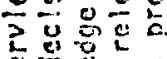

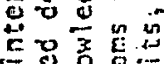

बह5

or

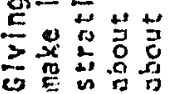

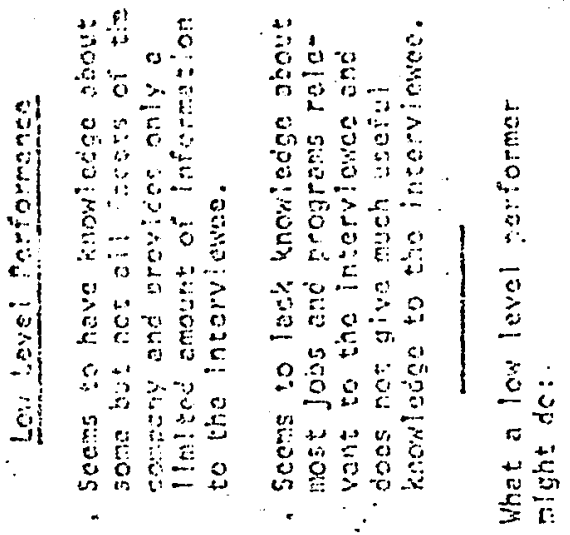

政

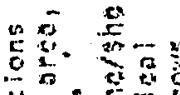

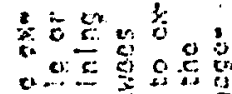

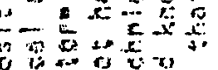

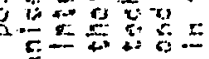

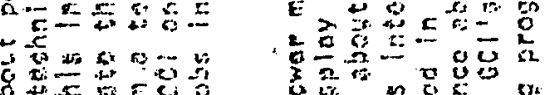

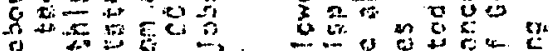

v 0 -

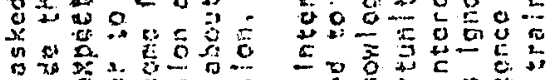

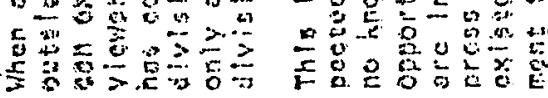

$\dot{v}$

$\omega x<z<+$ is

c.

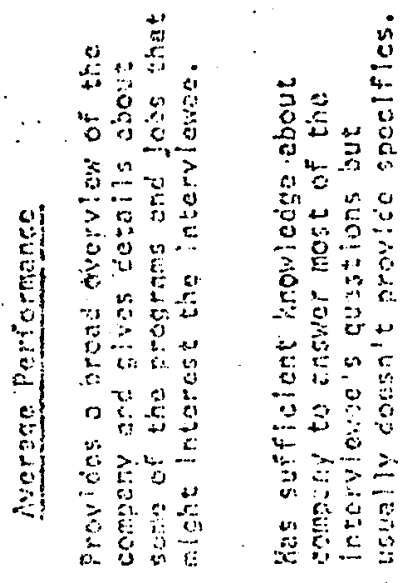

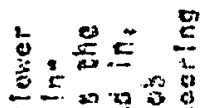

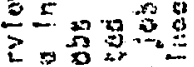

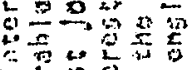

क

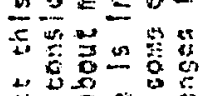

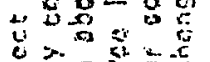

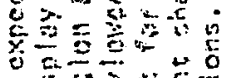

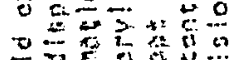

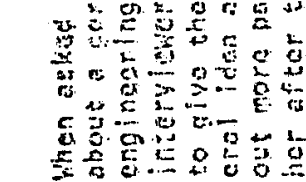

r

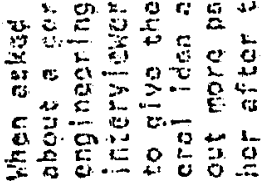

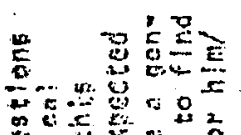

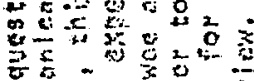

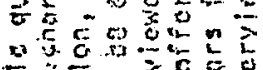

—

$\bar{y}=0$

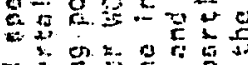

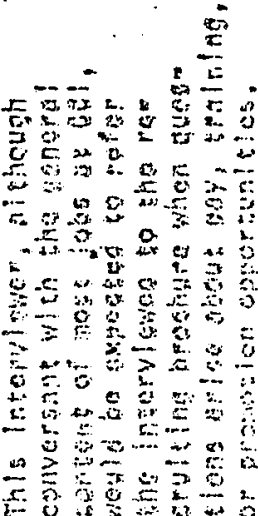

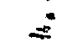

ans $x<x<x \rightarrow$ wides

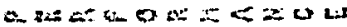
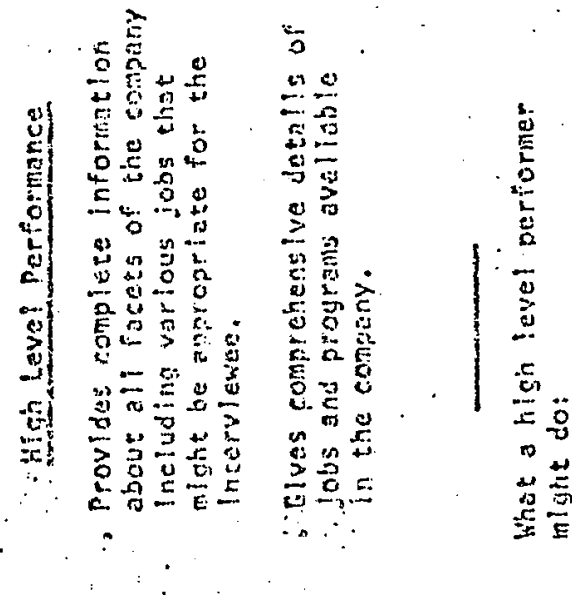

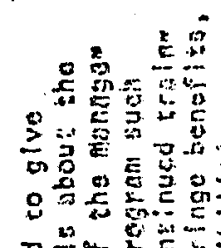

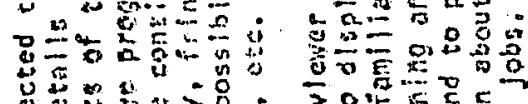

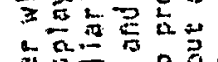

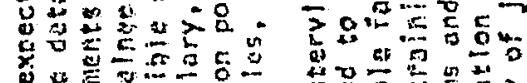

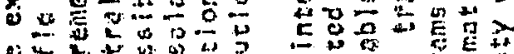

\&

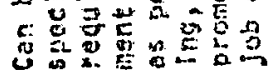

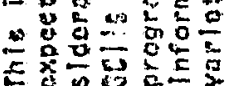

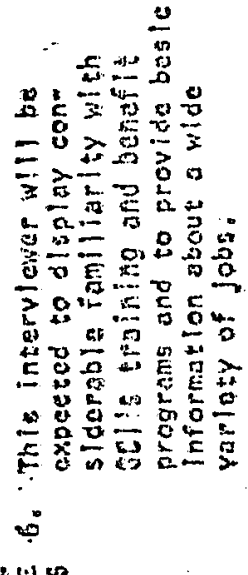

in $x<x a+1000$

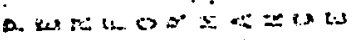




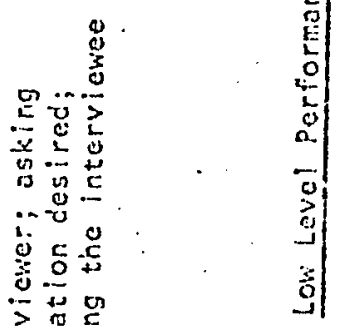

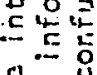

0

尘?

足:

กㄴำ

$\therefore$ 界导

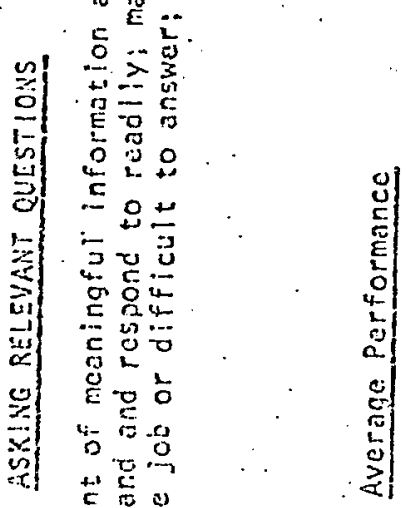

- 5 要这

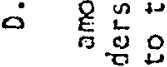

至范

옹

E

肴证。

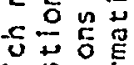

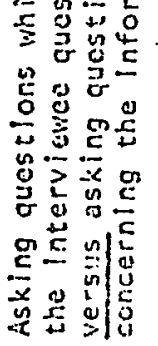

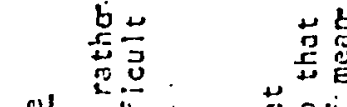

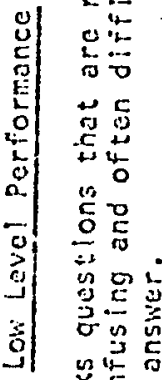

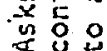

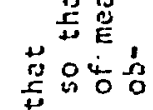

녿ㄴㄷㄴ

号号总

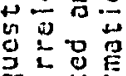

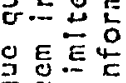

可通二

$>=-\frac{1}{3}$

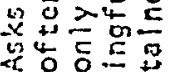

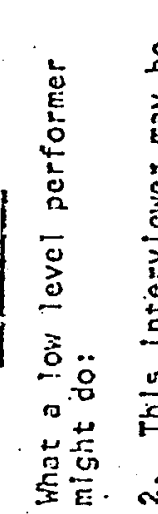

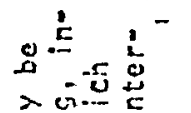

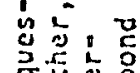

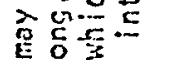

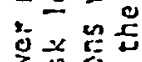

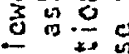

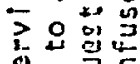

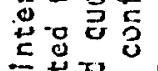

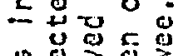

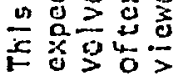

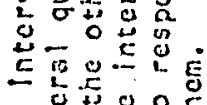

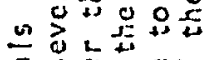

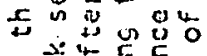

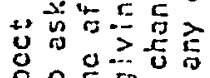

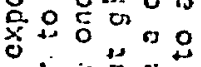

을

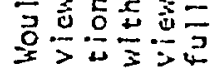

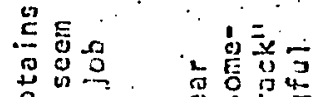

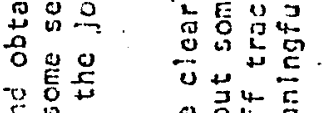

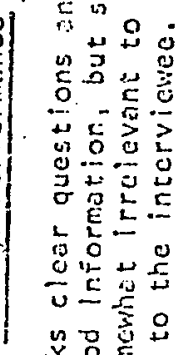

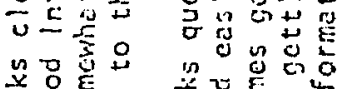

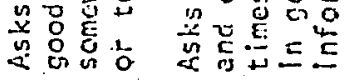

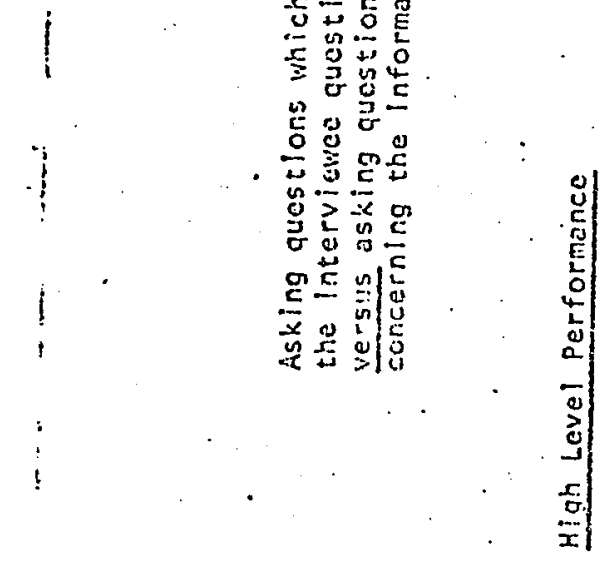

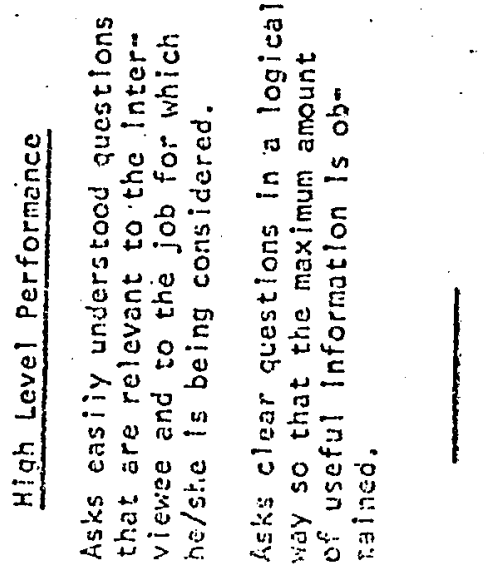

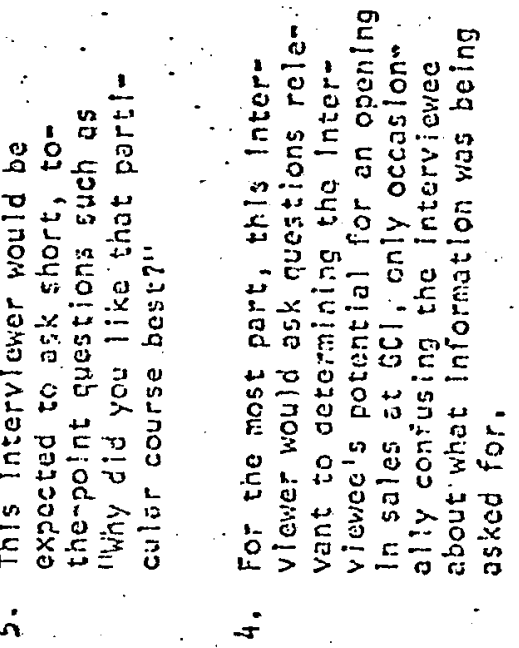

Is $x<\leq a$ us en

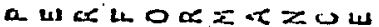
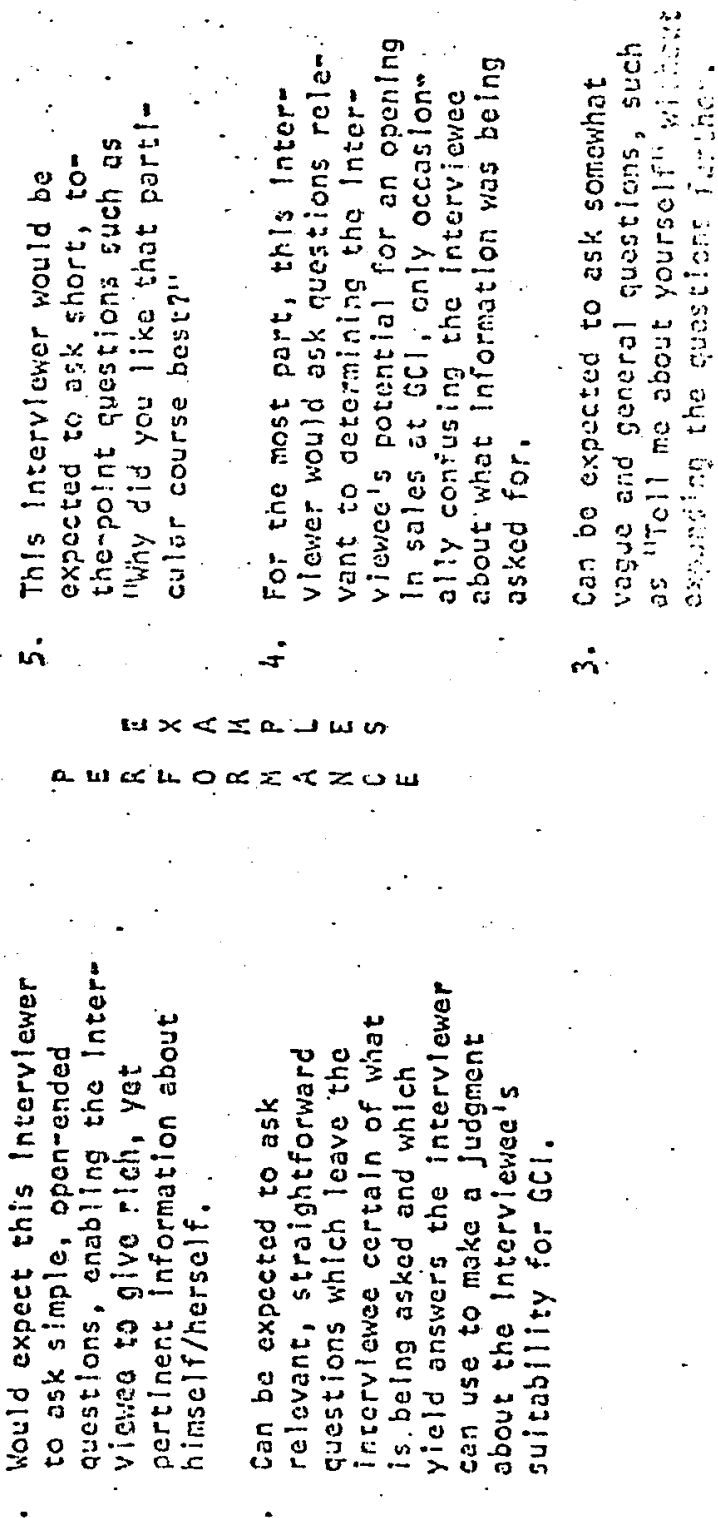

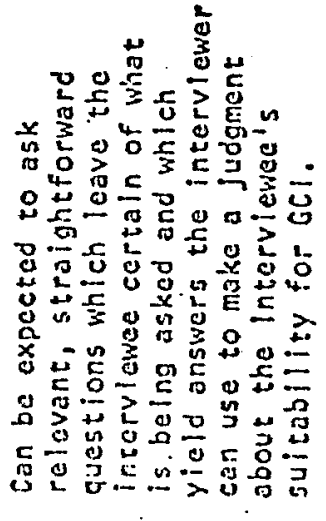

Reproduced with permission of the copyright owner. Further reproduction prohibited without permission. 


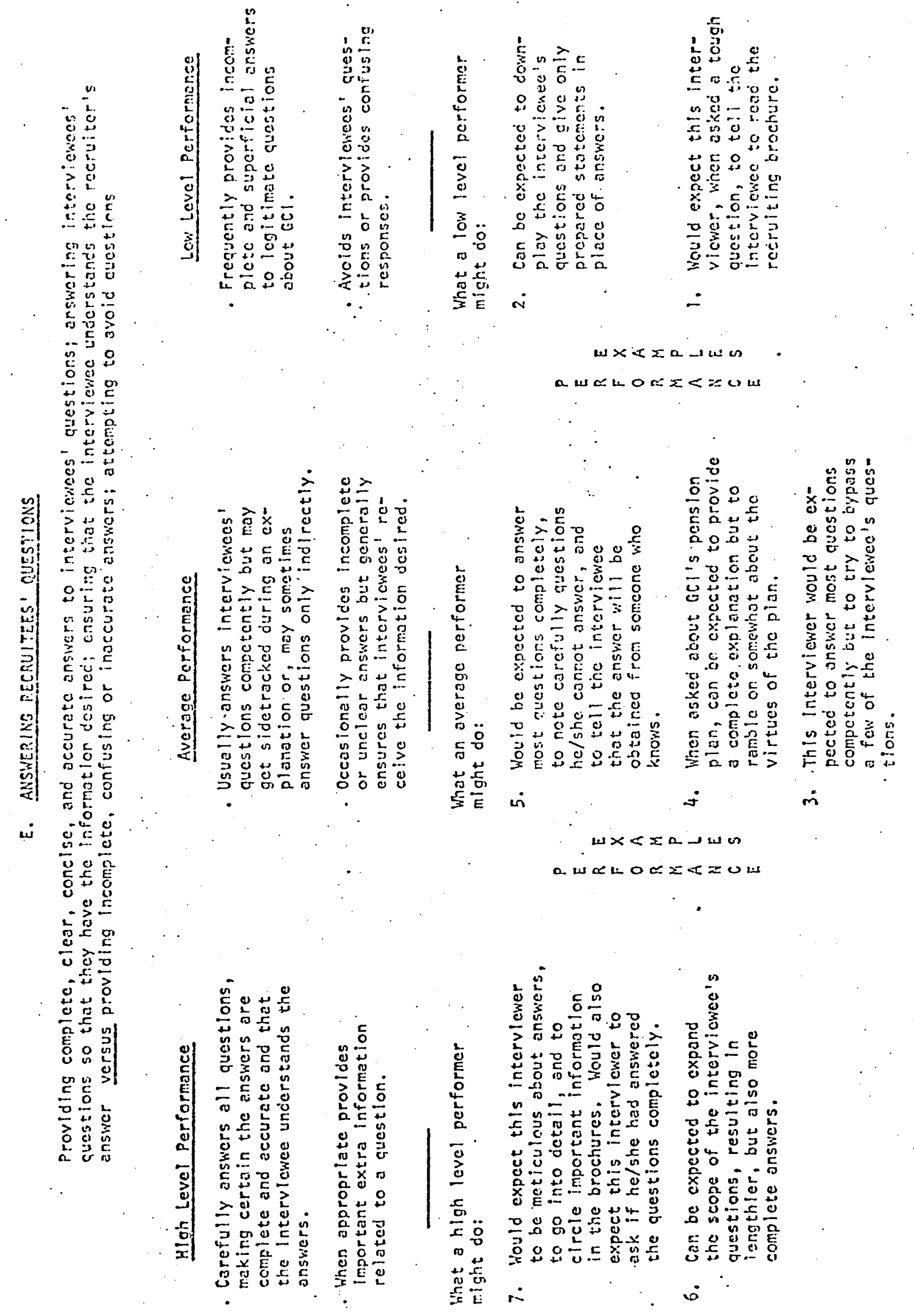

Reproduced with permission of the copyright owner. Further reproduction prohibited without permission. 


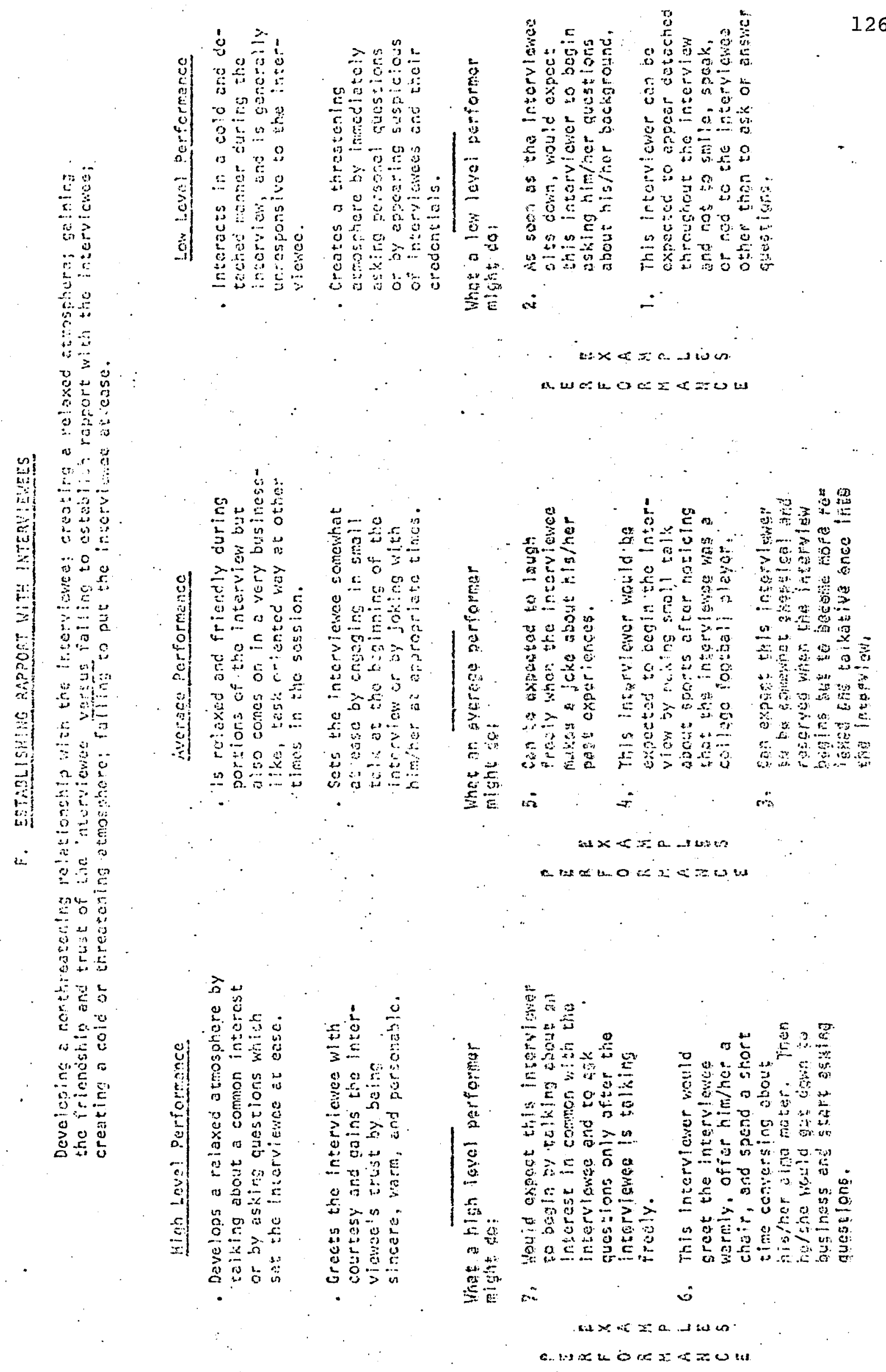


EXERCISE TWO

INSTRUCTIONS: This exorciso consists of two parts. First, you are asked to look closely at the picture presented to you, and write down as many observations as you feal relevant. Secondly, please wite down relevant inferences drawn from the people, setting and oljects in the picture.

\section{A. Observations Made}

1.

2.

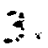

$1 !=$

5.

6.

B. Inferances Dran

1.

2.

3.

4.

5.

6. 


\section{JUDGMENTAL ERRORS}

- Insensitivity to Biased Data

- Inappropriate Causal Inference

- Over-reliance on Previously Formed Theories

- Irappropriate Weighting of Information 
Illustration of Biased Data Use

\section{Performance Factor: \\ Qual ity of Work}

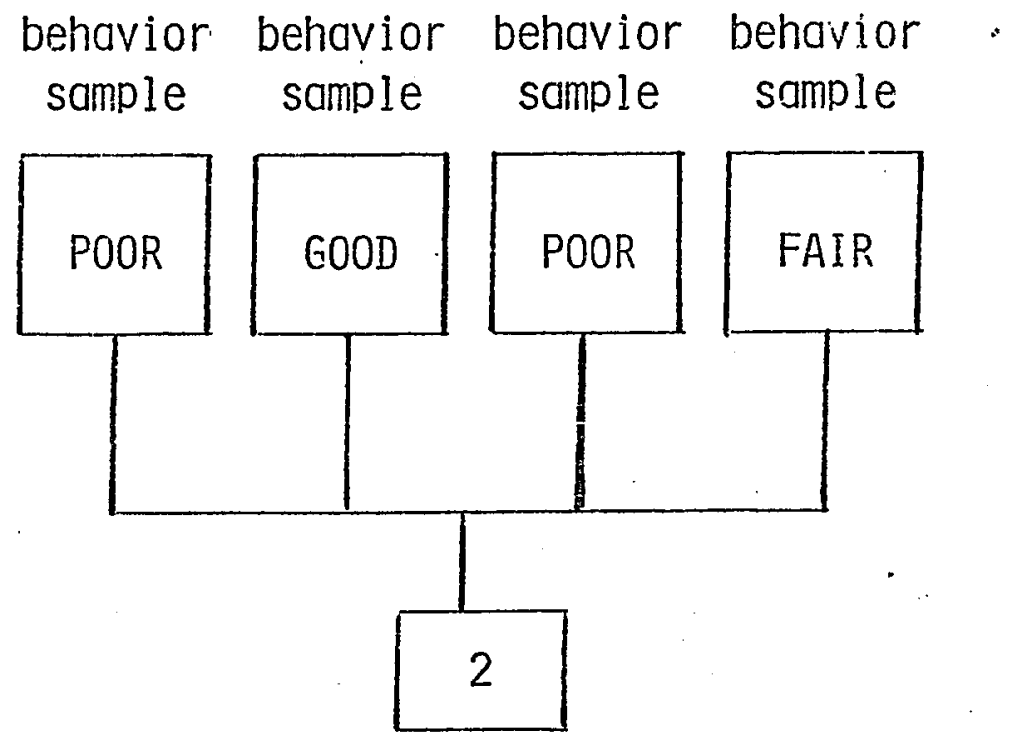


OVER-RELIANCE ON PREVIOUSLY FORMED THEORIES

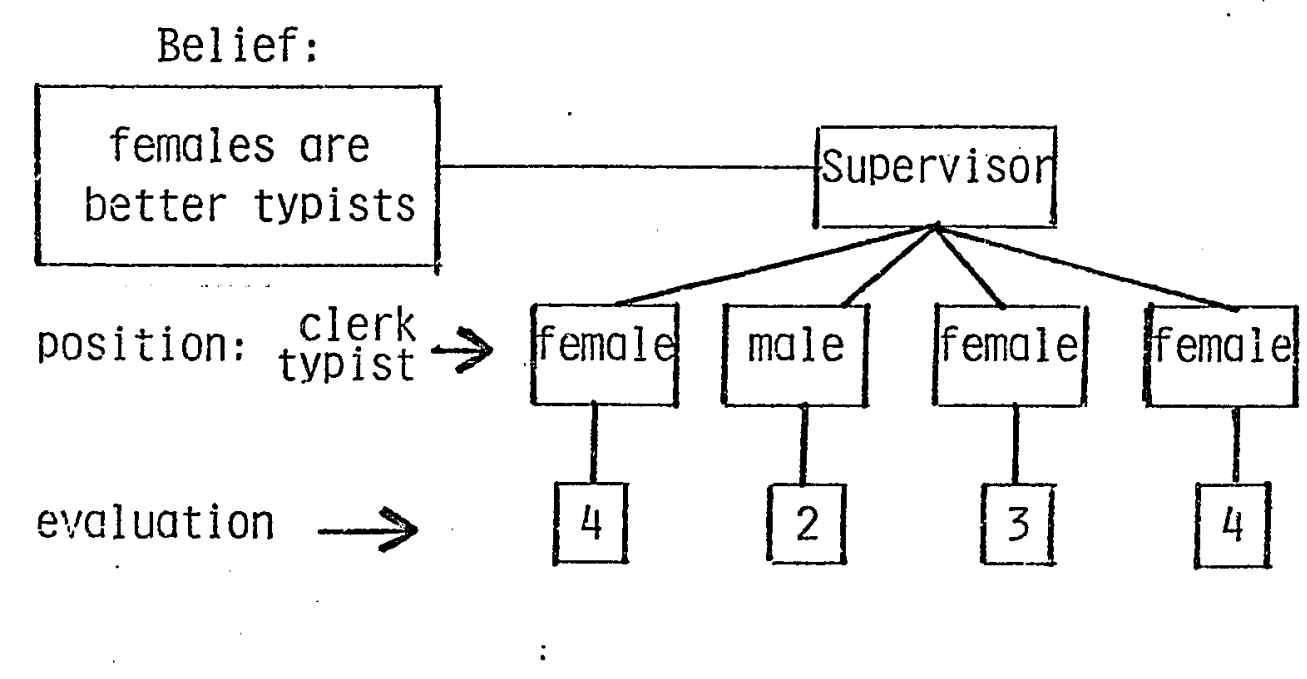




\section{ILLUSTRATION OF INAPPROPRIATE WEIGHTING}

Samples of Behavior

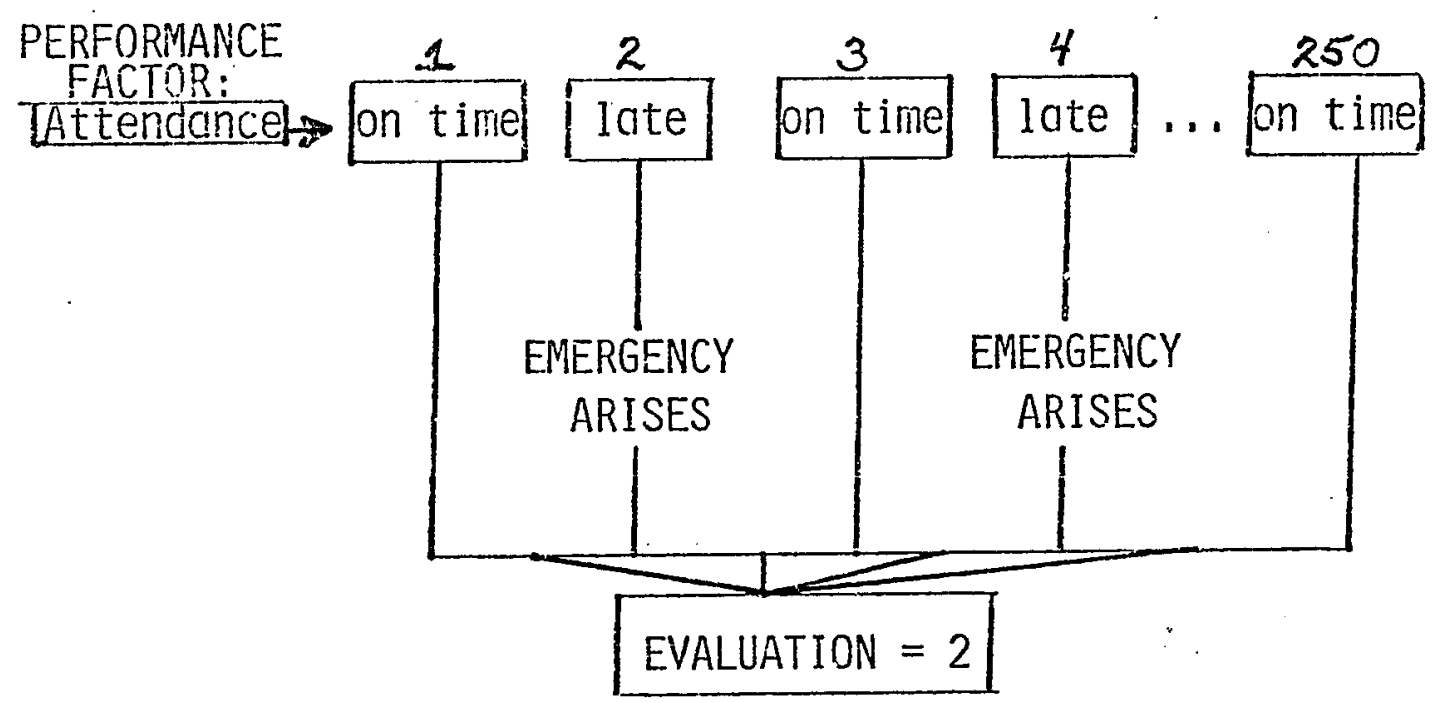


APPENDIX D

Schedule of Performance Evaluation Training

Reproduced with permission of the copyright owner. Further reproduction prohibited without permission. 


\section{PERFORMANCE EVALUATION TRAINING}

Training Sessions

Session A

$$
\text { April 12..8:30 - noon }
$$$$
\text { April 22...8:3ø - noon }
$$

Session B

April 14..8:30 - noon

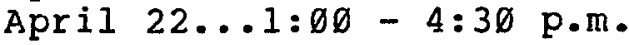

Session C

April 13...1:øQ - 4:30 p.m.

April 19...8:30 - noon

Session D

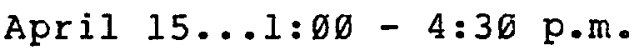

April 20...1:ø0-4:30 p.m.
Session E

April 14...1:ø0-4:30 p.m.

April $20 . .8: 30$ - noon

Session F

April 15..8:36 - noon

April 21...1: $\emptyset \emptyset-4: 3 \emptyset$ p.m.

Session G

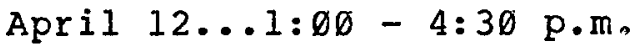
April 19...1:00 - 4:3ø p.m.

Session $\mathrm{H}$

April 13...8:3ø-noon

April 21...8:30 - noon

\section{PERFORMANCE EVALUATION TRAINING}

Registration Form

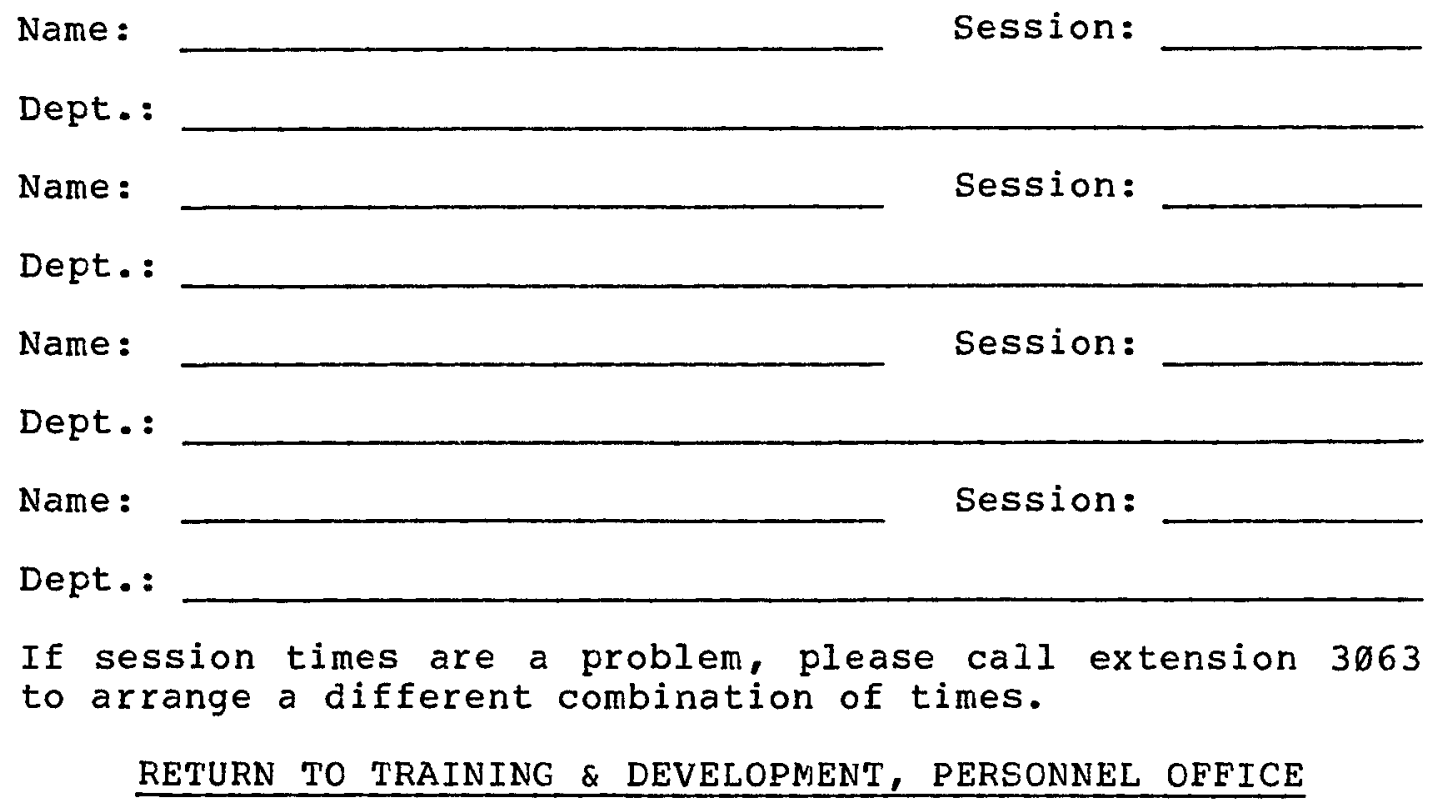


A.PPENDIX E

Old Dominion University Performance Evaluation Form

Reproduced with permission of the copyright owner. Further reproduction prohibited without permission. 
COMMONUEALTH OF VIRGINIA

Narne

Agency Name

Class Title

Date of Evaluation

\footnotetext{
Describe Briefly the Principal Duties in Present Job
}

CONFIDENTIAL

EMPLOYEE PERFORMANCE EVALUATION

\section{PERFORMANCE LEVELS}

4 - exceeds normat job reguirements

3 - meets normal job requirements

2 - improvement is needed to meser job requitements

1 - foils to meet job requirements

Acceptable satisfactory performance reguir tes an average rating of 2.75 , when rated "performance factors" are combined.

Soc. Sec. No.

Position No.

Sub. Division

Arency Code

Class Code Date Entered Present Position

PART I-PERFORMANCE FACTORS - CIRCLE THE APQROPRIATE PERFORMANCE LEVEL

1- JOB KNOWLEDGE/SKILLS - To what extent does the employee maintain a satisfactory level of job knowledge and/or job skills?

Remarks

2- QUALITY OF WORK - To what extent does the employee's work meet the required quality standards; i.e., accuracy, neatness and thoroughness?

Remarks 3- PRODUCTIVITY - To what extent does the employee accomplish the quantity of work expected of the
job assignment?

Remarks

4- RECORD KEEPING/DCCUMENTATION - To what extent does the employee adequately prepare and maintain records, writteri reports, correspondence, and files?

Remarks 
5- DEPENDABILIIY - To what extent does the employee perform work witiout close supervision or assistance?

Remarks

-

6- ADAPTABILITY - To what extent does the empioyee readily adapt to new situations and changes in reutines,

6- ADAPTABIIIY work load, and/or work assignments?

Remarks

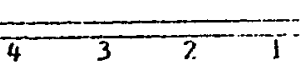

7- INITIATIVE - To what extent does the employee present new ideas, improve procedures or otherwise
demonstrate an awareness of clerical or technical changes related to the job?

Remarks

.

8- ATTENDANCE - To what extent does the employee maintain satisfactory attendance performance in regard to tardiness, early depariures, and/or absences?

Rernarks

9- RELATIONS WITH OTHERS - To what extent does the employee establisf, effective working relation-

ships when dealing with supervision, co-workers, and/or the public?

Remarks

10- SAFETY - To what extent does the employee work in a safe manner and observe safety practices? 
DETERMINING THE OVERALL E!ALUATION: ADD the number circled for each freformance factor, DiviDE the total by ten (I0) to fetermine the overall evalustion. Indicate the overall evaluation score by circling, or inserting and circling, the overall evaluation on the scale provided.

\section{Performance Levels}

Employes's performanct regularly exceeds the job regiuirements.

Fmployeze's performance meets tormal job requirements on a sustained basis.

Eingioyee's performance reflects that there is a need for improvernent on a iustained basis.

(1.99 \& beiow)

Srale

4.00

3.75

3.50

3.25

3.00

2.75

2.50

2.25

2.00

Employee's performance fails to meet the job requirements.

SUPERVISOR'S COMMENTS CONCERNING THE OVERALL EVALUATION:
1.75

1.50

1.25

\section{ק̈ART UI - DEVELOPGENTAL TRENDS}

i- SIGNIFICANT CHANGES - Indicate any significant changes in performance since the employee's last evaluation.

2- DEVELOPMENT AND TRAIVING: (a) Indicate recommendations for further cevelopment and training for purposes of preparing the empioyee for additional responsibilities or for the improvement of current job performance.

(b) Idertify any training or developmental activities the employee has completed since his/her tast performance evaluation. Such training was (check one) taken as a resuit of the supervisor's recommendation , or the employee's initiative TITLE TITLE.

TO THE EMIPLOYEE:

Yous are requested to sign on the line provided below to indicate only that you have had an opportunity to review and discuss your performance evaluation with your suger visor. YOUR SIGNATURE DOES NOT INDICATE THAT YOU AGREE WITH THE EVALUATION.

\section{EMPLOYEE'S COMMENTS:}




\section{APPENDIX F}

Trainee Reaction Questionnaire 
REACTIONS TO PERFORMANCE EVALUATION TRAINING

INSTRUCTIONS: Race each of the following questions, using the scale provided below. Place the number which corresponds to your answer in the blank beside the question.

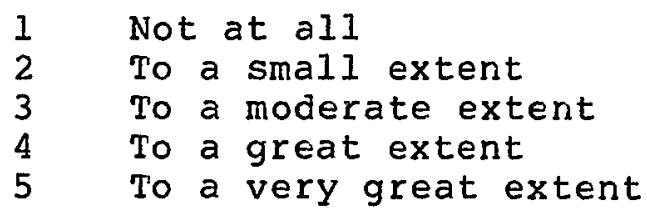

1. To what extent was the performance evaluation training beneficial to you?

2. To what extent was the videotaped lecture portion of the training beneficial to you?

3. To what extent was the practice/discussion portion of training beneficial to you?

4. To what extent did you feel like you were in need of some formal performance evaluation training?

5. To what extent do you believe all new supervisory personnel should receive formal training in performance evaluation?

6. To what extent do you believe all supervisory personnel (both new and old) should receive performance evaluation training?

7. To what extent do you believe all supervisory personnel should receive performance evaluation "refresher" training on a regular basis?

8. How frequently do you believe performance evaluation "refresher" training should be conducted?

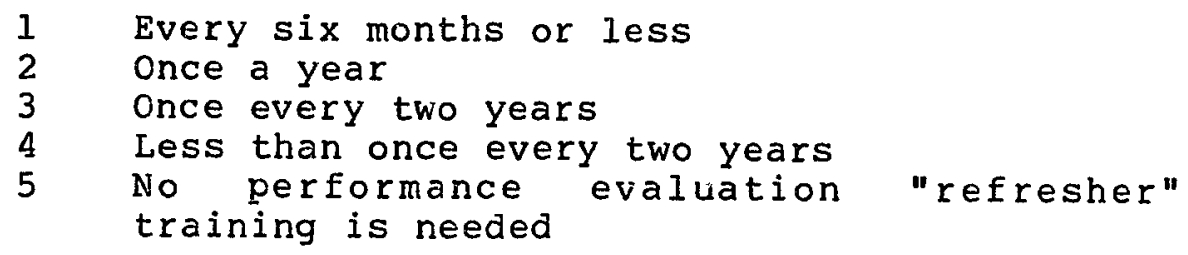


9. Have you ever received formal performance evaluation training?

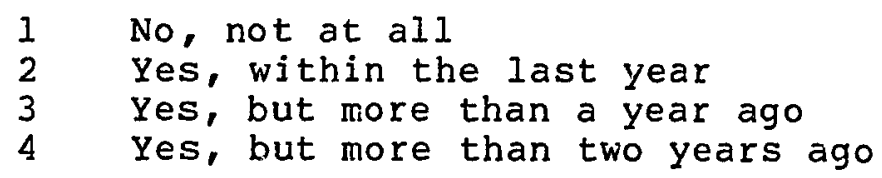




\section{APPENDIX G \\ Table of Mean Accuracy Scores for Laboratory Data}




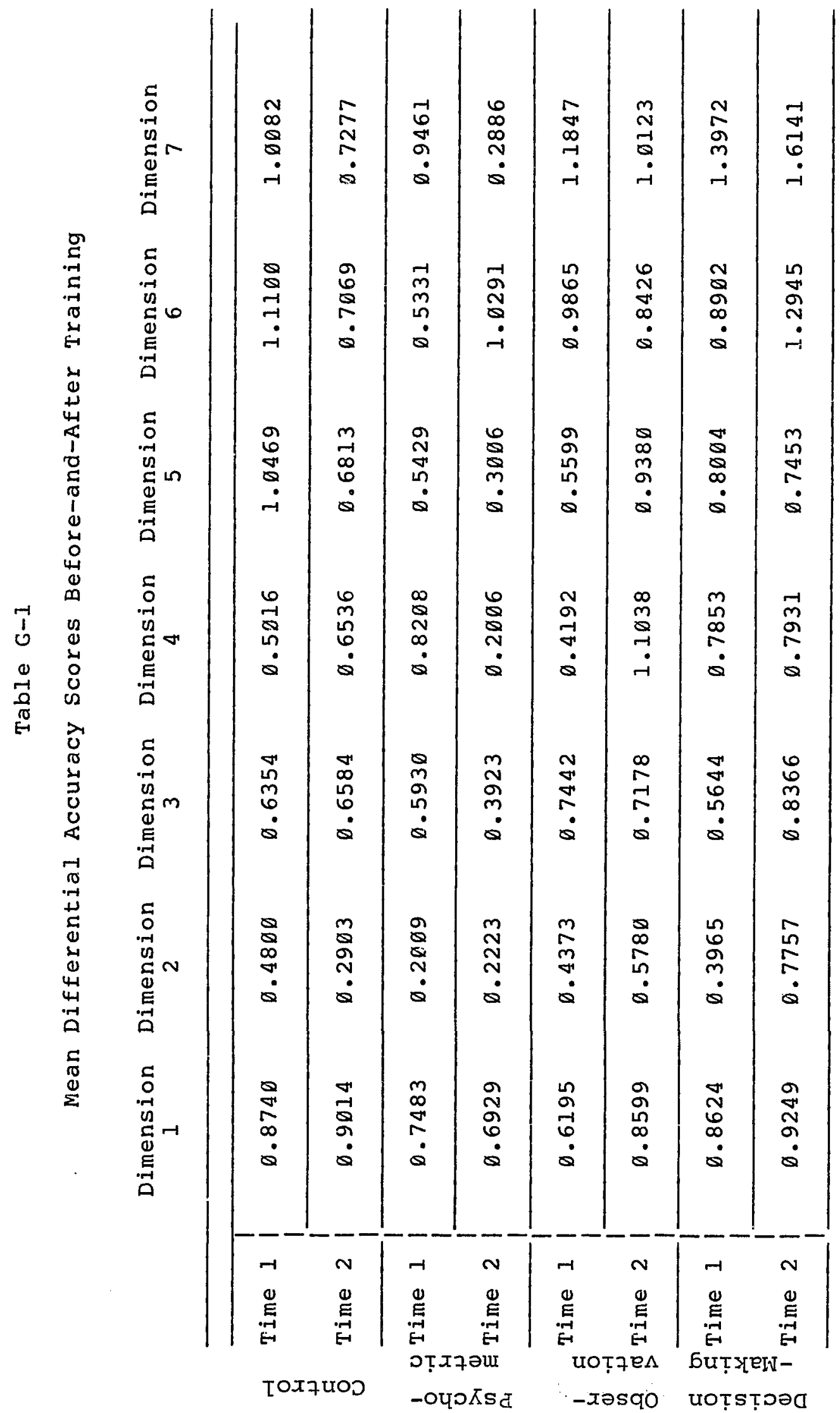

